\title{
The Global Charango
}

\author{
by

\section{Heather Horak}

A thesis submitted to the Faculty of Graduate and Postdoctoral Affairs in partial fulfillment of the requirements for the degree of

\author{
Master of Arts \\ in \\ Music and Culture
Carleton University
Ottawa, Ontario \\ (C) 2020 \\ Heather Horak
}




\begin{abstract}
Has the charango, a folkloric instrument deeply rooted in South American contexts, "gone global"? If so, how has this impacted its music and meaning? The charango, a small and iconic guitar-like chordophone from Andes mountains areas, has circulated far beyond these homelands in the last fifty to seventy years. Yet it remains primarily tied to traditional and folkloric musics, despite its dispersion into new contexts. An important driver has been the international flow of pan-Andean music that had formative hubs in Central and Western Europe through transnational cosmopolitan processes in the 1970s and 1980s.

Through ethnographies of twenty-eight diverse subjects living in European fields (in Austria, France, Belgium, Germany, Spain, Portugal, Switzerland, Croatia, and Iceland) I examine the dynamic intersections of the instrument in the contemporary musical and cultural lives of these Latin American and European players. Through their stories, I draw out the shifting discourses and projections of meaning that the charango has been given over time, including its real and imagined associations with indigineity from various positions.

Initial chapters tie together relevant historical developments, discourses (including the "origins" debate) and vernacular associations as an informative backdrop to the collected ethnographies, which expose the fluidity of the instrument's meaning that has been determined primarily by human proponents and their social (and political) processes. This work then, will contribute to new organology's prompt to consider instruments as dynamic proponants, inextricably entwined in human engagements. The work will also provide a measuring stick with which to ascertain the reach and impact of the charango in current global scenes.
\end{abstract}




\section{Acknowledgements}

Special thanks to Julio Mendívil at the University of Vienna for ongoing encouragement and mentorship throughout my Masters studies, in particular during my field work. Thanks as well to James Deaville at Carleton University, in particular for allowing me to embark on whatever I could dream up. Thanks to James Wright at Carleton University for enthusiasm, support and positivity. A nod to the few student colleagues I got to know at Carleton, you were wonderful. Universal thanks to Christi Loughery for true friendship and a lot of help, and to my mother, Linda Horak. Thanks to Camilo Gomez, Juan Francisco Sutta Cachi, Willy Rios and Julio Mendívil for charango instruction; and to Naomi Poole and Jeremy Sills for inviting me to Peru in 2015. Many thanks to all of the charango players I met during this research, who so generously shared their stories and lended their enthusiasm to this project. Your contributions were substantive, and of great importance.

Engaging in the labor of scholarship would have been impossible without the various work spaces I had the privilege to access during this long and somewhat transient period. I would like to acknowledge Stetson University College of Law in Florida, in whose library I spent countless hours; my cousin Carrie's back porch in Maine on which I labored in various phases; my mother's Florida home (and "the Lodge" at Timber Pines, including its very sweet staff) in which I did hundreds of hours of work on this project; also her farm in N.Y. State where I finished revisions during the Covid 19 pandemic. A tip of the hat to Café Molo in Wakefield, QC, and to my own cottage on the Gatineau River.

Much gratitude the Social Sciences and Humanities Research Council of Canada and MITACS Globalink for funding related to this project. 


\section{Table of Contents}

\begin{tabular}{lr}
$\begin{array}{l}\text { Abstract } \\
\text { Acknowledgements }\end{array}$ & i \\
Table of Contents & ii \\
List of Illustrations & iii-iv \\
Table of Interviews & v \\
Audio Index & vi \\
Preface: Imagining the “Global" Charango & 1 \\
\hline Introduction: The Charango and Its Reach & 6 \\
Section I: Background and Contexts & 16
\end{tabular}

The wood, the strings, and more

Chapter Two: Historical Context

The charango comes to Europe: Trans-local interventions and Indian tropes

Chapter Three: The "Origins" Debate

Heritage wrestling matches and Bolivians in the field

\section{Section II: Ethnographies}

Chapter Four: Finding Charango Players

Notes on field method

Chapter Five: "El Charango es mi vida"_-"The charango is my life"

Personal stories, emotional attachments, and mystical imaginaries

Migrant intersections and Andean identity:

Cesar Guzman Roman

Teaching "otherness":

Luis Parra Madriaga

Travellers and troubadors:

Yann Béréhouc: new music, new worlds

Sebastian Janis Cerda: ticket to ride

Ignacio Kaen: sentient journeys

The Sound of the Mountains: New Age mysticisms

and the "Pacha Mama" mystique

Marie Laduron: "The charango is my alter-ego"

Deni Plavčić: cross-cultural dreams

Different sounds, or sounds of difference? 
Ólöf Arnalds

Chapter Six: The Innovators

New musics in cross-cultural intersections

Jorge Cervantes

115

Ivan Latapiat

121

Patricio Zeoli

Conclusion: Is there a "Global" Charango?

References

Discography 


\section{Table of Illustrations}

\begin{tabular}{|c|c|c|c|}
\hline & Description & Source & last accessed \\
\hline 1 & $\begin{array}{l}\text { Ernesto Cavour with his 'Star' } \\
\text { charango }\end{array}$ & https://www.pinterest.com/pin/521432463079166990/ & $11 / 03 / 2020$ \\
\hline 2 & $\begin{array}{l}\text { "The biggest charango in the } \\
\text { world" (Serrano, BL) }\end{array}$ & $\begin{array}{l}\text { http://investuraholistica.blogspot.com/2010/06/el- } \\
\text { charango-mas-grande-del-mundo.html }\end{array}$ & $11 / 03 / 2020$ \\
\hline 3 & a 'siren' charango & $\begin{array}{l}\text { http://patagoniamonsters.blogspot.com/2010/10/pincoy- } \\
\text { mermaid-from-peru-to-patagonia.html }\end{array}$ & $11 / 03 / 2020$ \\
\hline 4 & $\begin{array}{l}\text { Tarazona's 'Hatun' charango } \\
\text { Photo from his website }\end{array}$ & $\begin{array}{l}\text { https://federico-tarazona.weebly.com/hatun- } \\
\text { charango.html }\end{array}$ & $21 / 09 / 2019$ \\
\hline 5 & $\begin{array}{l}\text { Violeta Parra, national folk hero } \\
\text { in Chile. Wall mural }\end{array}$ & Photo taken in Valparaiso, Chile by author $(\mathrm{HH})$ & January, 2016 \\
\hline 6 & $\begin{array}{l}\text { Ecuadoran street } \\
\text { performer/merchant }\end{array}$ & $\begin{array}{l}\text { Photo taken in market area in Riga, Latvia by author } \\
\text { (HH) }\end{array}$ & July 2019 \\
\hline
\end{tabular}




\section{Table of Interviews}

$(\mathrm{F} 2 \mathrm{~F}=$ face to face, $\mathrm{fklc}=$ folkloric, orig $=$ original, $\mathrm{pan} \mathrm{A}=$ pan Andean, $\mathrm{reg}=$ regional, $\operatorname{mix}=$ mixed genres, var=plays a regional/local charango variant, wind=also a wind player, perc=percussionist)

Music/style/genre listed in order of current preference/main focus of each player.

\begin{tabular}{|c|c|c|c|c|c|c|c|c|}
\hline & Last & First & $\begin{array}{l}\text { Int. } \\
\text { date }\end{array}$ & Via & $\begin{array}{l}\text { Interview } \\
\text { location }\end{array}$ & Country & Nationality & Music style/genre \\
\hline 1 & Arnalds & Ólöf & $9 / 18$ & F2F & Reykavik & Iceland & Iceland & Orig/songwriter \\
\hline 2 & Béréhouc & Yann & $9 / 18$ & Skype & Rheims & France & France & Orig/fklc/panA \\
\hline 3 & Latapiat & Ivan & $9 / 18$ & Skype & Lyon & France & Chile & Orig/mix/fklc/panA \\
\hline 4 & Dimitri & Nina & $9 / 18$ & $\mathrm{~F} 2 \mathrm{~F}$ & Vienna & Austria & Switzerland & Fklc/circus \\
\hline 5 & Perez & Antuco & $9 / 18$ & F2F & Paris & France & France/Peru & Luthier/Fklc/panA \\
\hline 6 & Plavčić & Deni & $9 / 18$ & Skype & Zagreb & Croatia & Croatia & Fklc \\
\hline 7 & Mendivil & Julio & $10 / 18$ & $\mathrm{~F} 2 \mathrm{~F}$ & Vienna & Austria & Peru & Reg/var/fklc \\
\hline 8 & Parra Madariaga & Luis & $10 / 18$ & $\mathrm{~F} 2 \mathrm{~F}$ & Vienna & Austria & Chile/Austr. & Fklc/panA/orig \\
\hline 9 & Alejo Cruz & Paulino & $10 / 18$ & $\mathrm{~F} 2 \mathrm{~F}$ & Vienna & Austria & Bolivia & Reg/var/fklc/perc \\
\hline 10 & Vila Quispe & Lidovino & $10 / 18$ & $\mathrm{~F} 2 \mathrm{~F}$ & Vienna & Austria & Bolivia & Fklc/panA \\
\hline 11 & Zeoli & Patricio & $10 / 18$ & $\mathrm{~F} 2 \mathrm{~F}$ & Berlin & Germany & Ireland & Medieval/fklc \\
\hline 11 & Rodriguez & Tito & $10 / 18$ & $\mathrm{~F} 2 \mathrm{~F}$ & Berlin & Germany & Peru/Ger & Fklc/panA/orig \\
\hline 13 & Vidal & Leandro & $10 / 18$ & F2F & Berlin & Germany & Argentina & Fklc/var/orig \\
\hline 14 & Janis Cerda & Sebastian & $10 / 18$ & $\mathrm{~F} 2 \mathrm{~F}$ & Berlin & Germany & Argentina & Fklc/panA \\
\hline 15 & Hernandez & Pedro & $11 / 18$ & $\mathrm{~F} 2 \mathrm{~F}$ & Vienna & Austria & Chile & Fklc/panA \\
\hline 16 & Bedoya & Luis & $11 / 18$ & $\mathrm{~F} 2 \mathrm{~F}$ & Vienna & Austria & Bolivia & Fklc/panA/reg/wind \\
\hline 17 & Ferrier & Claude & $11 / 18$ & Skype & Zurich & Switz. & Switzerland & Fklc/panA/wind \\
\hline 18 & Stocklin & Carole & $11 / 18$ & Survey & Brussels & Belgium & Belgium & Fklc/panA/wind \\
\hline 19 & Laduron & Marie & $11 / 18$ & Survey & Brussels & Beligium & Belgium & Orig/fklc/panA \\
\hline 20 & Ramos & Armando & $11 / 18$ & $\mathrm{~F} 2 \mathrm{~F}$ & Brussels & Beligium & Bolivia & Fklrc/panA/wind \\
\hline 21 & Mignot & J. Louis & $11 / 18$ & $\mathrm{~F} 2 \mathrm{~F}$ & Brussels & Belgium & Belgium & Fklc/panA \\
\hline 22 & Hernandez & Osvaldo & $11 / 18$ & $\mathrm{~F} 2 \mathrm{~F}$ & Brussels & Belgium & Mexico & Orig/fklc/panA/perc \\
\hline 23 & Guzman Roman & Cesar & $12 / 18$ & F2F & Granada & Spain & Peru & Fklc/panA \\
\hline 24 & Kaen & Ignacio & $12 / 18$ & $\mathrm{~F} 2 \mathrm{~F}$ & Granada & Spain & Argentina & Fklc/panA/mix/perc \\
\hline 25 & Duran Salas & Ignacio & $12 / 18$ & $\mathrm{~F} 2 \mathrm{~F}$ & Almeria & Spain & Spain & Fklc/panA \\
\hline 26 & Pena & Jose Luis & $12 / 18$ & $\mathrm{~F} 2 \mathrm{~F}$ & Seville & Spain & Peru & Fklc/panA \\
\hline 27 & Božičević & Zrinka & $12 / 18$ & Skype & Zagreb & Croatia & Croatia & Fklc/panA/wind \\
\hline 28 & Cervantes & Jorge & $01 / 19$ & $\mathrm{~F} 2 \mathrm{~F}$ & Lisbon & Portugal & Peru & Fklc/panA/mix \\
\hline
\end{tabular}




\section{Audio Index}

\section{Guide to the audio index:}

These sound samples collected during the field research are provided as sonic "snapshots" of various musical moments from this project. They are inserted throughout the text by footnote where relevant. Simply listen to each sample at the point in the text where it is footnoted according to the following list. Refer to the passages in the text where the indexed samples are footnoted for futher explanation of each beyond what is noted here.

1. Julio Mendivil demonstrating an Ayacuchano variant in Vienna, Austria.

2. Camilo Gomez's "charangon" (baritone fretless charango) from his second recording.

3. Encuentro Charangos Brussels charango orchestra playing "Virgenes del Sol" in Belgium.

4. Lucho Bedoya demonstrating kalampeo style in Vienna, Austria.

5. Paulino Alejo Cruz playing kalampeo at Bolivian National Day party in Vienna, Austria.

6. Cesar Guzman Roman demonstrating his busking repertoire from his youth in Granada, SP.

7. Ignacio Kaen demonstrating the walaycho variant in Granada, Spain.

8. Armando Ramos reciting his poem dedicated to the charango in Brussels, Belgium.

9. Jorge Cervantes and son demonstrating one of the son's interpretations in Lisbon, Portugal. 


\section{Preface}

At the outset of this project, the "global" charango was as much a question for me as it was a hypothesis. Has the charango, a folkloric instrument deeply rooted in South American contexts, "gone global" (Turino 2003)? ${ }^{1}$ If so, how has this impacted its music and meaning? The charango has circulated far beyond the Andes in the last fifty to seventy years, primarily in the international flow, exchange, and performance of what is broadly known as Andean music, which had formative hubs in Central/Western Europe. Yet the charango remains closely associated with its Latin American contexts in the minds and ears of most players and listeners. I initially imagined that the charango outside its homelands would be leading an interesting, experimental life - musically exploring the intersections of various contrasting cultures, genres, and scenarios outside of Latin America. In some ways, this is a study of an instrument-in-diaspora. However, invoking the term "diaspora" would be a misnomer, as neither the charango nor its players as they are dispersed outside of South America are clustered in any way that would befit the term in a customary sense. Regardless, it was precisely the musical life of the charango in "foreign" situations, i.e., outside of Latin America that I was interested in, in order to study cross-cultural processes in music-making that, I assumed, would necessarily be the result of its relocations. $^{2}$

\footnotetext{
${ }^{1}$ I use the word "global" in this work not to indicate that everyone, everywhere knows the charango, but rather to the extent that it has dispersed and circulated beyond its Andean/Latin American home (from various places in Bolivia, Peru, Argentina, Chile, Ecuador). I use it somewhat interchangeably with the term "international", but preferring to deemphasize the boundaries of nation states as meaningful markers, I will on occasion use "global" in this vernacular sense. Of course, the word and underlying intellectual developments has been worked over in academic debates that problematize it, pointing to it as a misnomer or smoke shield for yet another chapter of capitalist, corporate imperialism, especially (in Musicology) as pertains to relations of power within the "world music" scene (Turino 2003, Stokes 2011). These are valid critiques and will be held in consideration.

2 Throughout this work I will occasionally use the word "foreign" to indicate a musician who is not of Latin American descent, i.e. "foreign" to cultural contexts of the charango. Or, as above, I will use it to indicate looking at the instrument "outside" of Latin America (as an alternative to "diasporic"). "Culture" can refer to a conglomeration of social practices and traditions, histories and other points of reference, to which a group of people commonly refer,
} 
Along these lines, I imbued the charango with a kind of personhood in order to picture what this fascinating player might be doing on its musical walkabout. I may have picked up a tendency to personify the charango from the Andean world (both past and present) where it is often spoken of, or to, using terms of endearment to describe it (as with a child or pet, most commonly “charanguito") (Cavour 1980; Ramos 2018). Andean lore assigns mystical qualities to the instrument and promotes other types of personification insinuating agency that persists in modern vernacular expression and imagination (explored further in Chapter Five) (Turino 1983; Mesa Gisbert 2014). Blindly missing from my own (pre)conceptions were the players of the instrument, who essentially have provided the basis for this research, and are the source of its results.

In retrospect, I may have been picturing the charango in my own hands as I travelled, explored, changed and well, just had a cross-cultural multi-lingual good time while playing music. My very first charango teacher, a Chilean musician and Mayan astrology buff, always said that I was an "Enlazadora de Mundos" (a connector/entangler/leaper of worlds, a kind of culture-crossing archetype). Taken a step further, maybe I was imagining that everyone out there (playing the charango, or generally) is, in terms of cultural exchange, travel, language acquisition and musical taste, more or less like me. This raises several positional and cultural questions. Does this line of thinking reflect an ego-centricity that is born out of the privilege of colonial descent and cosmopolitan position? Or is it fundamental to humanness in general? Don't we all

identify with and practice. "Cross-cultural" then, will point to intersections where the contrasts and differences between two or more cultures is a point of attention. In terms of this study, "cross-cultural" intersections are of general interest where either a Latin American charango player is located in a European context, both musically and personally/culturally, and thereby, the charango is engaging in a "foreign" context outside of its "homeland contexts" (which are vast, and certainly include Andean terrains, but by no means exclusively). "Cross-cultural" may also refer to the intersection between European or non Latin-American players and their adopted Latin American instrument (the charango) including their engagements with its musical traditions and the cultures of its home contexts. It may also present itself in intersections between Latin American immigrant musicians with European or other immigrant musicians in European or Latin American scenes. The "crossing" indicates sharing, influencing and/or exchange that may or may not take place between actors in these social/musical situations. 
leave home each day presuming that we are the norm, and those who operate along other lines are "different"? Or is it a Western epistemology inherent in privileged subjectivity, as problematized by post-colonial theorists for quite a few decades now (Barenboim \& Said 2002)? In any case, I expected to find a great festival of "enlazadores de mundos" leaping around in all kinds of innovative interactions of music-making that stretch the bounds of this instrument, and of the people who play it, listen to it, and love it. What I found was nearly the opposite- and both far more and far less (musically) complex.

During this research, I located and interviewed twenty-eight charango players living in nine different European countries (most in Central Europe, one in Iceland, two in Croatia). ${ }^{3}$ These participants were recruited from a widely dispersed field of players who were not easy to find, as there is not a plethora of them in any part of Europe. Limitations of time and resources for the research played a role in recruitment. ${ }^{4}$ Some of these players are Latin American migrants, and others are Europeans of various stripes, with a few "hard to define" subjects filling in the cracks.

Most of these players are not primarily engaged in music-making that is off the beaten charango path (as documented in the Table of Interviews' last column). To the contrary, as the second section of this thesis will explore and reveal, their music follows customary traditions and popular trends all meandering more or less in a corral of Andean and pan-Andean music, broadly understood. Less than one-third of the charango players I interviewed are engaged in musical activities that stretch beyond the traditional or common, and for most of them, this is not their main focus. However in their stories I found some examples that address questions of culture and genre crossing with the charango outside of Latin America (Chapter Six).

\footnotetext{
${ }^{3}$ Austria, France, Belgium, Germany, Spain, Portugal, Switzerland, Croatia, Iceland. Interviews were conducted in Spanish, French, German and English. All translations in this work (from Spanish, primarily) are mine.

${ }^{4}$ See Chapter Four.
} 
The ethnographies touch on an array of disciplines and cross through currents of history that brought the charango to the fields in question. ${ }^{5}$ Intersections of economics and politics emerge here alongside more musicological themes such as aesthetic tastes of audiences, musical talents and skills of players. Material artifacts of the recording industry and the availability and crafting of instruments also play their roles, as do expressions of subjects' ethnicity and identities in both "home" and "foreign" contexts. All of these factors steer the trajectory of the global charango through the lives of the players involved in this study and will be presented here, guided by their narratives as a springboard for reflection.

Existing literature and research on the charango in particular do not provide much information on the question of its influx, presence or activity in European fields. Perhaps the 2019 publication of a first collection of writings on the charango (El Charango: Historias $y$ Tradiciones Vivas) marks a watershed moment in this area of study, however, it does not provide any new resources and few that relate to this work. Rather, it gathers together a selection of already existing writings related to the topic of the charango, with some insightful editorial overview (Mendívil 2018). Many of these writings are non-academic but nevertheless narrate a certain terrain of discourse related to the instrument.

In the quest to understand and define the charango from a perspective outside of South American contexts, it must be considered that "much of the power, mystique, and allure of musical instruments $[\ldots]$ is inextricable from the myriad of situations where instruments are entangled in webs of complex relationships" (Bates 2012). This and similar insights from new

\footnotetext{
5 "Fields" will be used in this work to describe "places" in a sense that encompasses not only a precise or broader geographical "locale", region, or area, but encompassing the social and cultural activity that takes place in processes and interactions of everyday life within them. Unlike its more academic reference to an "area of study", "field" in the sense I will use it refers more broadly to the life processes in places, such as in "field" work or "field" studyobviously not referring to a researcher standing out in a farmer's clearing, rather, more of a social location with loose geographical indicators, as per the common use of the word in social science research contexts.
} 
organology urge us to explore instruments in lived intersections of expression. And so most centrally, this thesis is a field study report of such lived intersections based on the ethnographies of charango players whom I interviewed in the fall of 2018, primarily in Western and Central Europe. Their data provides complex points of reference through which I have examined the charango's contemporary presence and musical activity in various (European) fields. Through my informants' narratives, this work highlights and explains the shifting discourses and projections of meaning that the charango has been assigned over time.

In initial chapters, I will tie together relevant historical developments, discourses, and vernacular associations to provide an informative backdrop to subsequent chapters drawn from the ethnographic narratives. The answer to the question, "What is a charango?" and to "What does it mean?" will thereby be proven to be fluid, and driven primarily by human proponents and their actions and interactions. This will contribute to the new organology's cue to consider instruments as "sites of social significance" (Dawe 2013). The work will also provide a measuring stick from which to approach the question from the beginning of this preface: has the charango "gone global"?

While it would be difficult to substantiate any definite claim, this thesis does show that the charango, except in the hands of a very few who engaged in musical innovation and experimentation, is still primarily a "folkloric" instrument whose ties to homeland musics, traditions, identities, and geographies remain strong. But it also shows that the charango has travelled, and been embraced by proponents whose identities are centered outside of the Andean world. As such, the global charango will remain an idea, a point of investigation and inquiry, and a way of articulating the study of the instrument in circumstances outside of Latin America. ${ }^{6}$

\footnotetext{
${ }^{6}$ A note on gender: As the Table of Participants (on page vi) shows, there were five female players and twenty-three male players interviewed, reflecting the reality that the charango is an instrument primarily (but not solely) played
} 


\section{Introduction: The Charango and Its Reach}

During one of my first meetings with my field work supervisor, I was introduced to his eclectic personal collection of charangos. The tour meandered from the small "chillador" charango with an armadillo shell back, to a larger flat "Ayacuchano" variant, to others. ${ }^{7}$ As we talked and plucked I admired the variety of sonic and aesthetic textures of the different instruments all called "charangos". ${ }^{8}$ He told me where he had found each one, what kind of music he played on them, and with what tradition and locality each was associated. As I touched and strummed them I wondered out loud: do instruments have some kind of innate character or personality, something that one connects with, or doesn't, when playing them? 'No, I don't think so," he said. "It's just an instrument: wood; strings; ...nothing more."9

I was surprised that he drew such dry lines around these precious objects which to me seemed to have so much personality. Ethnomusicologist Kevin Dawe has posed similarly, that "a musical instrument is much more than the sum of its parts [...] much more than the thing itself."

by men. Indeed (as in most affairs) there is much to say about gender regarding charango traditions. My research, however, was focused on the themes described above, as guided by ethnographic results. The same questions were posed to both female and male players to explore issues of the meaning and role of the charango in their musical lives. Gender did not emerge especially as a theme from the interviews. Hence, only in a few instances will gender be commented upon, most especially in the conclusion as pointing towards future research.

I was repeatedly coached to thematize gender issues despite their absence in the ethnographic narratives. In one case, I was queried as to why I had not focused on gender, since I was female. This question suggests that female scholars (more than males) should engage in gender analysis. If so, why? In another comment it was proposed that when female players were presented in this work, gender analysis should be engaged (suggesting that presentation of players of male gender would not require the same). Surely gender analysis, where engaged, would apply to everyone. There are gender issues to be explored regarding charango tradition, some of which appear obliquely in nationalist discourses about the instrument (Chapter Three). Otherwise, gender did not emerge from this ethnographic data as a primary thread, and would doubtless be an interesting focal point for future studies by scholars of any gender.

${ }^{7}$ Sound sample of Julio Mendivil playing the Ayacuchano charango variant Audio Index 1.

${ }^{8}$ His collection was by no means expansive compared to those of others I've seen, as well as collections in cultural centers and museum projects, such as the notorious collection of Ernesto Cavour in La Paz, Bolivia which is reputed to be the most extensive in the world. Along my charango playing and studying path since 2015 I have seen many collections of players, makers and aficionados, and each collection is usually accompanied by an equally detailed narrative of history, memory, construction, attachment, and knowledge capital about the instruments. Visiting a charango enthusiasts' collection of any size is a very personal experience that reveals a depth of attachment and feeling about the instruments that is striking.

9 Julio Mendivil, personal conversation, September 2018, Vienna, Austria. 
(Dawe 2003). In the Andean world, animistic beliefs and traditions around the charango also provide additional contrast to static organological approaches that would study an instrument as a material object to the exclusion of other possibilities (Cavour 1980, Bates 2012). Some new organologists promote investigations through Actor-Network theory that push the issue a bit further, to consider instruments themselves as actors/agents (Bates 2019). My own experience and viewpoint with instruments falls somewhere in the center range. To me, each assemblage of wood and strings (or other materials) seems to me to have a unique energy or "vibe", reflected in sound, but not exclusively. Certainly as artifacts, instruments carry a great deal of personal as well as cultural associations. Perhaps what I feel with the "wood and strings" is the energy of “the music itself'. This phrase, frequent in musicological texts would suggest that music could indeed exist without human engagement. But is a concept of music, or a musical instrument, as "itself" devoid of entanglement with human subjects of any use? And this was exactly the point of my professor - that the charango without human engagement is, well ... nothing.

This simple point was a ground-breaker in organology, which has moved far beyond the study of instruments as reified material objects to be measured against one another in isolation of social concerns and historical circumstances (Bates 2012). However, the push away from this static approach came later to the table in the study of musical instruments, according to organologist and ethnomusicologist Kevin Dawe. In "Guitar Ethnographies: Performance, Technology and Material Culture," Dawe writes,

...for instance, there was little or no mention of studies of musical instruments in Arjun Appadurai's (1986) seminal collection, The Social Life of Things: Commodities in Cultural Perspective. Yet with the publication of Eliot Bates' recent article 'The Social Life of Musical Instruments' (Bates 2012), we may wonder why such a useful and challenging publication arrived so late" $(2013,12)$. 
In the work Dawe mentions, Elliot Bates took the idea a step further, to suggest that we consider instruments themselves as protagonistic to explore new ways to "think through instruments" $(2012,366)$. Bates asks us to examine instruments as they are enmeshed in complex human relationships that are constantly in flux. In a spin off of Appadurai's seminal work, Bates wrote:

Even the same instrument, in different socio-historical contexts, may be implicated in categorically different kinds of relations. I this am arguing for the study of the social life of musical instruments (2012, 364).

Whether one agrees to commit to the idea of an instrument having a "life" or not, certainly (as we will see throughout the thesis) the charango has surfed the twists and turns of human contexts and engagements throughout its history to present and represent a variety of meanings and impacts to a just as varied group of human actors.

Theorists from other areas of study have also contributed to these kinds of theoretical developments in organology. Anthropologist and scholar of visual material culture Alfred Gell proposed a kind of agency that springs out of human entanglements, rather than existing outside of it (Gell 1998). In his work, Art and Agency, Gell pointed out that "the ways in which social agency can be invested in things are exceedingly diverse," and that artistic objects can become extensions of human social and political agency $(1998,18) \cdot{ }^{10}$ Gell and others indicate a shift in material cultural studies that would explain the move away from the study of instruments in isolation from their social and cultural roles and meanings.

Such perspectives are of great relevance to this research, which is less concerned with the charango as an artefact or static object than with the meaning of the charango at intersections of human activity and attention. Significations and associations pertaining to the charango have fluctuated wildly over its lifespan beginning with encounters between indigenous Andean

\footnotetext{
${ }^{10}$ Certainly, the prohibiting of certain instruments at various historical and political situations because of what they are perceived to represent (including the charango briefly, in the early days of Pinochet's dictatorship in Chile) would support this argument.
} 
peoples and the invading "conquistadores" and colonialists from mainland Europe (Spain) from which the instrument emerged more than five centuries ago (Gallac 1937, Cavour 1980). ${ }^{11}$ However, this study is not so much concerned with the ancient history of the charango, nor is it whatsoever about the question of the charango's origins - for much has been written on that subject, and with much debate. ${ }^{12}$ Rather, this study is focused on the charango's contemporary history and very current activity in human and musical terms with a view in particular to players in the places they live in Europe.

Here, the charango will be presented in an active human tangle, where its players play among listeners, dancers, and fans engaging in cultural rituals, practices, and musical lifeways associated with the instrument. These interactions take place at festivals and celebrations, in solo and group performances, and in formal and informal practices and jam sessions. The making, buying, selling, and admiring of the charango creates other interactions, and academic studies such as mine also contribute to the many activities which all, in some way, involve the charango and its musics. Most importantly, musical traditions are performatively re-created and replicated in various scenes, and sometimes new musics are forged. These activities take place in various locations and geographies, in analogue community functions in the Andes and elsewhere, and in digital archives, performances, and online teaching businesses with an international online public. In other words, the charango is, in modern times, a common point of interest for a both centralized and dispersed "community" of diverse people whose contact and activities are woven

\footnotetext{
${ }^{11}$ Here I refer to the inhabitants of Andean areas before the arrival of the Spanish.

12 These debates will be reviewed for the context they provide as to encounters in the field as well as to the overall "scene" in Chapter Three.
} 
around the wood and strings to be the something more that defines the fields of play of the charango, and perhaps, at least in part, the charango "itself". 13

These networks facilitate ties of friendship, engagements in musical exchange and pursuit of commerce and economic gain all involving the charango and its music. As in most human affairs, there are also disputes and divergences both interpersonal and international. Some of these connections are localized to one city, town or region and others stretch across national and continental boundaries. The movement of everything related to the charango, including ideas, political agendas and initiatives, senses of ethnicity and identity, public tastes and interests and other issues that seem unrelated to music, travel and loop along pathways of affiliation that are the circulatory system for an evolving answer to the question of what the charango is in any given place and time. These pathways criss-cross between "homeland"/"local" contexts and "foreign"/ "international" ones, often embedded in the same moments as well as occupying spaces online to the extent that one could maybe more accurately say that the charango is now "glocal", i.e., dynamically entwined in the spectrum of local and global processes. This term, repurposed by sociologist Roland Robertson from business and marketing terminology, may help to "transcend the tendency to cast the idea of globalization as inevitably in tension with the idea of localization" (1995). Applying Robertson's perspective expressed in the term "glocal”, what we can conceptualize as a "global" charango can be viewed not as oppositional to a "local" charango, but as involved in simultaneous if not integrated and intersecting processes. This will become apparent as we examine contemporary situations through the ethnographies of players living in European fields that guide this study.

\footnotetext{
${ }^{13}$ I use the word "community" here tentatively. One could also accurately call this a "network". My desire is to describe a context that these twenty-eight players' ethnographies are connected to, similar to the concept of "Art Worlds" as described in Howard Becker's work (Becker 1982). This "community" is both a dispersed and gathered "global" and "local" entity-in-motion whose focal point is the charango, or charangos.
} 
As much as the charango can be said to be any fixed entity or not, the range of meanings given to it throughout its history has been both vast and pointed. Organologist Ian Woodward posits that objects (such as the charango) are tangled in social narratives and that "the question of whether this is the same or a different social object depends on whether and how this is the same or different story" $(2007,174)$. This work presents diverse stories, i.e., social narratives, of charango players I interviewed in Europe in the fall of 2018 in order to examine the meanings and trajectories to which the charango is connected, socially and musically, in their situations. I will also look at how and why the charango has been imagined overall at relevant historical intersections, by agents motivated not only by artistic expression and personal attachment, but by politics, economics, and forces of history.

\section{Outline of Chapters}

Chapter One: What is the charango?

A further introduction, this section provides a basic orientation for the reader who is unfamiliar with the charango and its contexts. Forms, tuning, traditions and other basics will be mapped out in this section, which will also review key concepts in home contexts in South America.

\section{Chapter Two: Historical Context}

I will begin this chapter with a review of the charango as it entered European fields via France in the 1950s in the context of the emergence of Andean popular music, with which it is still primarily associated in most cosmopolitan scenarios today. Most important to this subject is Fernando Rios' historical account of the formation and evolution of pan-Andean music in Paris from the early appearances of the instrument in the 1950s through the reputed "boom" of the emerging genre on the streets and stages of Western Europe in the 1980s and 1990's (Rios 
2008). This work exposes the formative influence of leftist European subcultures in concert with Chilean and Argentinean musicians in Paris to the formation of pan-Andean music which looped through currents of trans-local exchange between Europe and South America, including intersections with the leftist Nueva Canción (New Song) movement, in which Violeta Parra played a crucial role. ${ }^{14}$ The charango's presence in this movement fortified certain concepts of the instrument as a symbol of indigeneity, but with a contemporary leftist, anti-imperialist twist and as a general signifier of rebellion that is still quite palpable today. ${ }^{15}$

Later developments in the street music scene in Europe (and North America, to a lesser extent) have drawn the charango into (or eliminated it from) amplified pan-indigenous performances that mix Andean sounds, instruments and images with those of North American native peoples in a hodge podge of visual and sonic display. These less strictly musical street spectacles insinuate a sort of natural-world-loving, earth-healing "pacha mama" spirituality as the sound song of the enigmatic "Indian" wearing a colorful feather headdress, and sometimes holding a charango. ${ }^{16}$ The stereotype of a "wise Indian", re-presented in sound, lights, and visuals next to the merchandise table reverberates with European tropes seeded in its colonial past. Ethnomusicologist Jana Jetmarová's work based on field experiences with this more recent wave of street performers who, she asserts, are the main vendors of these new versions of "Andean" music offers an analytical framework with which to understand the turn of trend (Jetmarová 2013). Lynn Meisch’s research on Otavalan street musicians and international sellers

\footnotetext{
${ }^{14}$ Connecting and circulating between localities on the two continents.

15 The idea of "indigeneity" in the trajectory of the charango has had fluctuating applications and meanings that will be clarified as to particular situation and context throughout this work.

16 "Pacha Mama"- mother earth. A Quechua word and concept that describes a planetary spiritual entity similar to the idea of a 'mother earth', i.e., a concept that the planet, the earth itself, is a kind of greater animate being that is a spiritual source point for all of life. This is a central concept among traditional Andean peoples that has been incorporated into mestizo worldviews as well, and in some cases, appropriated by non- indigenous New Age cosmopolitan actors outside of the Latin American world. (See footnote 102, p. 98, for further discussion of New Age ideology.)
} 
of "artesania" (handicrafts/textiles) in public spaces provides additional information on the international street scene in the early ' 90 s (Meisch 2002). ${ }^{17}$

\section{Chapter Three: The "Origins" Debate}

Pervasive contemporary debates on the subject of the origins of the charango saturate charango related literature of all kinds. Why? I will trace the relationship of these discourses to South American nationalisms, most especially to Bolivian and Peruvian perspectives, as articulated in Julio Mendívil's important article on the topic (Mendívil 2012). I will then explore how these issues play out in certain discordant scenarios I encountered in the field. Again, threads of reference to these discourses emerge through some of my ethnographic interviews (Chapter Five), with adjunct themes, and will be presented in the text.

\section{Chapter Four: Field Methods}

This brief chapter outlines recruitment and field method, and some of the issues and challenges in finding charango players to participate in this study.

Chapter Five: "El Charango es mi vida" (The charango is my life)

Sourced primarily from field interviews, this chapter sifts through the narratives and commentaries of the charango players I met to identify certain common threads that pertain to attachments to the instrument. Drawn from recurring statements such as "the charango is my life" and "it was love at first sight", these attachments are revealed through life stories and situations, emotional and psychological hooks, or romantic imaginaries connected to the instrument or to its home terrains in the Andes that sometimes overlap with the previous chapter. Sub-themes are presented through the voices and accounts of the players interviewed, and reviewed for common themes and intersections with the historical and political contexts that

\footnotetext{
${ }^{17}$ People from indigenous communities in Northern Ecuador.
} 
frame each narrator's situation. Relevant secondary sources are introduced to provide backdrop for analysis of the field data.

\section{Chapter Six: Case Studies: The Innovators}

Finally, the rare "innovators" who I encountered in the field will be curated. These are a handful of musicians who are, in some way, involved in genre-crossings, fusion, cross-cultural collaborations, or otherwise carving out new musical terrain with the charango in their (adopted) European contexts. In three selected case studies I will examine what factors have inspired them to stretch beyond the usual contours of genre and tradition and how positionality impacts their work. A close examination of their musical choices and activities in interaction with economy, audience and market demand, artistic curiosity, social relationships, questions of identity and musical tool kits will shed light on modern scenarios of music-making and the ever shifting boundaries of the charango as it moves through contemporary spaces in the hands of the musicians who play it.

As previously mentioned, this work should primarily be considered a field report on the presence and musical activity of the charango in various places in Central and Western Europe in the fall of 2018, and as such, is an examination of a handful of players of this particular folkloric instrument outside of its home contexts in that time period. Historical backdrops, relevant discourses and debates, and technical and musical information are all presented to facilitate meaningful interpretation of the "data" provided by these ethnographies to a reader with no familiarity on the topic. The charango has endured much in the vein of sweeping claims made by its human proponents throughout its life span of five centuries. I will not attempt to add to this litany of grand declarations; rather, I will attempt to present the stories of these players in rich 
contextual soil that is both an informative read, and engenders curiosity and further questions and discussions on the topics that emerge from this research. 


\section{Chapter One: What is the Charango? The wood and strings}

The word "charango "... since the middle of the twentieth century has referred to a chordophone comprised of five courses of strings, belonging to the lute family, with significant presence in the Andean musical traditions of Bolivia and Peru. The meaning of this word, however, has changed substantially in recent years, modifying at the same time the cultural and social value of the object it designates (Julio Mendívil, $E l$ Charango: Historias y Tradiciones Vivas, 2019).

Defining the charango would seem an obvious and concrete task, and in some ways it is. Generally speaking, it is a small guitar-like chordophone with roots, primary associations, and musical popularity in the South American Andes mountains regions and nearby urban areas. The standard contemporary version has a rounded or flat wooden resonator box, five courses of double strings and a standard tuning of G-C-E-A-E from top to bottom, with one bass string in the center paired with its octave $\mathrm{E}$ twin. That said, there are so many variations of these aspects (physical form of resonator box as well as its size, number of strings, doubles and singles, and tuning variations) that it can nearly be said that the charango has no standard at all, and that it is difficult, indeed, to define (Cavour 1980; Gomez Vela 2000; Cornejo Puran 2016; Mendívil 2018).

Within South America both historically and currently, there are many contexts in which the charango (with an array of names assigned to its variants - charangu, charanga, walaycho, quirquinchu, kalampeador, chillador, ronroco, charangon, etc.) bears only general resemblance to any description of a "standard" charango. Beyond curiosities of variation on traditional organological terms, these variants can be strong signifiers as to place (local, regional, and national), ethnicity and nationality as well as pointing to particular musics and repertoires (Stobart 1991, 2008; Grassler 1999; Ponce 2008; Turino 2008; Pedrotti 2012; Cornejo-Puran 2016). Similarly, musical choices, repertoires and playing styles are also laden with signs and 
meanings that situate its player in terms of place, ethnic identity, sometimes nationality and even "lineage" in terms of their mentors and musical predecessors. These "signs" can be very general indicators (for example of something like national identity) or reference something extremely specific (such as with whom the player studied, or the influence of famous players). In other situations, playing style, technique and repertoire choice or even variations in lyrics of the same tune, can index to which specific region or even particular village the player is connected (Cavour 1980; Paniagua Loza 2005; Turino 2008). This broadly heterogeneous area of musical culture really has no single point of unity (albeit many areas of overlap), not even in the name of the instrument itself. And yet, what a "charango" is is commonly understood in its strikingly diverse contexts.

Hence, it cannot really be claimed that there is a standard charango at all (and certainly no standard charango music). This should not be surprising if indeed instruments are defined primarily by their engagements in human interactions that are constantly in flux, as suggested by new directions in organology represented by such theorists as Bates and Dawe. However, short of embarking upon a global head count and musical assessment of charango players, let us state plainly that the instrument described in the paragraph above as the standard charango is indeed, the one most commonly played by the interlocutors in this study (unless otherwise indicated) and very likely, elsewhere.

This (so-called) standard charango is sometimes called the "mestizo" charango because of its emergence out of historical changes in Bolivia and Peru in the 1930s to 1950s. This period saw increased rural to urban migration and subsequent mestizisation processes (cultural and identity adaptations) that affected all areas of life (Turino 1993; Mendoza 2008; Mesa Gisbert 
2014). ${ }^{18}$ The charango moved in the hands of players from rural, indigenous contexts in the highlands into emerging modern and cosmopolitan scenes in cities where these miigrants encountered "criollo" and "mestizo" values that were dominant and preferenced. Certain adaptations in form and playing style evolved, for example, the addition of a centrally placed bass string which extended the low end of the instrument's range (Cavour 1980). In the cities, rural and indigenous preference for high pitches and fast strumming was now overridden by the more criollo taste for a balanced tonal spectrum (Turino 1988). The mestizo charango articulated melody lines that were plucked out in parallel thirds instead of embedded in strummed sequences that emphasized rhythm as was/is practiced in the countryside. The life of the rural charango as a singular instrument in the hands of courting young men, or as one of many cacophonous players in indigenous community celebrations was subsumed for staged performances in urban mestizo contexts catering towards more Europeanized (criollo) musical tastes. The guitar entered the mix in an accompanying role as the charango emerged as a solo instrument, motivating new lineages of players to aspire to virtuosity according to mestizo/urban musical aesthetics and pursuing performance careers for economic gain. These changes involved long processes unfolding over

\footnotetext{
${ }^{18}$ Ethnicity is a complicated topic in the Andes and in Latin America generally. "Mestizo" is commonly understood to indicate a mixed heritage of Spanish and Indigenous descent. "Indigenous" here generally refers to highland rural Andean people and usually Quechua or Aymara speakers. They sometimes self-identify as "campesinos", although campesino (rural) communities may include some mestizo people. These are slippery categories established in processes of colonial domination that manifest still today as a kind of class/caste system in much of Latin America. "Mestizaje" (Sp) or "mestizisation", then, is a term that describes processes of adjustment, accommodation, change, and some might argue, assimilation of indigenous migrants' culture towards more mestizo (mixed) or criollo (descendents of Spanish colonialists) identified norms and values as they established themselves in the cities in an effort to climb the social/economic ladder.

Thomas Turino has argued that mestizo culture demonstrates a kind of "shifting" identity, while others (including myself) would argue that mestizo, constitutes its own substantiated terrain with corresponding values, tastes and traditions (Turino 1984). What is vital to understand is the extremely dynamic and sometimes overlapping nature of these three categories of identity (criollo, mestizo, indigenous) in Latin America generally and in Andean contexts in particular. Extensive studies on these matters have been conducted by cultural anthropologists, sociologists, and scholars in Latin American studies (Pacini-Hernandez 2010). As pertains to musicological interests, these mestizisation processes have had a direct impact on the value (or un-value) given to the charango at various historical time-spaces, and have also made an imprint through its physical variations and associated musics.
} 
several decades within specific histories of modernization in national and regional contexts in Bolivia and Peru. ${ }^{19}$

In parallel trends, nationalist movements in both Bolivia and Peru made efforts to amalgamate musical "folklore" in service to the construction of national identity (Mendoza 2008; Mendivil 2013) The charango, just one instrument to get swept up in these currents, was inculcated as a "folkloric" instrument situated in "traditional" (hence, "national") music and promoted through government initiated cultural events and programs. It subsequently enjoyed a leap of status as a representative of national culture on these terms (Turino 2003). This of course led to later tugs of war over heritage rights to the instrument that still resonate in current times which will be explored in depth in Chapter Four (Mendivil 2013). Again, these changes were drawn out over several decades in various ways in different locations, cities and national contexts.

\section{Material Innovations}

Experimentation and variation of material form of the charango is a well-established aspect of its tradition. Indigenous/rural Andean contexts, well documented by established ethnomusicologists and student scholars, have documented a broad range of charangos varying in shape, size and tuning and used variably according to occasion, festival and time of year (Stobart 1991; Ponce 2008; Turino 2008; Pedrotti 2012; Cornejo-Puran 2016). Several other studies confirm the existence of charangos with resonator boxes resembling Sirens that are believed to have magical powers in courting rites of passage, reflecting Andean animistic beliefs as previously mentioned (Turino 1983; Mesa Gisbert 2014).

\footnotetext{
${ }^{19}$ See Arguedas 1985; Turino 1988, 1989, 2013; and Mendoza 2008 for more specic histories where these processes played out.
} 
Innovations of the modern/urban charango have become almost standard fare, including adaptations for amplification which is now frequently used in some performance scenarios and new genres (Andean-flavored "rock", for example). ${ }^{20}$ Some notable examples of charango variants are Bolivian Ernesto Cavour's infamous "star" charango, pictured below. The town of Serrano, Bolivia boasts the "biggest charango in the world" and Guiness World Record fame.

This enormous instrument was the effort of a volunteer troupe of luthiers and musicians in honor of charango player Mauro Nuñez, one of the Bolivian "greats" known for his inventiveness with traditional Andean instruments (BBCmundo 2005). ${ }^{21}$
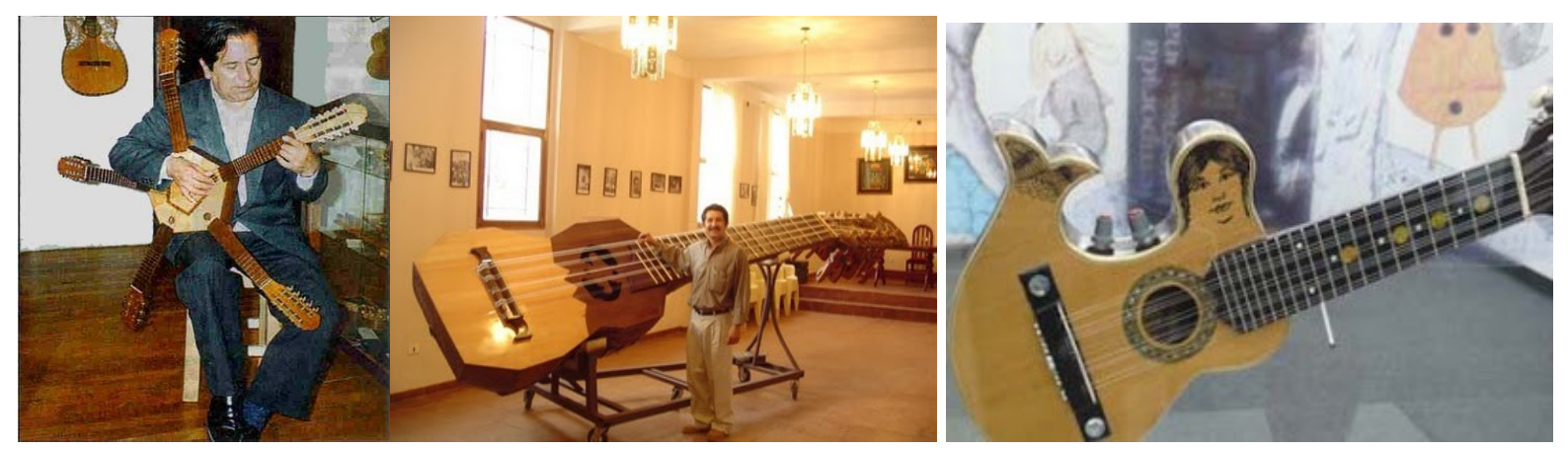

Left:1.Ernesto Cavour with his star charango; Center: 2. The biggest charango in the world (in Serrano, Bolivia; Right: 3. a siren charango (all pictures accessed online/ public domain).

A few more recent examples of material innovation stand out among contemporary players whose charangos push the edges perhaps to their breaking point, both in their physical form and in how they are playing these instruments. In these examples, we can see the interplay between experimentation in form and musical expression, and how the two are linked at the edges of contemporary charango music-making. To be clear, these are not interlocutors living in Europe, however, they present good illustrations of the point at hand.

Federico Tarazona's Hatun charango

\footnotetext{
${ }^{20}$ Los Tekis, Rockpata, a whole mini-genre of Andean flavoured rock...

${ }^{21}$ For more on this charango as a "tourist" attraction, see footnote \#71.
} 


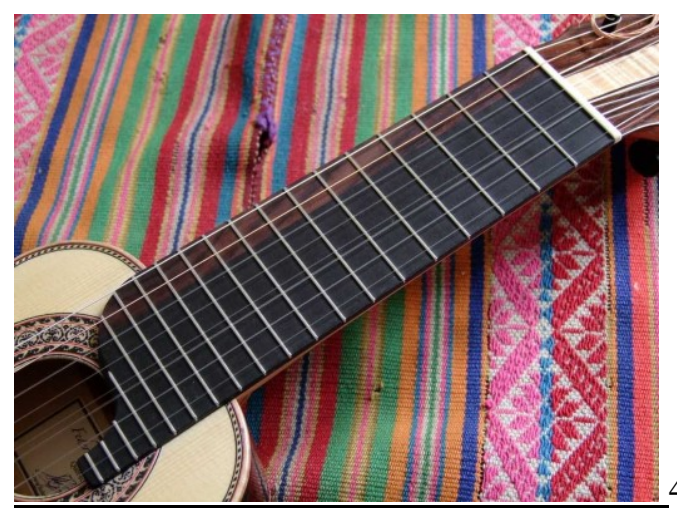

4. Tarazona's Hatun charango: Photo from his website.

Federico Tarazona is a charango player from Arequipa, Peru who now lives and teaches guitar (primarily) in Quebec City, Canada. He is a virtuoso known both in Latin America and Europe as well as in urban parts of Quebec and a skilled instrument builder. He has invented a flat-backed variant he calls the Hatun charango (with luthier Fernando Luna of Lima, Peru), which has one or two additional bass strings on the instrument, significantly expanding its lower range. These additional bass strings afford Tarazona a myriad of musical options not available on a standard five course charango. Tarazona's music and stage presence is very "classically" executed and styled. ${ }^{22}$ He performs a range of interpretations of both Andean and European art music pieces that require advanced skills. His base training in classical guitar strongly affects his approach to the charango, as evidenced in both his technical and musical choices. His desire to

\footnotetext{
${ }^{22}$ Indeed, this has contributed to his popularity both in Latin America and Europe, concurrent to trends in charango musical circles internationally that seem to regard the execution of European art music pieces by virtuoso Latino players in high regard (see Zeoli's comments, Chapter Six). This phenomenon may evidence the continuation of internalized colonial value systems as pertains to music exemplified in the elevation of European art music (over more popular - folkloric and traditional — forms) where events are staged primarily by mestizo Latinos, or in Latin American contexts. (Ironically, this trend also may point to the cosmopolitan nature of the actors in these scenes, or perhaps their aspirations to identify with cosmopolitan aesthetics).

Oddly I witnessed a similar occurrence with Tarazona as the star player in the "Encuentro de Charangos" that I attended in Brussels in Nov 2018. This event was organized primarily not by mestizo Latinos but by a Belgian woman. However, she may have been following popular trends in Latin American mestizo circles in her programming choices, as her Encuentro de Charangos is a reproduction of a popular Latin American form asserted because of her own affiliation and interests in Andean music.

Further, cosmopolitan trends in other instances have uplifted folkloric and traditional musical expressions (or at least, what gets promoted as such) as we will see in the emergence of pan-Andean genre discussed in Chapter Two. These various intersections point to the dynamic and complex nature of cultural processes as pertains to identities and allegiances. Although the terms "mestizo" and "cosmopolitan" serve analysis greatly, they also have limits as descriptors of complex and shifting identies and power relations within those formations that are highly dependent on particularities of context and circumstance.
} 
play a broader range of music beyond the traditional and local was a driving factor in his material innovation of this charango variant. ${ }^{23}$

Camilo Gomez: Lazador de Mundos (connector/leaper/engager of worlds)

Camilo Gomez is another musician pushing the edges of definition both in form and function. When I met Camilo in 2015 his primary instrument was a standard round-backed charango, and he was playing original repertoire not too far beyond what is being composed in urban Chilean contexts. However, Gomez's performances integrated an electric loop pedal to create layers of percussive and melodic sound behind the main melodic themes. ${ }^{24}$ These techniques were innovative, even in an experimental music scene like "Valpo" (Cornejo-Puran 2016)..$^{25}$

Gomez has recently released a second recording in which he has stretched even further beyond norms of charango playing (Lazador de Mundos 2018). On it, he plays a fretless baritone charango loaned to him by an inventive luthier for a trip to India. 'I'm not even sure if I can call myself a charango player anymore," Gomez stated in a recent conversation, referring to this latest release of original music that features this "charangon" in soundscapes influenced by an Indian/Eastern sonic palette, accompanied by a trio that features a jazz saxophonist and an Indian tabla player. ${ }^{26}$ The fact that the instrument is fretless affords certain opportunities in pitch variation, slides, and generally innovative technique that Gomez maximizes to express his pancultural instrumental charango-ish music. ${ }^{27}$ $\underline{\text { Innovative forms, traditional musics }}$

\footnotetext{
${ }^{23}$ Sourced from www.federico-tarazona.com; Tarazona, Federico, personal communication Brussels, Belgium Nov 2019.

${ }^{24}$ Available at: https://www.youtube.com/watch?v=3n2XJoJmm0s

${ }^{25}$ Personal field experience Jan 2016.

${ }^{26}$ Gomez, Camilo. Personal conversation via Facebook Messenger, March 2018.

${ }^{27}$ Sample from 'Lazador de Mundos' of Charangon Audio Index 2
} 
These innovations in physical form may offer a new interpretation on the meaning of the charango in (new) organological terms as is also the case with the innovators presented in Chapter Six. Given the taste for material innovation in certain corners, one might expect a similar tendency in the musical realm, as evidenced by the examples above. While openness to experimentation is acceptable in some cases (such as the scene in Valparaiso, Chile) it is not necessarily the case in others. Bolivian charango culture is notoriously traditional and Peruvian pockets are regionally very diverse, but also accustomed to folkloric interpretations, generally speaking. Traditional playing techniques and style are predominant in regions that are closer culturally and geographically to rural and indigenous contexts in the Andes. In these areas, there are diverse and specialized varieties of localized musical repertoires associated with the charango in its different forms and locations throughout the Andean zones. ${ }^{28}$

Many playing techniques are also regionally and locally specific. Strumming patterns, slides and prolonged tremolo are all indexes to certain regions. Costumery and dances as well as tune repertoire and lyrics provide further signs as to place. Enough local musics have been studied and documented by musicologists to easily support a claim of diverse charango repertoire, however not a general spirit of innovativeness in music-making (Stobart 1993; Grassler 1997; Ponce 2007; Turino 2008; Pedrotti 2012). In fact the charango, musically, has by and large remained close to musical tradition and folkloric repertory in most circumstances, even in diasporic situations, as my own study has evidenced. ${ }^{29}$ In some cases what is perceived as tradition is definitively, traditional. In other cases "traditions" have been imagined and

\footnotetext{
${ }^{28}$ Based on conversations with many players internationally and observations in the field, 2015-2018 as well as extensive ethnographic studies by scholars such as Henry Stobart, Thomas Turino, Italo Pedrotti, Jean-Marc Grassler, and others cited in this work.

${ }^{29}$ The term "diasporic" will sometimes be used to describe location outside of Andean or Latin American homeland environments along the lines of the vernacular use of the word "foreign", even though, as noted elsewhere, my interlocutors and their situations do not technically constitute a "diaspora", it is more in a metaphorical sense.
} 
constructed according to nationalist or other identity-based agendas as previously mentioned (Mendívil 2013). Subsequent tugs-of-war over which traditions belong to whom have peppered discourse over Andean music in general, and as pertains to the charango in particular (Mendívil 2018).

So, what is the charango? It is, of course, an arrangement of wood and strings (or other materials) although how these materials are assembled varies greatly both currently and historically. Although one can argue that there is little in the way of a fixed common denominator that defines a charango, a "standard" charango variant has been established in modern intersections. ${ }^{30}$ This standard charango emerged out of "mestizaje" processes in growing urban scenes in South America where criollo musical values based on staged performance, balanced tonal range, clear articulations of melody with harmony and "solo voce" were preferenced over the participatory, high pitched, cacophonous, rhythmic, communal music-making common to indigenous rural contexts (Turino 2008). To whatever degree a standardardized charango has become common, the many variants still being played as well as those being invented strengthens the arguments of organologists like Bates and Dawe, who would define the instrument by the great plurality of actions and interactions of its human agents (as discussed in the Preface).

Organologists' definitions aside, how is the charango understood by the people who engage with it? Besides material components, construction and form, can the charango be defined by the music that is played on it and by how people who play it feel about it? This can only be addressed ethnographically, as is the intent of this study. What particularly have various players in European contexts contributed to the meaning and trajectory of the

\footnotetext{
${ }^{30}$ Indeed, as innovation has been shown to be a common practice, does that not suggest a "standard" from which to depart?
} 
charango outside of its homelands? A review of the arrival of the charango to Europe in the following section will reveal much that is pertinent to the discussion and provide a crucial historical background to the ethnographies of the interlocutors presented in subsequent parts of this work. 


\section{Chapter Two: Historical Context: The charango comes to Europe- Trans-local interventions and Indian tropes}

Any study of the modern charango's presence and activity in Europe has to be contextualized by the history of the emergence of Andean popular music, or "pan-Andean music" as I shall refer to it. ${ }^{31}$ This new genre unfolded in large part on the streets and stages of central European cities as much as it was developed and reiterated in similarly urban and cosmopolitan environments in South America. ${ }^{32}$ In developments over several decades this music (and by extension, the charango) became associated internationally with left-leaning, antiimperialist political and social movements (in particular protesting the Vietnam War and later, U.S. interventions in Latin America). While none of the players whom I interviewed were motivated to play the charango specifically because of leftist political views, the contemporary connection of the instrument to left-leaning trends both in Latin America and Europe is still implicit in the instrument's image and reputation, and explicit in some of the repertoire that is played on it. ${ }^{33}$

\footnotetext{
${ }^{31}$ On the sticky point of genre terminology, scholars differ. Fernando Rios calls it "Andean popular music". This may be accurate as this genre has a larger audience and spread than localized musics from specific regions in Peru or Bolivia, but then, local musics are also "popular" within their own contexts. Julio Mendívil uses the term "Latin American music" (translated directly from "musica latinamericana") which in Peruvian contexts refers to the genre in question, as distinct from "musica andina" (Andean music, directly translated) which refers to local, traditional Andean musics from Andean zones (Mendivil interview 2018). In this work, I choose to allow the word "Andean" to remain, as this music is heavily flavoured with the sounds of instruments associated uniquely with Andean traditions, as distinct from other regions of Latin America, where charango, quena, and other Andean instruments do not proliferate. I use the term "pan" to allow for the recognition of the broad spread in both formation and location of this genre and its repertoire (i.e., formulated, as we will see, by musicians of all stripes on two or more continents, and hardly any "Andeans", in the end of the story, and incorporating disparate expressive practices from many Latin American traditions, not only Andean). Of course, no term is perfect, and all are referenced by specific context and situation.

${ }^{32}$ I use the term "cosmopolitan" not in the vernacular sense that refers to an "elite" socio-economic class, rather, in the sense that was developed by ethnomusicologist Thomas Turino, to identify a transnational cultural formation with shared ideas that are diffused among similar (middle class) social groups in dispersed locales by various forms of media (Turino 2008, p.8). It may be pointed out that Turino's theory does not account for categorical differences in social and economic power within cosmopolitan formations that mirror other colonial and post-colonial divides. ${ }^{33}$ I refer here to "top hits" in Nueva Canción repertoire such as Inti Illimani's "Venceremos", the metaphorical "El Condor Pasa" and other songs of this time with subtexts of resistance and solidarity themes.
} 
Unfortunately, source material is quite limited on this topic. Only one major study exists that explores the emergence of pan-Andean music in detail—Fernando Rios's article entitled, "La Flute Indienne: The Early History of Andean Folkloric-Popular Music in France and its Impact on Nueva Canción" (Rios 2008). Paris was indeed the first epicenter in Europe of a musical subculture in which the pan-Andean genre developed. In later decades (1970s) Italy became a hotspot, probably due to the presence and popularity of the Chilean band, Inti Illimani, who were based in Rome during their exile from 1973 to 1988 (Cifuentes 1989, 62; Fairley 2002, 47). Patricio Zeoli, one of the participants in this study, moved to Berlin in 1973 and spoke of a scene not unlike the one Rios describes in Paris (Rios 2008; Zeoli interview 2018). Of course, touring bands such as Los Incas and Los Calchakis circulated this music, along with scores of lesser known and informal groups (including those of several of my interlocutors), by performing on the streets and stages all over Europe (Tagg 1991; Van der Lee 1997; Rios 2008; Mendívil 2015).

Therefore, Rios' work will be used as a guide through the early developments of panAndean music as it unfolded via the initial musical sparks of transnational cosmopolitan Argentineans during the "party days" in Latinophile clubs in Paris in the 1950s and 1960s. The later involvement of Violeta Parra in this scene, and her role in subsequent translocations of the musical subculture and its politics back to home contexts in Chile will be reviewed (Verba 2013). An autoethnographic vignette of one of my own experiences in the mid 1980s further illustrates how this music was formed for and used by a certain brand of cosmopolitan leftist politics that circulated internationally during that time.

Later developments are considered as documented by Czech ethnomusicologist Jana Jetmarová. Her fieldwork with Andean street performers chronicles recent trends in sort-of- 
Andean performances. The performers she studied presented merged and amplified musical and visual tropes of a pan-hemispheric Indian to draw the attention of an increasingly disinterested European public, post pan-Andean music “boom” (Jetmarová 2013). A short auto-ethnographic vignette is provided as a very recent illustration from July 2019, along with relevant narratives from some of my interlocutors in the field. Lynn Meisch's research on Otavalan merchantmusicians (from Ecuador) beginning in the early 1990s is considered, as is Joshua Tucker's work on "Permitted Indians", to examine the meanings of these more recent developments (Meisch 2002; Tucker 2011).

The "Flute Indienne": musical symbol of an emerging genre

The association between the charango and leftist politics is best understood by examining the history of the emergence of pan-Andean music in transnational processes, as chronicled by Rios's study. In this work, he traces the earliest presence of Andean music in France to the 1950s, when Argentinean musicians from Buenos Aires introduced their interpretations of Andean sounds and instruments to bohemian and Latino clubs in Paris — in particular, L'Escale and La Candelaria, which were hubs of student and Latino cultural life in the Left Bank at that time. $^{34}$

These urban South American musicians from Buenos Aires had been exposed to Andean music from Argentina's northern areas by early Buenos Aires folklorists since the $1940 \mathrm{~s} .{ }^{35}$ They

\footnotetext{
34 This included the presentation of Andean tunes in "conjunto" formation (charango, guitar, quena, and bombo/drum). Initiated by the popular Argentinean group Los Hermanos Abalos of the Buenos Aires scene, this formation became standard practice in pan-Andean instrumentation internationally (Rios 2008, p 150).

35 The folklorist movement in Latin America consisted of urban cosmopolitans who gathered and archived or performed what they perceived to be "traditional" music and song for presentation and preservation as national "folklore". Sources were sought in rural communities and often from older people living outside of big cities. According to Rios and other authors (Fairley 2002; Verba 2013), this was one response to the rapid growth of industrial capitalism and the perception that "traditional culture" was being lost in the post-World War II swell of modernity. This 1950 s folklore boom grew by the mid 1960s into a more politicized musical groundswell called "Nueva Canción" which had great impact both in Latin America and globally in terms of leftist, socialist, communist, and especially anti-U.S. imperialist political movements.
} 
had also heard music from Bolivia played by musicians who had come to Argentina to make recordings in the cosmopolitan metropolis (since recording technology wasn't yet available in Bolivia). Earlier, in the 1920s, a few select urban Peruvian artists had also done the same (Rios 2008, 149). These visiting musicians were not indigenous Andeans from Bolivian or Peruvian mountain zones but rather, mestizos who were interpreting their countries' local Andean musics for the cosmopolitan scene in Buenos Aires, as well as developing it for commercial consumption back at home. ${ }^{36}$ The situation in Buenos Aires was much like what would later unfold in Europe.

Some of the musicians arriving from Latin America to the Paris scene came to study painting, and first picked up Andean instruments in musical jam sessions at L'Escale, where this "folkloric" music was being played. Among others, painting students Carlos Cacares and Carlos Ben-Pott, the founding members of what would become one of France's most popular Andean bands (Los Incas), met and began playing in this scene (Ibid 150-151). They were soon picked up and promoted by the French music industry agent Jacques Canetti and like other emerging groups (Los Calchakis), toured France, Switzerland, and Belgium with their 1956 freshman release, "Chants et danses d'Amerique Latine". ${ }^{37}$ The "new" (pan-Andean) music was promoted on this album (and many others) as generally, "Latin American music", featuring mestizo flavored Andean instruments (including the charango) as "Indian" instruments to a widening European audience. ${ }^{38}$ Promoters in theatre and film followed suit (Ibid, 151). The small clubs became party hotspots for Parisian cultural life, complete with film star sightings, press attention

\footnotetext{
${ }^{36}$ Here again "indigenous" refers to rural highland Andean peoples.

${ }^{37}$ Songs and Dances of Latin America

${ }^{38}$ Of course, what Europeans understood as "Indian" had more to do with stereotypes of U.S. American Indians than it did with Andean indigenous peoples, although what was being promoted here was the idea that all Latin Americans, in a sense, were "Indians". Certainly, the music presented on such recordings was far from any kind of indigenous expression in any part of the Americas.
} 
and international reputation as the new genre found its footing and sound in musical interactions between Latin Americans, French students and bohemians (Ibid, 151-152).

While the charango was most certainly upstaged by the "Flute Indienne" (notch flutes and later pan-pipes) as the "star" of this new popular music genre, it did become an important weight-bearer in defining what the international scene would come to (incorrectly) understand as "Andean" music. This secondary position shifted somewhat with the later emergence of music that featured the charango as a solo instrument in the hands of virtuoso players. This more recent "charango music" (which is primarily instrumental) has a broad canon today, somewhat overlapping but not entirely located in the pan-Andean genre, especially in music from the Chilean scene.

$\underline{\text { Violeta Parra and Nueva Canción }}$

While party happy French bohemians, students and immigrant or visiting Latinos gathered in "peñas" (read pehn-yahs...music club café type places) in Paris throughout the 1950s, the musical activities of folklorists in Chile continued to grow without the presence of Andean signifiers (such as the charango). ${ }^{39}$ The charango, in fact, was not really part of Chilean tradition (Cornejo Puran 2016, 23). According to Cornejo-Puran, there was some introduction of the charango into Chilean border areas in the north as a result of incoming Bolivian and Peruvian migrant workers starting in the 1940s through the mid-1960s. These migrants and their musical culture slowly became "Chileanized", but the presence of the charango previous to Nueva Canción was still scarce (Ibid, 24-25).

Violeta Parra was one of the most significant players in this folklorist scene, and was a song collector, interpreter (of the songs she collected), performer, songwriter and radio host. Her

\footnotetext{
39 This movement was a predecessor to the politicized "Nueva Canción" (New Song) movement that would expand far beyond Chilean terrains.
} 
famous 1954 radio program, Asi canta Violeta Parra established her as a folkloric interlocutor between "el pueblo" (the "common folk", read rural/poor/agrarian peoples, which in Chile, were not Andeans) and the cosmopolitan/urban population of Santiago. Violeta's own childhood roots in the rural parts of the country lent her credibility both with her rural subjects and with her citybased listening audience (Verba 2013, 284). ${ }^{40}$

Violeta, herself a musician, was just one artist/folklorist in a growing scene that would become more and more politicized throughout the following two decades as Nueva Canción emerged as a pan-Latin American social and political force. This was the cultural wing of a grassroots swell that would support pro-Allende campaigning through Allende's Unidad Popular. Later, Chilean Nueva Canción's focus became, necessarily, protest and resistance to the brutal government of right-wing dictator Augusto Pinochet, who ousted President Allende by military coup in 1973 with the support of the American CIA (Ellison 1998; Devine 2014). ${ }^{41}$

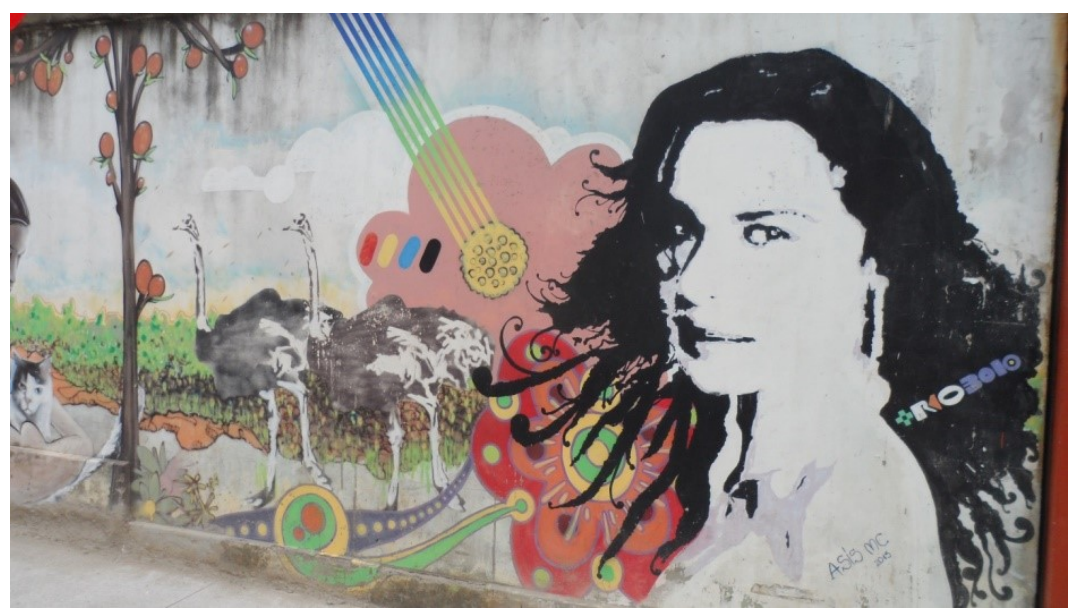

5. Violeta Parra, national folk hero in Chile. (Wall mural, Valparaiso, Chile Jan 2016 photo:HH)

\footnotetext{
${ }^{40}$ In fact, according to Ericka Kim Verba, Parra's show developed a surprising following among rural migrants in Santiago as well as among the rural poor who were the subjects of investigation (Verba 2013, 287).

${ }^{41}$ There is some debate on whether the CIA was directly involved in the 1973 military coup that put Pinochet in power. Common belief is that they did support the ousting of Allende even if they did not stage it directly. This fed leftist, anti-American sentiments both in Latin America and in Europe, with good reason given overall foreign policy during the times, including in Vietnam. Any debate on the matter is beyond the scope of this paper (Ellison 1998; Devine 2014).
} 
Violeta was a communist early on in her life. In that capacity, she went to Europe in 1955 to a Warsaw communist youth conference, and from there to Paris, where she edged her way into the effervescent scene at L'Escale and La Candelaria (Rios 2008, 154). Her seriousness and political views contrasted with the party atmosphere at the time. According to Rios' and Verba's research, the arrival of Parra into the Parisian scene had significant impacts on musical developments on both sides of the ocean (Rios 2008; Verba 2013).

Latin American musicians working in Paris steered clear of politicized repertory in the 1950s and early 1960s. Violeta Parra of Chile was among the few exceptions. A Communist party member, Parra came to Europe for the 1955 Warsaw International Youth Festival and, soon after, landed a solo gig in Paris at L'Escale (Saez 1999, p 7787). There, Nueva Canción's inspirational figure encountered Andean folkloric-popular music - most likely for the first time - listening to Carlos Ben-Pott and his Los Incas band mates (Rios 2008, 153).

Thus, Parra's introduction to the emerging pan-Andean genre, and to the charango, happened in the Latino peñas of Paris. Parra went on to be one of the first Chilean recording artists to pick up the charango and incorporate it into the Chilean folk music scene. Although she first heard the charango in Paris, she did not seriously engage with it musically until later, in Bolivia in 1966, as an instrument to accompany her original songs that would be recorded in Chile soon after (Ramiro Quiroga 2009).

Violeta Parra's relationship with Swiss wind player Gilbert Favre is another important element in the unfolding of transnational Andean musical crossings, and hence, to the movement of the charango beyond the Andes and surrounding regions in South America. Parra and Favre initially met in Santiago, Chile in 1960, and later lived together in Paris and Geneva, during Violeta's second and longer European sojourn from 1962 to 1965. In Paris, Favre seamlessly exchanged his Dixieland clarinet for Andean wind instruments to fit the pan-Andean music trend and later, returned to South America. In La Paz, Bolivia, he befriended and paired with Ernesto 
Cavour, Bolivian charango champion, and together they formed the notorious group, Los Jairas, which became both a Bolivian and international sensation.

Favre [...] first gained proficiency on his Argentine kena during this period [1962-65 (in Paris)] encouraged by Violeta Parra [...] An amateur Dixieland jazz clarinetist like BenPott, Favre used his technique to produce a round timbre with vibrato on the kena (unlike the overblown sound without vibrato preferred by Andean indigenous wind players). Angel Parra also learned to play the kena at this time, allowing him to join Los Incas on an ad hoc basis (Ibid, 153).

In these constellations Favre became a cornerstone figure in the formation and dissemination of pan-Andean music both within and outside Bolivia, earning him the nickname of "El Gringo" among Bolivian fans and friends; a handle that stuck as well on the international scene, so much so that one encounters casual references to him in the field on both continents today. ${ }^{42}$

Hence, the Parra family's 1962 to 1965 residency in Europe further introduced them to pan-Andean sounds, instruments and melodies. These were musical seeds and cultural ideas that they would sow and promote upon their return home to Chile in the Nueva Canción scene (Verba 2013, 291). They also introduced pan-Latin Americanist, left-leaning politics into the Parisian Latin American music scene during this visit (Rios 2008; Bianchi y Bocaz 1978; Cornejo Puran 2016, 31). Rios recounts,

The Parra family [...] had been deeply affected by their experiences in the French capital. "We returned from Paris playing music from Venezuela, Argentina, Bolivia, music from other countries" recalled Angel Parra (p.c.). His family's belief in the ideal of Latin American unity directly led to the standard Nueva Canción practice of combining "the (Andean) charango with the (Venezuelan) cuatro, the cuatro with the (Argentine) bombo... the (Andean) panpipe, the (Mexican) guitarron, all mixed together," which was intended to resignify these locally specific instruments to mean "Latin America" (2008, $154)$.

In fact, back in Chile the Parras established a club in the vein of the ones they had frequented in Paris, "La Peña de los Parra" in which they purposely promoted a serious and

\footnotetext{
42 "Gringo" is sometimes a perjorative term used to describe a North American or European. Here, his nickname was affectionate, as he is still loved in South America today for his work in Los Jairas with Ernesto Cavour. (Based on my own observations in both Latin America and Europe since 2015).
} 
politicized environment where the Nueva Canción movement would flourish even after Violeta's untimely death by suicide in 1967 (Fairley 2002, 15; Rios 2008, 154; Cornejo Puran 2016, 38). $\underline{\text { Leftist mobilizations and Latin American solidarity }}$

These early injections of leftist politics into the Andean music scene in Europe were reinforced by the French president Charles De Gaulle's strong interest in Latin American solidarity. His government's "Third Way" project aspired to create a third "bloc" that would challenge USSR/US bilateral world dominance. To that end, De Gaulle created ties with Latin American leaders and encouraged the cultural presence of Latin American expressions at home in France (Rios 2008, 157).

This general support of Latin American solidarity paired with anti-U.S. sentiments both in France and in the broader European population blew wind into the sails of pan-Andean music (thereby further circulating the charango) as politics shifted to the left in response to several USbacked dictatorships that dominated Latin America in the 1970s and 80s (Ibid, 157). Much attention was paid to Che Guevara's 1967 proclamation that he would stage a pan-Latin American Revolution from the epicenter of Bolivia. Writes Rios,

Many Europeans were fascinated by [Argentinean] Che Guevara's decision to instigate radical revolution in one of the few countries in the Americas with an indigenousmajority population. The Indian of the Andes quickly became a leftist emblem in the Old World...Guevara's highly-publicized guerrilla operation in Bolivia strengthened this indexical linkage, and catapulted the Andean Indian to a sign of defiance against U.S. imperialism $(2008,163)$.

Hence the cliché figure of the "Indian" with his crude, annoyingly high-pitched, dirty charango, in the eyes of early Spanish colonialists had progressed to the status of revolutionary countercultural hero in the eyes of leftists internationally.

French youth in particular, buzzing with the revolutionary spirit from the May 1968 student protests in Paris, mobilized both culturally and politically in the Latin America solidarity 
movements. They especially embraced the association between Che's revolution and Andean signifiers, to the extent that "many... began to wear Andean lluchus (wool hats with ear flaps) and ponchos" (Mestris-Benquet 1998; Rios 2008, 163). The poncho, of course, "had previously been adopted by musicians and student activists in post-1952 Bolivia and early 1960s Argentina" and Nueva Canción's rock-stars-in-exile, Inti Illimani, “wore a uniform of ponchos on stage until 1980" (Fairley 2002, 51). It then spread further among students and young musicians across the rest of Latin America and the Andes, where it was not previously customary attire. ${ }^{43}$

This growing international solidarity movement against U.S. political maneuvers in Latin America was both reinforced by and set the stage for the further popularization of up and coming exiled bands from Chile. In particular, Nueva Canción's Inti Illimani and Quillapayun quickly became world famous presenters of what the world would (mistakenly) come to see as "Andean" music. These bands conducted world tours during their exile years, and partnered with various international artists in support of anti-Pinochet resistance efforts at home as well as of leftist and socialist Latin American liberation movements in general (Fairley, 2002). ${ }^{44}$ The international experiences affected their music-making, as they collaborated and worked with artists in many different cities and countries.

Inti Illimani, for example, after many visits, established a new home base in Rome, Italy. It has been remarked that their interactions with Italian musicians played a significant role in their musical evolution. Particularly in later developments, such as their 1982 release Palimpsesto, the Italian, Spanish, and European classical traditions' influence took a prominent

\footnotetext{
${ }^{43}$ A point made to me by Jonathan Ritter in reviewing this work.

${ }^{44}$ On one of "Inti's" infamous solidarity tours I had my first exposure to pan-Andean music and the charango in Boston, Massachusetts. At a concert by US American feminist activist Holly Near with Inti Illimani as her stage band and special guests I saw and heard the charango for the first time.
} 
position (Ibid, 56). This was certainly the case for many artists who were forced or who chose to

live in exile during the years of Pinochet's regime (1973-1990). Says Cornejo-Puran,

The musical importance of exile for those who lived this kind of forced experience deserves to be addressed in the future from a viewpoint that extends beyond politics. Musically, and from the position of the charango player, (the exile experience) affected (musical) language learning, and made new and innovative modes of composition and interpretation of the instrument possible, with an opening of new rhythms for the chordophone --- continuing the legacy of the New Song - and with a constant intercultural dialogue between various musicians, not only Chilean, but also from all over the world. Out of this a new urban charango emerged that continues to generate a vast and rapidly developing repertoire, that will enable new approaches to pedagogy locally, from outside to inside $(2016,55)$.

\section{The charango at the front}

In these bands the charango was an essential player and signifier of "Andeanness" both visually and acoustically for audiences internationally. It also made its way towards the front of the stage in the hands of accomplished players such as Horacio Duran of Inti Illimani. Writes Cornejo-Puran:

Duran was probably one of the most important charango players in Chile and Latin America, transforming himself into not only an accomplished player with his own styleto the credit of the unique way he understood the instrument- but as, implicitly, the main ambassador of the charango in the eyes of the world. His role was a defining one as the only solo player within the Chilean Nueva Canción movement, set apart from his colleagues, who were all accompianists (Ibid, 57-58).

Many players followed suit as conditions, influences and pioneers such as Duran and others drew the charango further away from its customary role as an instrument of accompaniment in formulaic "conjunto" ensembles and gave its players invitation and opportunity to explore solo or feature performance. ${ }^{45}$

On the wings of the Condor

\footnotetext{
${ }^{45}$ It would be remiss to not mention some of the other historic cornerstone "greats" of charango soloists: Bolivian Ernesto Cavour (of Los Jairas) and his teacher Mauro Nuñez (of Sucre, Bolivia), Jaime Guardia (Peru), and Jaime Torres (Bolivia/Argentina) are just a few of the "biggest" headline names to mention, considered the "fathers" and historically important virtuosos of the instrument.
} 
Mention must be made of the role of Paul Simon's adaptation of the well-known neoAndean tune "El Condor Pasa" which helped fuel the dispersion of pan-Andean music. ${ }^{46}$ This U.S. American folk artist first encountered Andean sounds in Paris where he connected with Jorge Milchburg who played with Los Incas. Milchburg, who is connected to the authorship and folklorization of the song (albeit not directly its author/composer), allegedly gifted Simon with a recording of Los Incas Amerique Du Sud album, on which the infamous tune had been recorded. Simon later used the instrumentals from this recording as a dub track for his English version of the song, released on his and Art Garfunkel's cornerstone album Bridge Over Troubled Water in 1970 out of New York City, which became a countercultural staple of North American hippies (Rios 2008, 161). Of course, "I'd rather be a hammer than a nail" is still a "baby boomer" classic in North America and well known on the global popular music circuit as well.

In Andean circles, it has become such an overplayed standard in that many musicians still joke about it ("El Condor ya pasó" — the Condor has already passed) including some participants in this study (Guzman Roman interview 2018). Despite that, it is still performed frequently, as it has broad resonance, reach, recognition and tip-stimulating effects on so many audiences to this day (Dorr 2007; Zevallos Aguilar 2014). ${ }^{47}$ The condor may have "passed" for many, but a lot of popular music artists globally still cover the song. "The condor", in fact, has made its way into almost every genre of music, including folk, jazz, rock, metal, new age, world beat and ambient shopping mall/elevator muzak mixes, whilst scores of amateur musicians are still playing with this song across genre, instrument, language and nationality. Certainly, the charango is not a leading instrument (quena predominates), but many charango soloists (even contemporary

\footnotetext{
${ }^{46}$ Authorship of the song belongs to Daniel Alomia Robles, Peruvian composor (Rios 2008).

${ }^{47}$ Much scholarship exists on the spread and popularization of this song, as demonstrative of globalization and transnational cultural processes. See Dorr 2007; Zevallos Aguilar 2014.
} 
concert charango players such as Federico Tarazona) perform this popular pan-Andean hit, which still has broad appeal to most audiences, if not to the musicians themselves. ${ }^{48}$

$\underline{\text { The world of recordings }}$

Finally, not enough can be said about the role of recordings in the circulation and development of pan-Andean music and its effect on musicians. Many of my interlocutors (both European and Latino) reported that they learned primarily or greatly from recordings (Yann Béréhouc (vinyls), Leandro Vidal (CDs), Deni Plavčić (YouTube), Nina Dimitri (vinyls), Ivan Latapiat (cassettes/Chile), and Luis Parra (vinyls/Chile)). Certainly, the desire to record, the actual recording process, the promotion, sale, consumption and circulation of recorded material (in the form of vinyl records initially; later, cassettes and CD's; and now digital and online media) were (and are) factors in human movement, sometimes across borders, cultures, and circumstances, both directly and indirectly. ${ }^{49}$

\section{European Streets as World Stages}

As pan-Andean music grew in popularity throughout the 1970s and 1980s, multitudes of new groups arrived in Europe from South America. Accounts date the peak of Andean music in central Europe to the 1980s through mid-1990s during which Andean music groups flooded pedestrian zones, squares and metros, clad customarily in bright ponchos and signatory ear flap hats now associated with left leaning politics, indigeneity, and rebellion (Mendívil 2015; Jetmarová 2013; Rios 2008).

\footnotetext{
${ }^{48}$ Tarazona played his version in his feature set at the Encuentro Internacional de Charangos en Brussels, Belgium in November, 2018 which I attended during my field studies. Available at https://www.youtube.com/watch? v=qI_c t3C Q Q \& $=243 \mathrm{~s}$

${ }^{49}$ A few examples: 1. The first recordings of Bolivian musicians were made in Buenos Aires, because recording facilities were not available in Bolivia. These trips were costly and entailed lifestyle adjustments. 2. Many panAndean musicians' recordings were only sold off stage (or on the street) so musicians had to tour to make money, and living conditions during these tours were often harsh. 3: The hand-to-hand circulation of clandestine cassette tapes during the Pinochet regime in Chile involved risks that could result in imprisonment or death. In more current examples, the circulation of pan-Andean music outside of Latin America via recordings has stimulated travel and tourism to Latin America, for example in the case of French charango player Yann Béréhouc, or in my own.
} 
According to my interviews, some players came as groups sponsored by festivals or promoters and others came as individuals and circulated in the scene to put groups together on site. These bands particularly prove an interesting point for further consideration as they were a site of homogenization of a broad variety of local South American music traditions that did not necessarily overlap. The players in these ad-hoc groups turned to the canon of the emerging genre as represented by more prominent groups with recordings that were circulating internationally. Their sparse common musical ground forced them to copy existing and create new repertoire, hence contributing further articulations to the emerging canon (Perez, Ferrier, Peña, Guzman Roman interviews, 2018).

Several of my interlocutors came to Europe during the peak years, recruited or even selected back at home with promises of big stages, tours and festival performances, only to find out that nothing of the sort awaited them (Mendívil, Cervantes interviews 2018). Under these circumstances, they simply joined the others on the streets and had to improvise tours and make their way independently. In other situations, promises were kept in the sense that they did tour with the support of a local contact (either a Latin American or European promoter/manager) but endured terrible housing, touring, and work conditions for exploitative economic remuneration. Rios recounts a similar tale told to him by a member of the group Bolivia Andina, whose European representative "took off with the money and left the members stranded" in an analogous transcontinental scenario (Rios 2008, 166).

Julio Mendívil was one of the players invited to go to Europe (Germany, in 1990) on (what turned out to be) false promises of professional type stage tours. Like many others at that time he turned to the street scene in various musical combinations, where he performed and toured for several years playing charango with a variety of Latin American musicians in many different 
countries. In an interview in October 2018, Mendívil offered some alternative viewpoints on this supposed Andean music "boom” in Europe. Said Mendívil,

The greater [European] public has a cliché in their head about what [they think] Latin American music is, but it is a public focused on consumption, not appreciation of the music. There is very little interest in Latin American music. Earlier, it was [seen as] more exotic. But it wasn't until groups started playing other music, like the Beatles or whatever [on Andean instruments] that they started to make much money. Andean [local/regional] music never had a life on the street... Bolivian folkloric music was easier on the European ear and did a bit better, but there was never any big reverence for the music. If we played folkloric/local music, people would not stick around. If we played "El Condor Pasa", things that people knew, they would stay... I wouldn't say that there was [ever] an Andean music "boom" [...] I would say that yes there were moments where a lot of music was sold on the street but "music of the Andes" is part of the European imagination because they saw it, not because they listened to it. The people would say to you, "oh, the poncho groups in the street!", and you would say yes, please, can you suggest a song? [But] they didn't know! They didn't know one single song. The image is of the Andean with his poncho playing his pan-flute (Mendívil interview, 2018).

Other players reported different experiences. Antuco Perez, a Bolivian charango player, arrived in Paris in 1984, initially to play festival and concert stages, and soon thereafter joined the circuit of street players touring and performing in city centres. Establishing a home base in Paris, he was a founding member of a group called "Altitud": a Latino crew of mixed nationalities who he says composed original music and recorded and toured with three albums. "My music was different," he told me.

People said, you're going to die of hunger (playing that, because you won't earn any money), but it was the opposite [...] The charango follows me, and my way of music. I never trapped myself in folklore" (Perez interview 2018).

Although this player's career has a long and varied trajectory that still cycles between France and Bolivia, most of the musical samples he provided me with can be firmly placed in the folkloric pan-Andean genre. These tunes, documented on YouTube, lean heavily on Andean musical and instrumental signifiers, despite the occasional addition of elements such as drum kit and electric 
guitar. ${ }^{50}$ Only one sample track he provided had some jazz and samba type flavorings and a piano introduction, but this track, part of a tribute album dedicated to Bolivian charango great William Centellas, is an exception. ${ }^{51}$ Perez, who now lives in the outskirts of Paris, has almost entirely left the world of performance to work primarily as a luthier of high end instruments for European clients.

Some European musicians (besides the infamous Favre) joined in the pan-Andean music action (Ferrier interview 2018). Still others were children at the time, and were exposed to Andean instruments that would become central to their own future musical careers.

French musician Yann Béréhouc was an adolescent when he first saw the group "Boliviamanta" playing in the street with Carlos Arguedas on charango. He spotted him again at the "Festival de l'Humanité" a few years later, a large event presented by the Socialist and Communist parties in 1979 in the center of Paris, as many events and rallies at that time. Béréhouc's interest was sparked and he soon acquired a charango and began to learn to play based on his training in guitar. His main source was a neighbor's large collection of vinyl recordings (produced in both Latin America (primarily Argentina) and France) which supposedly, according to Béréhouc, was one of the largest in Europe at the time. With the charango, Béréhouc says he found "freedom from traditional, laborious (European) ways of studying an instrument," such as he had experienced on the guitar. The charango, introduced to him in the leftist milieu of Paris, opened up an "alternative" door that he has since fully embraced. He currently lives outside of Paris, in Rheims, and has an active solo performance career on charango (and ronroco (a baritone

\footnotetext{
${ }^{50}$ His current group "Luz del Ande" includes aficionado/ Japanese transplant to Bolivia, Takaatsu Kinoshita on guitar) Sample available at https://mail.google.com/mail/u/0/\#search/antucoperez.ap\%40gmail.com/FMfcgxvzKbMfvQfFQpNJfJnzpPmlDBCS ?projector $=1$

${ }^{51}$ Available at https://mail.google.com/mail/u/0/\#search/antucoperez.ap\%40gmail.com?projector=1
} 
variant)) both in Europe and abroad, with frequent appearances in Argentina. (Béréhouc interview 2018).

Swiss player Nina Dimitri was also first exposed to the charango when she was very young. Dimitri is the daughter of prominent circus and theatre teachers and artists who since her childhood have run a school with a concert hall in Verscio, Switzerland. It was here that Dimitri was first exposed to the charango in 1971, when the Bolivian band Los Jairas came to perform. Dimitri, five years old at the time, was fascinated by the small, high pitched instrument. "I was enchanted," she told me. "I loved the music, the melancholy sound, the high pitch, the fast strumming, the small size...” (Dimitri interview 2018). Soon thereafter, Bolivian guitarist, singer, charango player and painter Alfredo Dominguez became Dimitri's first teacher. Beginning at age eight, she was coached intermittently by Los Jaira's principal charango player Ernesto Cavour. These musicians stayed for short visits to perform and returned periodically in between other tour dates. "I cried every time they left," recalled Dimitri (Ibid 2018).

She filled in these gaps between her lessons by listening to the many vinyl records from South America that the visitors shared with her family. She says she "listened and listened" to these recordings throughout her childhood, learning the tunes and figuring them out by ear on the charango. Her earliest performances were on the street, as was the trend at the time. Acquiring her skills in these kinds of scenarios, she developed a booming singing voice for which she is still noticed today in performances with her circus/theatre troupe in which she integrates the charango (Ibid, 2018).

These two players' stories offer examples of how the emergence and circulation of the charango vis-a-vis pan-Andean music in Europe impacted participants in this study, even those who were not yet adults at the time. Both Béréhouc and Dimitri are Europeans in whose lives the 
charango has come to take a central place and meaning as a direct result of the history that began in Paris and rippled across the rest of Europe over several decades. Both have nurtured social and musical ties across the ocean to the charango's home contexts as well as with Latino friends living in Europe (as have other participants such as Carole Stocklin, Marie Laduron, Zrinka Božičević, and Ignacio Duran Salas) as a result of their engagement with the charango. Béréhouc and Dimitri are just two of many musicians on both sides of the ocean who were impacted by these historical/musical developments.

\section{$\underline{\text { Andean-ish Street spectacles and pan-Indian representations. }}$}

By the mid/late 1990s the presence of pan-Andean groups in central European cities down-shifted and there was a dramatic change in the visual and sonic style of street presentations. Performers took on exaggerated visual symbols such as face-paint, feather headdresses and costumes resembling certain North American native peoples' ceremonial dress (Jetmarová 2013, 187). ${ }^{52}$ The sale of merchandise expanded beyond the customary musical recordings in order to grab the dwindling audiences' attention and money (Bedoya, Mendívil interviews 2018; Jetmarová 2013, 187). Amplification was frequent and sometimes sound and light shows were added to the mix. Thus, fewer acoustic players were necessary to create a large presence, and revenue could be shared between just a few, which was advantageous as street earnings were shrinking. The opening of Eastern Europe may have provided some opportunities with publics that were previously unfamiliar with the pan-Andean genre (Jetmarová 2013, 187). In some situations, the sale of textiles and artisanal handcrafts replaced musical performances altogether. Indigenous Otavalans (from Ecuador) were the primary drivers of these merchandise sales and by the mid 1990s constituted a formidable network of sellers not only in Europe but also throughout the U.S. (Meisch 2002).

\footnotetext{
52 Jetmarova here refers to costumery taken primarily from Lakota tradition.
} 
In many ways, these pan-Indian music and merchandise spectacles share very little intersection with the charango, as it seems to have faded far into the background if present at all. However, as "later stage" (sort of) Andean music performances in European fields, we will consider them from various points of view.

Ethnomusicologist Jana Jetmarová undertook extensive fieldwork with primarily urban/mestizo musical groups (mostly from Ecuador) between 1996 and the early 2000s, both in Eastern and Western Europe and later, in the U.S. and Canada. Their street performances mixed Andean musical textures and imagery with those of some North American Indian peoples. The groups she studied (such as the Ecuadorian band "Chayag") used playback and recorded sounds (such as wolf-howls or nature sounds) that invoked a naturist, "earth-loving" subtext to these performances. Instrumentation varied, but Andean winds or North American native style notch flutes dominated among the groups she studied. Some shows included the reenactment of a "sacred ritual" such as the native North American practice of "smudging" $(2013,188) .{ }^{53}$ In these musical, sonic and visual street shows, players "performed" a romanticized, exaggerated representation of North American Indians that harkened to the European (colonialist) notion of the "noble savage". Presenting a contemporary caricature of the earth protecting, spiritually wise Indian of the "New Age", these colorful, dramatic shows captured the attention of a naïve/uneducated audience (Ibid, 188).

Julio Mendívil, ethnomusicologist who himself performed somewhat earlier in the street scene, offers some thoughts on the appeal of these kind of spectacles to audiences in the German scene with which he became familiar.

\footnotetext{
${ }^{53}$ Smudging entails the burning of sage or other dried herbs in a special bowl and wafting the smoke towards the receiver with a large feather. This practice has been taken up in new-age circles of non-native people as a nod to native tradition, but not always acknowledged as such. I speak from personal experience, primarily in subcultural "New Age" settings in North America since the mid-1990s. More on "New Age" in footnote 102.
} 
Why do German people love these 'false' Indians? These musicians confirm the historical imagination [that] Germans [have] of American Indians. Growing up reading Western fantasy stories by Karl May, many Germans see American Indians in a very romantic light, equating them with respect for nature and spirituality. They also see American Indians as victims of oppression and dispossession by European colonialism. Through conversations with pedestrians I experienced that many Germans thought we were poor indigenous people who needed their support and solidarity despite the fact that we played with very expensive equipment. Did they need us to be poor people to whom they could be generous? In this sense, in order to be successful in Germany, 'Indian'[/Andean] groups keep nourishing these cultural clichés (Mendívil 2015).

Ethnomusicologist Joshua Tucker agrees that these kinds of performances "perpetuate the exoticization of indigenous peoples” (Tucker 2011, 392). Germans, he says, have had “a romanticized notion of independence, fortitude, and cultural authenticity associated with American Indians [that] drove a widespread fascination with the American West" since the nineteenth century (Ibid, 391). According to Tucker, this expresses currently in a wide range of ways, including everything from public interest in Native-American flavored world beat and New Age music to German hobbyists who stage weekend reenactments of Plains Indians' powwows (performed and consumed by Germans) (Ibid p.391). ${ }^{54}$

Some of my own interlocutors offered objections to these more recent trends in street representations from a more personal angle. In disgruntled tones, more than one told me that "los Ecuadoreños" (the Ecuadorans) had "hijacked" the street music scene, dressed as "Indian payasos (clowns)", playing poorly, and "giving a bad name" to Andean music (Bedoya interview 2018). Some blamed "the Ecuadorans" for the downfall in popularity of Andean music in Europe, although other sources, such as Meisch, indicate that they were already part of its earlier, peak period (Meisch 2010). Further bitterness was felt because, according to some players from the early phases, many "competent" Andean musicians were left no option but that of return

\footnotetext{
${ }^{54}$ Of course, similar histories and subsequent stereotypes prevail beyond Germany in the rest of Europe.
} 
migration or alternative jobs because they were no longer able to make a living playing music in Europe (Parra, Cruz, Perez interviews 2018). ${ }^{55}$

Luis Bedoya, a Bolivian who was one of the first Andean musicians to arrive in Vienna,

recounted some of his experience with this history, and how it affected his group.

When I came to Europe, we were respected. The European public respected our culture, and we respected theirs. But when so many groups came, they didn't come to play artfully; they played to make money, not even to present the music. When we had played, we played to survive, yes, but we wanted to present the music well. But when the avalanche came, it all went downhill. ${ }^{56}$ If our group had been charging $\$ 5000$, now there was a group willing to do it for $\$ 100$. I would call my contacts and they would say, well, we have another group, and they play the same instruments. And so we lost the contracts.

I had an experience here in Floriansdorf, [a suburb of Vienna]. There was an Ecuadoran group playing with feathers [headdresses] and they had playback [amplification/back tracks], they were playing there and an American guy came along and he was watching, and said to me, "So, where are these guys from? You must know [...] They seem more like clowns than anything else," he said to me. "I am an Indian," he said. "I'm a North American Indian. They are pretending to be us!" he said. I had this experience. And there was a huge wave of this all over Europe, and, they didn't want to listen any more, some people. And they would sell, they sold the same CD's, the same music, with a different label on it. There was a lot of cheating people, and robbing the music from other groups [to sell it]. We lost the desire to play because people didn't want to listen any more. Before there were a lot of people who wanted to listen, or who paid attention: it was something new. But we weren't using amplification, or recorded tracks. It was something natural (Bedoya interview 2018). ${ }^{57}$

Although Bedoya objects to the unethical behavior of some performers and has problems with the quality of their music, his indignation about being put out of business by the increase in competition probably biases his view, understandably. It is difficult to say how certain politics, attitudes and power structures between groups of street performers or individuals within the same groups in the street scene may have played out. Whereas some ethnographic and historical data points to a tendency to unify across differences that may have been insurmountable at home

\footnotetext{
55 They were "competent" according to their own personal assessments.

56 This refers to the sudden influx of many new groups.

${ }^{57}$ It is worthy of note that although Bedoya states that people did not want to listen to these amplified spectacles, he also described a scene in which people in fact were gathered to observe it. In Mendívil's article, he asks why German audiences "loved" these performances. The fact that there were enough of them to sustain several years of field study by Jetmarová would also indicate their popularity among the general street public.
} 
(such as between mestizo urban players and others from highland/indigenous context, or between certain historically oppositional nationalities) narratives like Bedoya's demonstrate that panLatin American solidarity did not necessarily rule the day in the Andean music scene abroad, any more than it did in the home contexts.

Julio Mendívil adds some additional perspective to the situation:

There are of course critical voices speaking against the perpetuation of these 'gallant Indian' representations. Some Latin American immigrants argue that those groups are misleading their German friends. Nicknames like 'Incapaches' [a mixture of Inca and Apache which sounds like 'incapable' in Spanish] or 'mega-Indios' [mega-Indians] show that many Latin Americans do not welcome this representation. They denounce the appropriation and instrumentalization of indigenous culture by urban Andean musicians in the diaspora (Mendívil 2015).

Jetmarová however claims that “Andean musicians have admittedly borrowed North American native artifacts, but they have not pretended to be actual Indians from the United States or Canada" $(2013,188) .{ }^{58}$ In fact, Jetmarová further argues that these Andean(ish) performances constitute contemporary assertions of "hemispheric pan-Indianism" that have positively impacted the identity concepts of the musicians involved as concerns their own internalized conflict around indigeneity as mestizos [emphasis mine: HH]. Writes Jetmarová:

Because in Europe it is understood as a part of a uniform hemispheric Indian culture, Andean indigeneity gains the same positive attributes as the indigeneity of Native North Americans. As a result, pan-indigeneity has become an important part of the identity of the musicians in Europe. [...] The question remains as to what extent this process involves the construction of an identity aimed at European recipients and to what extent it constitutes a pan-Indian identity internalized by the musicians themselves $(2013,192-$ 193).

Jetmarová argues that these players have, over time, begun to re-evaluate negative concepts of indigeneity from their home contexts. She sees the musicians' use of an assortment of indigenous symbology in their homes, styles, and personal décor, as well as in their album art

\footnotetext{
${ }^{58}$ However, one might question the relevance of this claim if the selling point of these groups is to present exactly this illusion to the European public.
} 
as evidence. She also notes that some have made efforts to network with North American Indian groups. Further, Jetmarová claims that their integration of a pan-hemispheric Indian "brand" has, in transnational loops of these groups and their recordings, made a contribution to the "rehabilitation" of indigeneity back in their home countries. To support this claim, she points to groups such as Chayag from Ecuador, Alborada from Peru, and K'alamarka from Bolivia who have all succeeded in Europe under a pan-Indian image that has subsequently been well received back in their home countries. Jetmarová argues further that their international musical success under a pan-Indian image has contributed to "the process of indigenous social rehabilitation and political emancipation [at home]" through the popularization of their music in home contexts (Ibid, 196).

These claims stand on slippery terrain, however, as it is difficult to assess the social impact of these bands in home contexts, especially as regards the expression of indigenous subjectivities in music and the public's understanding of and response to this pan-Indigenous image (Tucker 2011; Mendivil, conversation Oct 2018). Further, it is not uncommon in many music scenes that success abroad for any band or artist engenders a raise in status back at home. Still, Jetmarová’s analysis pokes at the complexity of the matters at hand.

In Tucker's own work, which offers a detailed analysis of two Peruvian bands with international reach (Uchpa and Alborada), he urges us to "evaluate with care" and contends that there may be some "wiggle room" for indigenous actors to assert themselves even within existing [hegemonic] ideologies and situations (Tucker 2011, 406-409). Perhaps that is the crack into which Jetmarová peers in order to attempt to understand the layers of meaning and interaction in the performances of her mestizo Andeans as pan-hemispheric mega-Indio hybrids in the eyes and streets of European colonial descendents. 
At the very least, Jetmarová's work stands as documentation of more recent trends of street performance in European (and North American) fields, in particular documenting changes in musical styling, costumery, commerce and technology. In the flash of headdresses and war paint, and the sonic headlining of the Native American flute alongside the Andean winds backed by the sonic boom of recorded drum and bass tracks, does the charango still have a life in the street at all?

In July 2019 I encountered a sole Ecuadoran wind player dressed in full pan-Indian costume with large merchandise tables in front of a loud battery powered speaker system near the market area in Riga, Latvia. His solo notch-flute was backed by a loud playback mix of the sounds of Andean conjunto (with a very faint charango), along with ambient "nature sounds" mixed into the recording (wind, water, rain, thunder, etc.) and some rock-steady beats to round out the Carlos Nakai meets Incapache meets Los K'jarkas meets Nirvana vibe. His merchandise on one side was a double sized table of cheap mass-produced costume jewelry. On the other were several racks of wolf and bear t-shirts interspersed with dream catchers of various sizes.

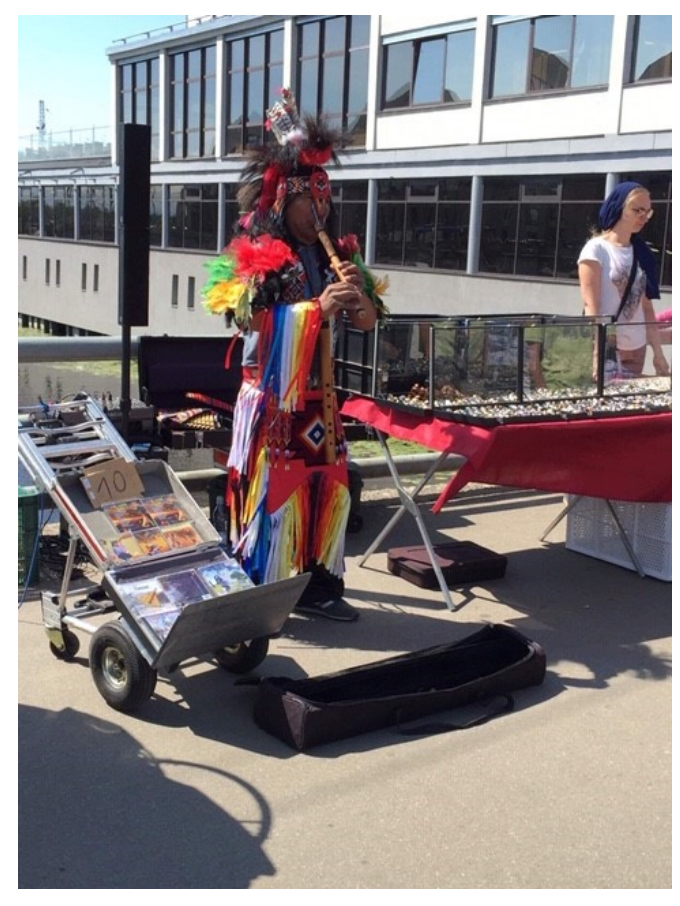

6. Mega-Indio in Riga, Latvia, July 2019 photo HH 
I introduced myself to the performer (and confirmed that he was Ecuadoran) who told me that this solo playing and selling gig of his was an annual summer route through former Soviet Bloc countries. "Se vende major" he said. It sells better. Fairly, these countries have only been open to travelling South Americans since the early/mid-1990s. ${ }^{59}$

I would argue that this scene illustrates that the charango's street life in Europe has been almost fully upstaged by the Andean (and Native North American) flute (as was evident in the above field situation) which has also become sparse; employed primarily as a sonic draw by travelling salesmen such as the one above, probably mostly during the warm seasons. ${ }^{60}$

Of the charango players I met in Europe in 2018, only two were performing on the streets, and neither in a formulaic "conjunto". Both of these players are young travelling types, financing their meanderings with street and train busking tips, forming duos and trios when they could with whomever they met along the way for comeraderie and increased sonic punch. Neither was setting up with full amplification, costumes or hat tricks. They do not employ gestures to indigenous motif, real or imagined. Rather, they are both young travelling, street musicians who play tunes from a variety of typical charango repertoires all connected to panAndean music. ${ }^{61}$ The others I came to know during this work were primarily (sporadically) engaged musically on concert, festival, educational or party stages in scheduled shows with formal listening audiences.

Bought and Sold: Commodification and modern Capitalism

This history of the emergence of pan-Andean music demonstrates that its constellation as a genre is strongly contextualized by evolving processes of modern capitalism in cosmopolitan

\footnotetext{
${ }^{59}$ As a side note, he did not accumulate any kind of sizeable audience while I was there, although some people stopped to examine the merchandise.

${ }^{60}$ And as described by Lynn Meisch in her work on Otavalan merchants, although due to new travel and immigration constrictions, that scene may have since changed dramatically as well (Meisch 2010).

${ }^{61}$ More on their activities and perspectives will be presented in Chapter Five.
} 
frameworks. Music's commodification as a product for buying and selling is not to be taken lightly. Research has shown that Andean music's roots in indigenous and rural contexts is intrinsically interwoven with (non-commercial) community ritual and celebration, with seasonal and daily life activities, and with inclusive and participatory values (Stobart 1991; Turino 2008; Pedrotti 2012). Yet pan-Andean music was molded by its cosmopolitan agents' political agendas, embedded in economic transactions of both need and greed, and sold in ideological packaging to consumption-based audiences - even where the product was "rebellion" to capitalism and imperialism.

In later phases pan-Andean music was re-dressed in performances that mobilized "noble Indian" visual and sonic reference points to stir the European historical memory in hopes of retaining the interest of the public. The skeleton staff still enacting these "Andean-ish" performances scaled down acoustic instrumental performance and boosted merchandise sales to try to ensure a continuing revenue stream. In those changes, the charango has become a background player, barely present at all in the most recent decades of street scenarios.

Although the charango's introduction into transnational contexts was immersed in the modern pan-Andean "conjunto", it has since definitively taken its ground as a solo/leading voice in the last two decades. This indicates a significant shift in intersections of performance that, as new organologists would concur, alters the meaning and impact of the instrument. The charango is now appearing primarily on stages, (rather than street performances, and rarely, at that) in current European contexts. Accordingly, is the music changing? Some virtuoso and solo players now pursue individual domestic and international careers both in South America and abroad. However, by and large their musical expression continues to refer to already existing common 
repertoire ("traditional"/“folkloric"/national musics and pan-Andean repertoire) and wellestablished playing styles.

As the story illustrates, the charango's postion as a signifier has changed often throughout time, depending on the agents at play and the players' agendas. New organologists would encourage the question, how do new conditions of engagement affect the signification of the instrument? Certainly, what remains of leftist or counter-cultural symbolism surrounding the charango may or may not linger for some time. The charango, quite recently a common sonic presence on the streets of European cities in pan-Andean musical performance, is now hardly known by the general European public. Charango players are sparse, so my field work did involve some shaking of the bushes, so to speak.

On the other hand, very recent re-enactments of South American "International Charango Encounters" (Encuentros de Charango) in both Brussels (in 2018) and Berlin (in 2015) (and probably some other European cities) bring a dispersed crowd of "aficionados and curiosos" together in concert or mini-festival type scenarios. ${ }^{62}$ This may point to a resurging interest in the charango appealing to the "world music" sensibilities of cosmopolitan audiences in Europe. Or, more likely, these encounters have just enough of a ragtag following of players, enthusiasts, touring charango players from South America, Latino immigrants and curious world-musicloving Europeans to bring together a small crowd for a concert or two every few years. Hence, the charango in current European intersections could be considered a not-often-seen instrument that indexes (to those familiar with it) both its folkloric history as well as a recent, but past era in pan-Andean street performances.

The history shows not only several contemporary shifts in the charango's image, but how its link to indigenous Andean contexts has been mobilized by non-indigenous actors and

\footnotetext{
${ }^{62}$ People who are affiliated with or curious about the charango
} 
dispersed to cosmopolitan audiences in transnational loops. This reinforces a central tenet of new organology that locates the meaning of instruments in lived human processes which demonstrate, in this case, that positions in Europe connected to developments in Latin America strongly affected the charango's meaning to its players and audiences (Dawe 2012). In the next chapter, I will review how nationalist discourses have staged a heritage tug-of-war over the wood and strings, a dispute in which the charango has felt the pull between competing stakeholders in ongoing international disputes over its origin, and how these discourses sometimes manifested in the contexts of this study. 


\section{Chapter Three: The Origins Debate: Heritage Wrestling Matches and Bolivians in the Field}

Cultural nationalism is the semiotic work of using expressive practices and forms to fashion the concrete emblems that stand for and create the 'nation', that distinguish one nation from another, and most importantly, that serve as the basis for socializing citizens to inculcate national sentiment [...] Cultural nationalism is not a celebratory or entertainment-oriented frill attached to serious political work; it is one of the essential pillars upon which the entire nationalist edifice stands. Music, dance, visual arts, political speech, and a broad variety of other expressive cultural practices, in turn, are at the center of cultural nationalist projects (Turino 2003, 175).

The charango is a Bolivian instrument, whose birth place is Potosi. ${ }^{63}$

The question of charango origins has spurred a charged and persistent debate over ownership rights to the instrument as heritage property. This debate historically and currently has been driven primarily by nationalist agendas in Bolivia and Peru. Bolivia and Bolivians, in particular, have a pattern of making sweeping claims in this regard. Indeed, wherever you dip your toe into the musical and cultural world of the charango, you will quickly stub it on a hotbed of questionable assertions that the charango "belongs" solely to Bolivia, and is, ipso facto, "a Bolivian instrument". Peru weighs in close behind, refuting Bolivian claims in order to defend its own stake in the instrument's heritage (Mendívil 2013, 74; Valdillo 2015). Indeed, many people I have spoken to who are involved with the charango consider the question of origins a tired argument. It would probably be left to lie were it not for Bolivian "traditionalists" both within and outside of Bolivia. ${ }^{64}$

\footnotetext{
${ }^{63}$ Daniel Villavivencia (charango instructor), personal conversation with author, February 2018.

${ }^{64}$ In musical circles, this word - "traditionalists" - seems to be used to soften the probably more accurate termnationalists.
} 
In fact, the charango's roots have been traced to both Peruvian and Bolivian territories in the Andes, as well as zones in border areas of Argentina and Chile. ${ }^{65}$ By most accounts that approach the question along traditional organological lines, it belongs to the lute family, and by widely read estimations (such as Ernesto Cavour's book) it is a spin-off of the vihuela and other Spanish chordophones (Cavour 1980, Tarazona 2008). ${ }^{66}$ Other assertions have suggested connections to small chordophones from Mexico, original roots in the Canary Islands and one author (Chalena Vasquez) even traced an etymological link to an east African Bantu word, "kikongo" (Mendívil 2018, 26). Evidently, it is difficult to locate any direct predecessor to the charango, as there have been so many variations of the instrument's physical form as previously discussed, as well as of course, countless small stringed instruments in circulation in the Americas and Europe for centuries.

Most of the debate centers on the exact location of first appearances of the charango in the regions in question, even before they were demarcated with nation state borders. This of course casts the whole nationalist controversy into a somewhat absurd light. ${ }^{67}$ None of the claims can be adequately substantiated with empirical or scholarly evidence to date, and so "the origins debate" continues to be a site of dogmatic and divisive posturing that sadly, causes seemingly endless discord in interpersonal interactions, community scenarios and international debates. Almost everyone I interviewed in this study had an unpleasant story to share in this regard.

The most recent public flare up over the origins question was in 2006 , when in a faux pas diplomatic move, Chilean president Ricardo Lagos gave a charango to Irish musician Bono as a

\footnotetext{
${ }^{65}$ Beyond this (and the wider European fields as discussed in the previous chapter), the charango is becoming increasingly popular in Colombia and Ecuador; has some presence in Mexico, and has a known aficionado following in Japan.

${ }^{66}$ Much of this information is collected in Ernesto Cavour's substantive publication entitled El Charango: su vida, costumbres, $y$ desventuras (Cavour 1980). This is an important collection of traditional organological information on early appearances of the instrument despite its bias toward Bolivian claims on origin.

${ }^{67}$ Federico Tarazona, personal conversation, Brussels, Belgium 2018.
} 
symbol of diplomacy and friendship (Arie 2006). This unleashed a vicious polemical fight over heritage proprietary rights. It expressed itself initially as a Bolivian government decree, followed by a Peruvian government decree, followed by response from the Bolivians and a subsequent flurry, over the next few years, of non-scholarly writing on the topic that resulted in a PeruBolivia standoff (Chaquilla 2006; Tarazona 2007; Mendívil 2013, 62). Only Julio Mendívil’s work from 2013 offers a critical angle on the topic in his consideration of the role of emerging nationalisms in the wrestling matches over the heritage "rights" to the instrument (Mendívil 2013).

In this 2013 article Mendívil systematically analyses the influence of nationalism in the charango origins debate, and presents recent discourse about the instrument in historical context. In a detailed chronology, Mendívil outlines how political interests and conditions have influenced the popular image of the charango, which has vacillated in and out of favourable light. He begins with a review of early accounts by colonial scribes that dismissed the charango as a "rustic and deficient copy or, even, fossil of European chordophones" (Ibid, 65). In this narrative, the story of the charango was situated in a "tragic discourse" as a "creation of the dispossessed" and "mere reproduction of European instruments" (Garcia 1949, 112-113 in Mendívil 2013, 65-67).

Mendívil then tracks the slow turn of opinion starting in the 1940s and 50's that revindicated the charango as a proud symbol of indigenous perseverance through the emerging ideology of indigenismo (campaigns and policies that gestured at the revaluing of indigenous lifeways and people). In Peru, the slowly increasing population of Andean migrants to Lima began to break down social and political power holds of the Spanish-descended "criollo" upper class (Turino 1988). In Bolivia, it was the 1952 revolution that initiated the beginnings of 
modern indigenismo and with it, a reconsideration of folkloric music as an important component of national identity. In this new framework, the charango was no longer the dirty, rustic chordophone of the "backward Indian", or a "deformation or fossil of European instruments in America" (Mendívil 2013, 67). Cast into the theatrics of patriotic spirit, the charango was now seen as an innovative native invention that indexed a heroic indigenous identity, and as such, rose to emblematic status for indigenist nationalism (Ibid, 68). These new indigenisms continued to gain ground through the next several decades in both Peru and Bolivia.

In simultaneous trends discussed in the previous chapter, the Nueva Canción movement began to emerge, sweep through Latin America and tour internationally. These developments promoted a new reputation for the charango as a symbol of revolutionary Latin American resistance to capitalism and US imperialism. This association dovetailed with ethnic nationalisms and postmodern multiculturalism that now exalted and exoticised indigenous Andean culture to synthesize a modern image of the instrument (Ibid, 69). Certainly the 2006 election of Bolivian president Evo Morales set the stage for the international blow up that same year. Morales, the first indigenous leader of a country with an indigenous majority, had won on a platform that promised a unified indigenous Bolivian nation. ${ }^{68}$ Public mood was certainly ripe to rally around the new government's loud objection to Lagos' diplomatic gesture with Bono. Thirteen years later, the Morales government's indigenist campaigns have corralled public sentiment to firmly embrace claims on the charango as Bolivia's national instrument (Kohl/Postero 2010, Mendívil 2013). ${ }^{69}$ This history certainly demonstrates that Bolivian (or Peruvian) concerns with cultural appropriation did not begin with the 2006 debates over charango origins.

\footnotetext{
68 "Indigenous" here refers again to rural highland people living in Andean zones.

69 The Evo Morales government's platform articulated a strong indigenist politic that promised to "refound the nation" and "decolonize" Bolivian society. However, this focus was combined with populist and socialist tendencies
} 
Ethnomusicologist Fernando Rios has pointed to earlier controversies as pertains to debates over Andean music domains. While not expressly focused on the charango, his article entitled "“They're Stealing Our Music": The Argentinisima Controversy, National Culture Boundaries, and the Rise of a Bolivian Nationalist Discourse," demonstrates not only a historical pattern of Bolivian contest over questions of musical appropriation, but evidences the dynamic exchange that took place in fact between Argentinean and Bolivian musicians and folklorists during the formative processes that established national folkloric repertoire in both countries (2014).

Rios recounts the Bolivian reaction to an Andean musical scene in the 1973 film Argentinisimo (The essence of Argentina/Very Argentine). In the scene in question, Bolivian charango transplant Jaime Torres performs the tune "Hasta otra dia/Desde que te conoci" with his group. The release of this film, initially popular with Bolivian audiences in La Paz, was met with an explosive response by the Bolivian government. A formal complaint was addressed to UNESCO. Writes Rios, “...many scholars contend [that it] prompted UNESCO’s initial involvement in intangible cultural heritage issues (e.g. Sherkin 2001, 44-55; Jafstein 2007, 2-3; Ivey 2009, 30)" (Ibid, p 208). The film was quickly pulled from the Bolivian market and Torres henceforth, steered away from performances in Bolivia, since he no longer felt welcomed there despite his Bolivian roots (Ibid, 212).

Rios also points out that the stage for this explosion over the scene in Argentinisima was already set by simmering nationalist objections to the use of Andean instruments, including the charango, by Argentine and other non-Bolivian musicians (Ibid, 204). According to Rios, Bolivian contests have often found their playing field over singular Andean tunes such as “Ojos

that have been seen as conflicting by some scholars. For a critical review of the Morales government in context of indigenist politics see Kohl \& Bresnahan, 2010. 
Azules", "Dos Palomitas", and others: not to mention the infamous "El Condor Pasa", in which the ongoing skirmish took on a North American dimension through the adoption of the Andean tune by American folk legend, Paul Simon (Ibid, 217). As Rios points out,

...many Bolivians have observed (that) foreign exploitation of the country's natural resources (e.g., tin, oil, natural gas) and the annexation of its national territories (especially Chile's takeover of the entire coastal region after the 1879-84 War of the Pacific) have long ranked among the most potent elicitors of Bolivian patriotism (198).

Clearly, the charango has gotten caught up in a crossfire that extends far beyond the domain of music and culture, at least from a Bolivian perspective.

\section{Nationalist paradoxes}

Ethnomusicologist Thomas Turino offers some relevant theoretical frameworks towards understanding these dynamics in Nationalists, Cosmopolitans, and Popular Music in Zimbabwe (Turino 2000). In this book, Turino points to intrinsic paradoxes which all modern nation-states have to negotiate. Nations, according to Turino, are formations that strive to replicate a commonality through various structures, institutions, and emblems such as "diplomats, finance and foreign ministers, airports, national sports teams and dance companies, flags, and anthems" (Ibid, 15). At the same time, nations need to be able to claim uniqueness or they will not be able to hold a distinct place among the others. According to Turino, this creates an unresolveable tension in the national project overall which includes the development of "national" music and generally, "national heritage" (Ibid, 15).

Turino explains:

Distinguishing emblems and discourses (e.g. of "national character") are thus required to circumscribe nations. When available, indigenous or "folk" arts and practices are often key emblems because they offer the sharpest contrast to cosmopolitan forms. Distinctly local indigenous practices and emblems are also crucial as indices of actual affective identities and bonds which can help imbue the rather abstract concept of nation with sentiment (Ibid, 15). 
Certainly, claims on the charango in both Bolivia and Peru fit within this analytical framework, with the charango as a folkloric emblem that can only be "owned" by one Nation State in order to distinguish it from the others as evidenced in the ongoing disputes.

The second paradox identified by Turino is found within the nation state itself. This refers to the need for distinct local identities in order to consolidate a national identity that stands out as unique against the rest. However, these distinct local "ethnicities" within the nation also constitute a potentially divisive threat. "Nationalist discourse," Turino writes, "thus creates potential rivals within its own territory (Herzfeld 1997)" and the task of the modern nation state is to balance "the needs and threats inherent in both localism and cosmopolitanism - that is, between the twin paradoxes of nationalism" (Ibid,16).

These paradoxes are managed, according to Turino, by distilling locally diverse practices and forms into homogenized symbols that are taken out of original local contexts and fitted to national and international cosmopolitan frameworks. In charango terms, a "standard" and "urban/modern" charango has evolved, and continues to evolve, according to cosmopolitan musical demands both inside and outside Latin America. This homogeneity is expressed in musical lexicons and repertoires in a dialectic dance with audience tastes, performance spaces and market places.

Arguably this sort of distillation and emblematization of culture is also driven by the need to commodify and sell cultural products on today's international markets, which includes tourism. In Turino's terms, a national identity must promote its distinctiveness on equivalent terms with other nation states. However, this distinctiveness should result in just enough exoticism, but not so much as to be uncomfortable to visitors. In a kind of conceptual international museum with hands-on installations, art forms and artefacts, practices and musics 
are taken out of context and made palatable and accessible enough for cosmopolitan (read tourist) access. ${ }^{70}$ The standardized, emblematic charango (and even more so, the "pan pipe") has been promoted not only as the keeper of tradition, but the port of entry for curious cultural tourists craving a fix of exoticism that the nation state in question claims to uniquely possess. Concepts of the "authentic" come into play as the charango, and its "Indian" player, is put up for sale on the world market, sometimes by the "Indian" himself. ${ }^{71}$

One common point of argument has been a claim that Bolivia alone is "the only country to have thousands of varieties, thousands of ways [charangos] are played, tuned, and constructed", and similar points along those lines. ${ }^{72}$ Aside from the existence of a similarly diverse charango cultures just across the border in Peru, this sort of argument seems to loop back on itself - unless "diversity" is conceived as a singular unifying feature, as it often is in liberal "multicultural" discourses. ${ }^{73}$ Indeed, the presentation of the "thousands" as one singular entity of Bolivian heritage may adequately resolve the potential tension between the local and the national, as the argument is made to defend the singular ownership of the charango by the singularly distinct Nation State of Bolivia.

Do the interests of ethnomusicologists and certain kinds of cosmopolitans in local campesino and indigenous musics (such as kalampeo from Norte Potosi region) figure in to this

\footnotetext{
${ }^{70}$ This, certainly, was evidenced on the streets of Europe as discussed in the previous chapter.

${ }^{71}$ When I was in Sucre, Bolivia, people repeatedly advised me to go visit "el charango mas grande del mundo" (the biggest charango in the world), in Serrano, Bolivia (Illustration 2). This massive charango replica, constructed by a clever bunch of luthiers and players in the town, can now boast Guinness World Record notoriety. When I asked musicians if there was a good music scene of charango players in Serrano, the answer was universally, not really. Contrary to advice, I did not go to Serrano, as I was more interested in music-making than construction stunts, although about once a year, apparently, a group of musicians gather and "play" the gigantic charango.

${ }^{72}$ Mendoza, Jose. Personal communication by Facebook messenger, Dec 2018.

73 "Multiculturalism" as a term seeded in liberal discourse aims (problematically) to conceptualize an equalized and unified entity of diverse cultural groups, devoid of positional or post-colonial concerns that may point to enormous power differences within the "multitudes". These problems have been examined by scholars such as Charles Taylor, Smaro Kamboureli, and William Kymlicka (Taylor 1994; Kamboureli 1994; Kymlicka 2014). It is used in this work with an awareness of critical viewpoints of the discourse from which it has emerged.
} 
analysis? ${ }^{74}$ Among a certain set of "global" types (that would include me), the difficulty of learning and understanding a musical style that is counterintuitive to western musical patterns and forms has a certain motivating appeal. If the challenge of learning to play the standard charango (whose string set up is baffling enough to an entry level foreigner) is not adventure enough, kalampeo requires an unsupported trek into rough highland terrain far beyond the international tourist museum, metaphorically and musically speaking. One must question, perhaps in light of current (hipster) trends in cosmopolitan situations internationally, if exotic beyond the exotic is a new version of "far out man" that spurred earlier baby boomer ethnomusicologists such as Turino to make their way into rural highland communities to study Andean music, or for that matter, any of his peers or predecessors.

Personally, I ended up in the workshop of kalampeador and nationalist Daniel Villavivencia in Sucre, Bolivia because of my charango teacher from Chile. Camilo Gomez, ( a young charango innovator aligned with hipster and New Age trends already introduced in Chapter One ( $\mathrm{p} 22$ ), had chased down the golden snitch of kalampeo with the same instructor a few years previously, probably with better results. ${ }^{75}$ In sync with this seemingly Chilean trend, Italo Pedrotti, charango composer and professional player did his graduate field work in communities in Norte Potosi, also in pursuit of the enigmatic kalampeo tradition (and has rendered a substantial and credible academic thesis on the topic. $)^{76}$

\footnotetext{
${ }^{74}$ Kalampeo is a style of charango playing centered in rural communities in the North of Potosi area of Bolivia. It is characterized by a melody that is embedded in strumming patterns, which emphasize upward strums that are central to expressing its rhythmic pattern and what makes it sound unique. On a side note, there are certain charango variants associated with this style of playing. Metal strings are most typical. See Audio Index 4 and 5 for sound bites of kalampeo style playing.

${ }^{75}$ See footnote 102, p. 98 for an explanation and analysis of the issue of "New Age" trends.

${ }^{76}$ Jean-Marc Grassler's "Bolivie- charangos du Norte Potosi” (1997) and Henry Stobart's (2006) extensive ethnographic work on Andean life cycles, including the place of the charango in the same region are further examples of cosmopolitan/European musicologists specialized fascination with this unique local musical tradition popular in the highland regions of Norte Potosi.
} 
Perhaps then, in a subsequent development of Turino's theory, the new cosmopolitan vogue in the current charango music scene will turn towards local musics to find the exotic beyond the exotic as the hottest new item on the global stage. The contest will then be not who owns the charango, but who owns the most "interesting" one. Until then, cosmopolitan kalampeo curiosos (curious people) and bohemian explorers of local musics will constitute an odd fringe group of multi-culti enthusiasts who are often otherwise innovative and non-traditional in their musical practices and sensibilities, but tourists nevertheless - if not by our own intent, by the mental assignments of our hosts and/or the overarching post-colonial and socio-economic umbrella. $^{77}$

\section{$\underline{\text { Diasporic Intersections }}$}

How do these twists of nationalist discourse, politics, and constructed meanings play out in scenarios outside of Latin America? One Bolivian charango player whom I interviewed during this study, Paulino Alejo Cruz, presents an interesting angle on the question. Born and raised rurally in a mining community in the Norte Potosi region (kalampeo territory), his initial years in music were as a percussionist playing "electronica" in the urban Bolivian scene. ${ }^{78} \mathrm{~A}$ few years later, Cruz took up the charango, primarily for export - to join a group departing for Europe. In Europe he toured and performed both Bolivian folkloric and homogenized pan-Andean repertoire that had become popular on a standardized urban/modern charango (round backed, five double courses of strings, standard tuning).

Years later, from his immigrant position in Vienna, Cruz followed and celebrated the election of the Evo Morales government in 2006, and felt encouraged by his pro-indigenist

\footnotetext{
77 Threads can be connected between this sub-group of cosmopolitans (myself, Turino (a US national), Camilo Gomez, Italo Pedrotti and other Chileans) with the interests and tastes of earlier folklorist movements in our home contexts referred to in other chapters of this work.

${ }^{78} \mathrm{He}$ is probably referring to amplified, popular "rock" in a broad sense.
} 
positions and policies. Because of these developments at home, Cruz has turned his musical attention (back, sort of) to the more rural and indigenous styles of charango playing that had surrounded him in his childhood (in particular, kalampeo). At the time I met him, he was known among his peers in the small Viennese scene of Latin American musicians as "el kalampeador" (the one who plays kalampeo charango). Interestingly, Paulino never disclosed to me whether he identified as indigenous, or not, and although I did ask directly, I did not press him on this matter. It was my guess, in this situation, that although the charango's status could vacillate radically with twists and turns of rhetoric fuelled by political and social agendas, the confidence of a player of actual (as opposed to perceived) indigenous descent (i.e., rural, highland Andean people) about his own identity was not as easy to establish. For logical reasons and perhaps most especially for a subject dis(located) to a former power center of colonialism, he may have required more confidence in me before disclosing this, or, the definition was blurry and less meaningful to him than I thought. ${ }^{79}$

I did hear Paulino Cruz perform kalampeo style music at a Bolivian National Day celebration in Vienna in November 2018. Interestingly, this extremely patriotic/nationalist party had many attendees who were not Bolivians. One of the charango players in the headline band, for example, was a Chilean whom I had interviewed for this study (Pedro Hernandez). This rotating multi-instrumentalist in the Austrian scene (as he recounted) attended with his sister and other non-Bolivian friends. I was there as well as an invited guest, with a Croatian charango player and his Austrian friend. The repertoire was a predictable spread of Bolivian folkloric/mestizo music, apart from Cruz's set representing kalampeo music from Norte Potosi, which inspired an enthusiastic reaction from the crowd. ${ }^{80}$

\footnotetext{
${ }^{79}$ Much like the situation of Cesar Guzman Roman, to be discussed in Chapter Five.

${ }^{80}$ Paulino Cruz playing at that event audio index 5.
} 
Nationalist discourses in the field

I first encountered nationalist claims to the charango in Bolivia, in a conversation with the aforementioned kalampeo instructor who boldly and unwaveringly declared that "the charango is a Bolivian instrument, whose birthplace is Potosi”, period [my emphasis: $\mathrm{HH}] .{ }^{81}$ According to him all other claims made on the charango were appropriations of Bolivian folkloric heritage. No amount of friendly suggestion, discussion, or argument to the contrary could have dissuaded him from his defensive certitude on that point. ${ }^{82}$

During my field work in Europe I stumbled once again upon Bolivian resentments and claims of ownership from a well-known Bolivian player who lives in Paris, Jose Mendoza. I had met this particular man at a charango musical event in Brussels. ${ }^{83}$ In a string of text messages sent at a later date, he let me know that he objected to my research project on the grounds that it did not credit the charango as a Bolivian instrument. Later, also via messenger, he unleashed an inflammatory string of objections and opinions in a delayed response to my initial messaged request to interview him. His arguments were vehement and many-layered, mixing the above opinion about Bolivian proprietary rights with other resentments and feelings as well as some legitimate points of concern.

One of his main points was "the appropriation of the charango by foreign nationals (Europeans) who are really "guitarists that take up the charango for its "exoticism" to boost their careers on the world stage." ${ }^{84} \mathrm{Within}$ this statement lies a legitimate critique of European cosmopolitanism and the selling of perceived indigeneity of the charango to international

\footnotetext{
${ }^{81}$ Villavivencia, Daniel. Personal conversation, March 2018.

${ }^{82}$ Conversation with Daniel Villavicencia in Sucre, Bolivia.

${ }^{83}$ At this event Mendoza, fairly inebriated, had latched onto me physically and made inappropriate sexual comments while posing for a photo. I relay this to expose sexual harassment seeded in a kind of "machismo" that may intersect with strains of nationalism.

${ }^{84}$ Mendoza, Jose. Personal communication via Facebook messenger Dec 2018.
} 
audiences. This comment of course has some context as presented in other chapters of this work and might even be argued to be the case with some of the musicians interviewed for this study (Yann Béréhouc comes to mind).

From another perspective, related situations have been well chronicled and similarly critiqued by ethnomusicologist Michelle Bigenho in two different books (Intimate Distance: Andean Music in Japan 2012 and Sounding Indigenous: Authenticity in Bolivian Music Performance 2002). These works are situated in her seventeen-year engagement with a Bolivian folkloric group, Musica de Maestros, with whom she toured extensively in Japan. This group was part of a large network of Bolivian musicians who presented Andean and Bolivian folkloric music in Japan, selling what Bigenho problematizes as a "constructed version of indigeneity" through the staged musical and dance performances to Japanese audiences (Bigenho 2002). Of course, this situation pertains as well to the history of the charango's arrival to Europe as analyzed in the previous chapter. In the performances described by Bigenho, non-indigenous urban Bolivian musicians were the agents of appropriation and "resale" of Bolivian indigenous tropes (Ibid, 2002, 2012). Bigenho's work corroborates the broad reach of this pattern that certainly is not limited to European or non-Latin American performers, contrary to Mendoza's point.

In another comment, Mendoza was dismissive of charango players who are not "true charanguistas" (advanced solo charango performers) but rather, guitar players who play the charango. I interpreted this initially as an expression of Bolivian purism along the same traditionalist lines as origins claims and stringent views on physical form and musical repertoire. However, Luis Bedoya, a Bolivian musician himself and "quenista" (wind player) living in 
Vienna provided some context to this viewpoint in his own narrative that may explain it differently.

$\mathrm{HH}$ : Do you consider yourself principally a charango player?

Luis Bedoya (LB): No. No, I am more than anything, someone who plays quena-quena or zampoña, more than anything, that's my instrument-- yes. My father played charango and my uncle. I was interested but, when I started to play, it was quena. And later I decided to play charango. Charango because, at my house we received a lot of people from the countryside, so I had a lot of contact and I learned a few tunings from their places... well, I mean, these were things that happened spontaneously, that I learned spontaneously. It wasn't that I was that interested... Mostly I was focused on quena. I arrived to Europe as a quenista (in 1979), because well, there was a charanguista who played in the group... and if he was missing I would play the charango.

HH: Did many of the other musicians in the group also switch around instruments?

LB: Yes, yes. It was very flexible here in Europe. But in Bolivia a quenista was a quenista, a charanguista was a charanguista (author's emphasis).

HH: So because of your position outside of Bolivia, you had the opportunity to play the charango more professionally than you would have had if you had stayed in Bolivia?

LB: Yes, yes, in my way of thinking, as I was a quenista-quenista, but I knew other instruments: I started to play guitar, charango, zampoña (Bedoya interview, 2018).

In Bedoya's home context in Bolivia, there was a strong and fixed identification with just one instrument for each musician. In Europe, musicians were more flexible and took different musical roles depending on situation and need. Perhaps having a "shallower bench", (fewer players available) musicians had to be less rigid in their allegiance to just one instrument. Perhaps Mendoza's objections to charanguistas who are really guitarists, not "real" charango players is related to the case as described by Bedoya. From his Bolivian perspective, specialization would be the normal and reputable path. However, as I saw at the Bolivian party in Vienna (which was hosted by Bedoya), national divisions may also break down in some diasporic situations into a more flexible and inclusive environment where pan-Latin American identity trumps national allegiances. 
To what degree do foreign scenarios engender a breakdown of rigid traditionalist views and practices? Or do these spaces strengthen and reinforce tradition and national allegiances? As Luis Bedoya attests, traditions around single instrument players were abandoned in his European contexts for a more flexible approach. But Paulino Cruz's reinvigorated interest in articulating a Bolivian (indigenous) identity through the practice of indigenous music from his homeland, as well as Jose Mendoza's defensive nationalist stance on the origins question, suggests the opposite.

Experiences are also mixed among foreign (European) players. French player Yann Béréhouc reported poor reception in Bolivia, to the degree that he, like Jaime Torres so many decades earlier, has elected to avoid further engagements there. He also endured a reactionary online controversy with some Bolivians around one piece of original charango music he had titled after a town he had visited (in Bolivia). In this case, commentators objected to his "appropriation" of the name of the Bolivian town for use as the title of his composition, which Béréhouc named after the place where he composed it (Béréhouc interview 2018).

In another case, Bolivian-trained Swiss player Nina Dimitri was proudly paraded around as a showpiece by her musical friends while living and studying in Bolivia. Among Bolivians in Europe however, she experienced being excluded from social interactions with the (Bolivian) players she had employed to tour with her. These same Bolivians also criticized her for crossing genre lines to play with Swiss jazz players. In Dimitri’s experience the nationalist and traditionalist judgments against her by Bolivian collegues were much stronger in Europe than in Bolivia (Dimitri interview, 2018). ${ }^{85}$

\footnotetext{
${ }^{85}$ Dimitri's case may have intersections with gender issues, which as previously noted, did not emerge strongly in this study. However, in Dimitri's case, gender (or rather, Bolivian machismo (male chauvinism)) might have been an influential factor in her experience. In Bolivia, where she was well received, Dimitri was married to a male Bolivian musician of high repute. In the dismissive situations she described in Europe, she was forging a solo career
} 
Many histories, many perspectives

The very recent publication of a volume of writing on the charango, El Charango, Historias y Tradiciones Vivas (2019) edited by Julio Mendívil signals a first effort towards gathering a body of literature on the subject of the charango. While not solely a collection of writings on the origins question, the volume does present a large section on that theme, if for no other reason than that it constitutes a large part of what has been written thus far. This proves, in numbers of pages, that a large space has been occupied by this persistent debate for at least the last fifty years in both academic and public discourses. In his introduction, Mendívil takes an expressly diplomatic tone, seeming to aspire to set a more tolerant and inclusive way of approaching the varied opinions of the charango's dedicated aficionados, both scholarly and not. Writes Mendívil:

Since the beginning of the $20^{\text {th }}$ century, one of the central topics in research about the charango has been to determine its origin [...] After half a century of research in which it was attempted to substantiate the most conflicting hypotheses without having arrived at any convincing result, it might be more appropriate to speak of the divergent manners in which interpreters and researchers have imagined the history - or more accurately, histories - of the charango. In this sense, the collected texts of the first part should not be evaluated according to their truthfulness, rather for their relevance within a certain paradigm, whether scientific or not, and also by virtue of their place within a concrete political and social program. In sum, then, they suggest that the different historical representations proposed by the authors - including mine - are simply discourses that attempt to explain the same historical occurrences on the basis of divergent data and from various points of view. They are, if you like, and to put it in musical terms, variations on the same theme (Mendívil 2018, 24).

A noble gesture to be sure, Mendívil's reflection on a divisive issue might relieve some of the tension around the topic, and set the tone for more productive discussion. Indeed, as he points out, the diversity of the discourses themselves simply evidence lively and important histories,

and hired male Bolivian colleagues to accompany her. Beyond disapproving of her musical stretch away from traditional charango repertoire, were her male Bolivian musical colleagues in Europe threatened by her filling a leadership role? Did her affiliation with her male partner in Bolivia "buy" her acceptance among Bolivian friends? Probably. 
musical engagements, and social and cultural trajectories of the charango, as well as the political agendas that have impacted the conversation, the politics, and interactions on diverse fields of play. In this sense, the charango is defined not only in the social interactions of musical play, but in verbal and written discussions and debates. Seen from the perspective of new organology, the charango is as much these discourses as they are articulated and exchanged as it is the materials from which it is made, and the music that is played on it.

The origins debate draws the charango, as Mendívil says, into "political and social programs" of nation states striving to articulate the particularity of their greatness (Ibid 2019). Here, the charango's organological meaning once again can be best defined in terms of its involvement in human affairs - in this case, that of political tugs-of-war between relatively poor countries with long histories of struggle against colonial and imperialist invasion and control. In these discourses, the charango is imagined by the nationalist as symbolically, a "permitted (and celebrated) Indian" waving the flag of the nation, but, as problematized by Turino, only one flag can be held (Turino 2000; Tucker 2011). The reality of course is quite different: the charango's connection to diverse Andean zones and peoples' as well as to varying mestizo traditions in urban locales, dis-organizes nationalist claims (consequentially prolonging this debate).

The emergence of pan-Andean music has broadened the instrument's reach even further into global cosmopolitan situations, including the European fields in which I interviewed charango players for this study. In the next chapters these players' stories will take the foreground to illustrate the charango's current meanings and musical trajectories as the players themselves understand and perform them. Their lived histories, feelings, points of view and experiences as well as the music they are making with the charango in contemporary 
intersections will further articulate its signification from the perspective of new organology as mediated through complex social and historical processes. 


\section{Chapter Four: Finding Charango Players: Notes on field method}

As is predictable with field work, mine was an unfolding process of trial and error that included the task of finding charango players living in places in Europe that were not too far flung from my home base for several months in Vienna, Austria. On the way there I scheduled a stopover in Iceland, and had my first interview with singer-songwriter and charango player Ólöf Arnalds. On a second stopover in Paris I met in person with Antonio (Antuco) Perez, and via Skype with Yann Béréhouc (Rheims, FR) and Ivan Latapiat (Lyon, FR) as there was not enough time to travel to their locations in person. I met and got to know Yann better a few months later at the Encuentro Internacional de Charangos (International Charango Meeting) that I attended and performed at in Brussels, Belgium, en route to Spain. ${ }^{86}$

Landing in Vienna, my field work supervisor Julio Mendívil also joined the participant group. At that time he didn't know of any other charango players in Vienna. Over time and with some dedication, I managed to find five more in Vienna, four of whom I interviewed. I attended three live performances in Vienna in which these players participated. One took place in the basement community space of a Latino immigrant project. On my first visit to that site far outside the city center, nobody was there and the doors were locked. But there was a poster on the door advertising a concert at a later date, and so I returned to this establishment again several weeks later. That night there was a concert with several musical performances in honor of Latin American women. I attended with the intention to network and "find" charango players and was surprised that there was already one there (Lidovino Vila Quispe). The musicians at this event gave me the names of several more contacts to pursue. Among others they provided me with the

\footnotetext{
${ }^{86}$ A rehearsal of the "charango orchestra" that I participated in at that event, playing "Virgenes del Sol"- a standard of pan-Andean music well known in Europe- Audio Index 3)
} 
name of Luis (Lucho) Bedoya, one of the first Andean musicians to arrive in Vienna, according to him and others in the community. I was also given the names of Luis Parra Madariaga and Pedro Hernandez, from Peru and Chile respectively, both charango players who have been living in Vienna for several decades. Paulino Alejo Cruz showed up later that night, and we made an immediate connection. I met with him several more times, once for an interview, and once at Julio Mendívil's apartment, for an instructional group session in "kalampeo" style playing, where the two met for the first time.

The second event I attended was a Bolivia National day celebration in November, to which I was invited by several of the charango players I had by that time met and interviewed. I also invited Croatian player Deni Plavčić, as he had never heard a live performance of Andean music before. Plavčić, whom I had only met via Skype, took an eight-hour bus ride from Zagreb with his charango and ended up joining in the playing and dancing at this event. He was ecstatic to finally heard the music he had been studying on YouTube played live by Latino players, and connected with several of them for future contact. Finally, I heard my own professor (Mendívil) play the charango in a restaurant in Vienna called "Acapulco" with an ad-hoc group of Latin American musicians that rotate and perform a mixed Latin American repertoire on a regular basis at that establishment. Pedro Hernandez was in the room as an audience member, and I introduced him to Julio Mendívil. Through these small encounters, I like to think that my presence and work in Vienna created some new connections between charango players and musicians who had not previously known each other.

I interviewed one other charango player in Vienna - Nina Dimitri, from Switzerland. I met with her in her Vienna hotel one morning before a performance she was touring with her family clown and circus arts troupe, in which she plays the charango and other instruments. After 
our meeting, she invited me to the show that afternoon. The performance was world class. The role of the charango (actually, a ronroco, a baritone variant) was primarily on the sidelines of the theatrics as a provider of sonic texture, certainly a unique forum for the instrument. ${ }^{87}$

I recount these details about my Vienna experience because the story of how I found charango players there highlights a number of points about ethnographic fieldwork. First, the fact that I was based in Vienna meant that I had some time to seek out and find people through "snowballing" technique where one person referred me to another, and that person, to another, etc. As I gained a bit of trust with one interlocutor, he or she sent me to another, and so forth.

A similar scenario unfolded in Granada, Spain, where I spent four weeks at the end of my field study period. In one instance while in Granada, a charango player actually got in touch with $m e$, as he had heard about me from someone else. Granada is a small place and in particular the musical "scene" is quite bohemian, international and concentrated in the small-town-like Albaicin neighborhood with a fair presence of Latin Americans. All of these factors made it easy to network along lines of human acquaintanceship as I made them.

Some of the other participants in the study were referred to me by people I knew as well, but most were players I became aware of because they were members of a charango players' Facebook group called “charanguistas y charangueros". I delved deeply into this group with almost nine thousand members from all over the world to fish out any players listing a European location. Each one of these people was then contacted with a personal message and a link to a website I had put together as a calling card for my research (www.globalcharango.com). This proved to be a pretty good method of locating members of such a dispersed field. Most of the

\footnotetext{
${ }^{87}$ Sebastian Cerda, a travelling musician, also mentioned playing charango in a street theatre troupe that he toured with in central European countries when he first arrived from Chile. His story is touched on in the next section.
} 
people I contacted were responsive, and in the end about one third of my participants were reached in this way.

The project website which I had to put together before my departure from Canada turned out to be a great asset — not, as I had imagined, for reaching a larger participant group by online survey (which I did post, but received little response to) ${ }^{88}$ Rather, it put forward a professional image that I believe helped people I was "cold contacting" in such an impersonal way (via FB message primarily) to take me, and the work seriously.

As players were identified and contacted, I made some choices as to where I would travel outside of Vienna to conduct interviews within the limited time frame of four months. I travelled to Berlin, a city where I had formerly lived, and ended up meeting with four players and a luthier there. I also chose to go to the Encuentro de Charangos in Brussels, where many charango players from diverse locations were gathered. There I was only able to conduct three interviews, as the event was busy and time was short. However, it proved to be a great opportunity to get to know many charango players in an international charango "community" scenario, as well as to participate in a group performance and have many informal conversations, some with people I had contacted or spoken with already (Béréhouc, Mendoza, and Tarazona). I have since had contact with a few of the people I met at this event, some in connection to this research, and others as pertains to possible future collaborations.

Finally, I did end up face to face with a few participants who to my surprise did not identify primarily as charango players (Lucho Bedoya, Claude Ferrier, Osvaldo Hernandez and Raul Ramos). In these cases, most did play the charango, but had another instrument they identified with more primarily. In those cases, given the effort, time, and expense involved in getting face to face, I went forward with the interviews, and in each case, the information and

\footnotetext{
${ }^{88}$ See footnote 104 for futher explanation of the survey's failure.
} 
stories they were able to share were highly informative and relevant to the questions of the research. As the study progressed, I realized that multi-instrumentalism was a common denominator among many charango players anyway, so these participants were not by any means irrelevant.

In conclusion I must mention the warmth and openness with which I was received by the vast majority of musicians whom I interviewed for this study. Our common interest in and engagement with the charango seemed to create an easy point of connection. Most potential participants were very excited and pleased to hear about my project, and very accommodating to my requests to speak with them. Some shared very personal stories and spoke about emotional and private matters. I was given a number of CDs as gifts, was welcomed into peoples' homes, cooked for, invited to shows and parties and even taught a few new tunes in some cases. I account for this warmth and feeling of friendship through conversation and music as both a general texture of Latino culture (many were Latino) as well as a kind of bond over a common interest - the charango. My command of Spanish language certainly facilitated the process for the Spanish-speaking participants, and I'm sure made them feel at ease. I also felt that for the majority, being asked to tell their stories as musicians was perceived as an honor and point of pride, somewhat akin to being contacted by a journalist or radio show producer. Most musicians already live on the fringes of society economically, and many have, contrarily, spent a fair amount of time and energy seeking the limelight. In any case, I am very grateful, even touched, by their trust in me and their willingness to share their stories. 


\title{
Chapter Five: "El charango es mi vida" / "The charango is my life": Personal stories, emotional attachments, and mystical imaginaries
}

\author{
Charango papacito, wawita de pechos, llok'alla bandido, maestro pataiperro. \\ Charango peladingo, ninito viejo. Cuantos pensaran que te dominan, sin sospechar que tu \\ nos dominas a nosotros? \\ Charango little papa, nursing child, young rebel, wandering teacher, naughty boy, old \\ child. How many think that they rule you without suspecting that it is you who are ruling \\ us?
}

(Cavour 1980, 7)

This poetic passage by Ernesto Cavour is from the dedication that opens his seminal 1980 work, El Charango: su vida, costumbres, y desventuras (The charango: its life, customs, and misadventures). This volume is the first and only extensive publication by a single author dedicated to the charango. In this passage, Cavour addresses the charango as "little papa", "nursing baby", "naughty boy", "wandering teacher", "old child" and other terms of endearment and relationship one would use for a human actor, in both Spanish and Quechua. As previously noted, it is in fact common in the Andean world to speak about and to the charango in distinctly loving and human terms, most commonly as "mi charanguito" (my little charango, in the sense one would say "my little son", or "my little "Scout" or "poochie", if it were a puppy). In the most animistic of examples, Andean myth in some regions suggests that the charango can carry magic powers if blessed by a siren's spell, that can then be used (by a young man) to lure a (female) mate into a love entanglement (Turino 1983). The above passage by Cavour lists nicknames and terms of endearment that give us the sense of the charango as a diminutive, animate being that has big agency. Cavour, whose book title suggests that the charango has a "life" and has "misadventures" like a sort of Andean Huck Finn, finishes his dedication by saying to the instrument: "How many have mastered you, without suspecting that it was you who were the master of us?" (Ibid 1980, 7). 
Here, the charango is drawn into bonds of intimacy by its human agents (in this case Cavour) imbuing it with a spirit that gives it a certain magical, animate quality. New organologists might assert that in these types of intersections, the charango takes on these lifelike qualities because that is how its proponents interact with it (Dawe 2008).

The Andean custom of assigning agency and "being-ness" to inanimate things was not something I had on my mind as I synthesized this chapter. Rather, what grabbed my attention were certain recurring phrases in charango players' interviews that expressed strong feelings about the instrument. I was curious why so many said things like, "the charango is my life", and perhaps even more commonly, "I fell in love at first sight," when describing their first encounters with the instrument (Laduron interview, Parra interview 2018). I followed this thread to examine other statements that expressed emotional attachments, associations, and projections that the players connected with the instrument, such as "the charango is my alter-ego"; "it is like a life companion"; and "the charango is everything/encompasses everything (to me)" and so forth (Laduron interview 2018; Parra interview; Roman interview 2018). Why does the charango inspire such emotion in so many of its players? How do they speak about these feelings in the context of their own pathways with the instrument? What are the intersections between these personal perspectives and the more historical, social, and political forces at play? Why and how do they conceive the instrument as having agency in their lives? Is there a connection to be made here with traditional Andean belief systems around the instrument? What does the perspective of new organology contribute to these considerations?

This section will foreground discourse that speaks to these questions, in the web of commentary made by players involved in this study. One Icelandic player presents an exceptional and contrasting case of social and emotional neutrality towards the charango, which 
raises its own array of questions about the relationship of context and human projections on the significance of the instrument itself, and questions about cultural difference. To conclude, I present a poem surprisingly similar to that of Cavour's dedication which was re-discovered among the ethnographic recordings I collected towards the end of the writing of this chapter. The section will finish with a re-iteration of this endearing lyric by man-to-his (little) charango; not just wood-and-strings, but in his mind, heart, and life, much more.

For me, you know what the charango is to me?
Everything! Everything, everything, everything. (Guzman Roman interview 2018)

\section{Migrant intersections and Andean identity: Cesar Guzman Roman}

Cesar Guzman Roman is a forty-seven-year-old Peruvian living in Granada, Andalucia, in a mini-diaspora of fifty to sixty extended family members who have all followed his migration path to the south of Spain. From their original home in a rural location in the high Andes, his young parents first migrated to the coast, and a decade later, to Lima, where they settled in an indigenous migrant neighborhood for most of the years of Guzman's childhood. Guzman, then, grew up in a primarily indigenous Andean diaspora community on the edge of Peru's growing capital city.

Guzman describes his people as "humilde” and "timido' (humble and shy or timid) with a deferential social manner which, he explained, is inherent to the culture of his community's lower socioeconomic class. This habit, and what he explains as his peoples' sense of defeat and of inferiority, was something that was transformed for him by playing the charango. Says 
Guzman, "Music gave me everything — especially the charango" (Guzman Roman interview 2018).

Cesar Guzman Roman (CGR): When I was eleven or twelve, my brother bought a charango, and he had it for a week, and then he abandoned it, so I thought, ok, this is a small instrument and I was small, at eleven, so I thought well hey man, let's see what happens, so I started playing a little, and practicing it, and I liked it, I liked the instrument. Partly also it was a way of life too, because [...] the situation in Peru was difficult [...] and it was like an escape for me, and also a way to make money, because what I did was, learn to play in order to play on the buses.

HH: Was that like people who come into the bus when it stops to sell snacks?

CGR: Yes exactly $[\ldots]$ Well what happened... that changed my life. We played in the buses after school, we were a group, like, 'I'll play charango, you play siku, let's go to the bus'-without guitar. [We used] charango and quena or siku (Andean wind instruments). ${ }^{89}$

HH: What kind of repertoire?

CGR: Well for example, "Ojos Azules" (starts to play and sing Ojos Azules, transitions to "Poco a Poco" [also known as "Canción y Huayno"] $)^{90}$

HH: Beautiful, you sing well! I can imagine you at twelve, singing this...

CGR: Yes, well now my voice is lower, but I can still sing it. So, we had three songs...

HH: (laughs) wow only three songs?

CGR: Yes, [we played] Ojos Azules, Poco a Poco and [Walicha] (mumbles) I think. So you know what happened? They liked us a lot, and we made money too, and I remember the first time I went to play, imagine, I made more in than my father, more than he made daily $[\ldots]$ My father was a shoe repairman, which has a salary of $[\ldots]$ nothing $[\ldots]$ and at the end of the day I had fifteen soles. My father made four hundred per month. I thought, "I earn more than my father!" And so I said, man...this was a very good thing for me!

HH: And so your musical career started...

CGR: Yes. Besides that, I liked it... I liked the instrument. For me, you know what the charango is to me? Everything! Everything everything everything. You know what it

\footnotetext{
${ }^{89}$ This instrumentation, in particular the absence of a guitar, is more akin to indigenous forms of Andean musicmaking, and in this case may reflect an earlier stage of Guzman's "mestizajización" (a transition from indigenous reference points to values more associated with urban/mestizos) as is typical adaptation process for migrants from the Andean areas to large, criollo and metis dominated cities (Turino 1988).

90 Audio Index \#6, a clip of Guzman Roman singing during the interview.
} 
gave me? Besides giving me money, it gave me confidence in myself, totally. To-talmente (emphatically). Psychologically, emotionally [...] Why? Because before I became more rich, I was actually very shy, very shy.

HH: Before age eleven?

CGR: Before eleven or twelve or thirteen years old, I was very shy.

HH: Well, that can the most difficult time of life ...

CGR: Yes, but I was living in Villa Maria [de Triunfo-a primarily indigenous migrant neighborhood in Lima south]. It was like that. I was shy. In the lives of my brothers too, they're still shy. We are timid people, from the mountains, imagine how we are. A bit submissive, defeated [...] I am not defeated now, but it was music that gave me this. I'm not humble. Humble in the good way, yes, I am humble but not in the way that I'm going to lower myself because you are from Lima and I'm from the mountains [...] This (indicating to the charango) gave me my self-esteem, it means everything to me.

HH: That's very profound.

CGR: For me, yes, it means everything to me.

HH: So this broke a belief about (socioeconomic) class?

CGR: For me yes. And besides that, do you know what happened? It made me popular in school!

HH: With girls?

CGR: Yes, also, of course. Because before it was like "oh that's the guy from the mountains who plays in buses". But when we played in school, with my group, every time the girls were like "ahhhhh" they screamed, oh look at the guys playing there, they are "musicos" [positively]! So, for me, it gave me a leap... well it's because of the charango that I'm in Europe...

HH: But that's another story that we'll get to... What made the difference for your colleagues in school? That they actually heard the music? Or what?

CGR: Because they saw us not in the buses but as young guys from Lima who were playing romantic Andean (popular) music, the girls liked this music. They didn't see it as something from the mountains. They saw us as, look those boys play instruments, they are musicians who played really nicely. They were thinking about their quinceañera ${ }^{91}$, about falling in love... I think the people developed a taste for it. The music initially was from the mountains, very much from the mountains, but with time it changed, we added more instruments, it became more sonically appealing, before the music from the Andes

${ }^{91} 15^{\text {th }}$ birthday party—like a "coming out" tradition for Latina girls. 
was more limited. I'm talking about vernacular music, about the people who listened to it.

But I'm telling you the charango is very important to me, it changed my life; it gave me everything. I play other instruments, but the charango gave me everything. It gave me security, it gave me money, it's the reason I could come to Europe.

Thomas Turino's study of the music of Andean migrants in Lima helps locate Guzman's story in a historical context of class differences between migrants and the elite Spanishdescended "criollos" in Peru's capital as expressed through musical practices (1988). According to Turino, Andean music's acceptance in Lima happened in three phases over many decades predating Guzman's happy start as a busker on public buses.

The first phase (1910-1940) was a period of primarily "tokenistic" appropriation of certain Andean sounds and musical signifiers into Western and criollo musical forms by criollo musical agents for presentation to audiences of the urban elite in Lima. This was synchronized with political initiatives to revalorize "the Indian" and "his folklore" (indigenismo). ${ }^{92}$ Early "indigenismo" in this time was part of an emerging national identity project in response to the threat of US political, economic, and cultural imperialism. As "lightly" indigenist as this period may seem from today's perspective, it was a great departure from the policies and attitudes of dominant forces in Lima since it's founding by Spanish colonialists in 1535. The first three hundred and fifty years of the city's history marked a long and repressive era for everyone but Spanish colonialists and their "criollo" descendent landowners. These ruling classes celebrated and cultivated all things Western and European, and denigrated and discouraged all things "indigeno", including dress, customs, language, and musical practices (and instruments, including the charango), which were not tolerated (Ibid, 130). Writes Turino:

Jose Maria Arguedas (1985:8), among many, has noted that it was thought to be "shameful" to perform highland music in Lima until well into the present century.

\footnotetext{
${ }^{92}$ And perhaps a precursor for cosmopolitan scenarios on the streets of Europe many decades later as discussed in Chapter Two.
} 
Puneño migrants supported this view, noting that even until the 1970's there was a general reluctance to perform their own indigenous musical traditions in Lima because of urban- criollo prejudices and the "shame" or "embarrassment" (verguenza) they felt in regard to their highland heritage (Ibid, 131).

Turino analyzes this phenomenon through Gramscian theories of hegemonic processes. In Gramsci's (and Turino’s) view, what Guzman (and Jose Maria Arguedas) describes is a complex and self-perpetuating belief system that reinforces migrant submission to the dominant Limeño "criollo" (Spanish descendents and the upper-class elite) tastes, values, and judgments. This is a process, points out Turino (via Gramsci), that requires the continuous reinforcement and "involves internalized consensus" which exists in tension with the group's own self-interest (Ibid, 129). Other post-colonial and social justice writers use the more psychological term "internalized oppression" to explain the phenomenon, which has now become common in social justice activism and scholarship. The shame and embarrassment mentioned by the subjects of Turino's study can be seen as parallels to the self-defeating or "humbled" countenances of the lower-class migrants that Guzman spoke about in his personal testimony about becoming a charango player, many decades after this historical period.

In this same period, in developments in highland cities such as Cuzco and Puno, mestizo cultural articulations were beginning to be promoted in the hopes of it being adopted as the "national" standard of folklore. Competing with criollo interests in Lima whose primary attention was on black Peruvian music from the coast (as a potential emblem of national folklore), these efforts were galvanized in a musical song (and dance) form called "huayno", in which the charango was foregrounded (Mendoza 2008). In Cuzco these efforts were primarily expressed through a radio show called "La Hora del Charango", which became a symbolic focal point for mestizo highland identity. As the charango filled a starring role in these musics, charango players now adopted certain playing techniques such as plucking and pinching out the 
melody apart from the typical fast strumming techniques in which it was embedded in highland tradition in order to appeal to the tastes of the urban elite who were driving these initiatives (Ibid, 98). The charango was featured in this mestizo huayno music and now became more accepted outside of indigenous highland/rural contexts. Its new "melodious" voice was "upgraded" (via new techniques) just enough to be acceptable to the mestizo elite, while at the same time creating, for their initiatives, a symbolic bridge to the rural Andean majority. Although efforts of the Cuzco elite to predominate as the representative "national" folklore failed, the mestizo charango emerged and won great popularity throughout the country in huayno music. As an Andean representative on the national scene, the charango hence became widely associated with "a certain degree of rebelliousness against the social order"; i.e. the criollo hegemony in Lima (Ibid, 99). ${ }^{93}$

This development and popularization of huayno and promotion of Andean music by the mestizo elite in highland cities connected to a second distinguishable period for popular music in Lima from the 1950s to the 1960s. During this period, Andean music was commercialized in the city (and later circulated back into highland communities) through a plethora of live performances in tents (coliseos), the growth of the recording industry, and promotion through radio shows. The large numbers of highland migrants that had established themselves in Lima created a viable commercial audience. In this phase, says Turino, "The focus shifted from the Inca past and a pan-Andean image to the contemporary regional cultures of specific departments" (Turino, 1988, 134). ${ }^{94}$ The industry supporting this music was run by profit-driven entrepreneurs external to the migrant communities (Ibid, 134-137). This period trailed off in the late 1970s and early 1980s, just around the time that Guzman's family arrived in the capital from

\footnotetext{
93 This signification was later was reiterated by leftist and Nueva Canción trends, as we have covered in Chapter Two.

94“"Departments" are in this context akin to Canadian provinces or U.S. American states
} 
the coast, where his parents had made their first migration out of the highlands several decades before. Importantly for Guzman, the charango's popularity had been well-established by then.

The third phase of highland music in Lima, in which Guzman's story would be placed, was marked by the further shift towards regional migrant identification as well as the active engagement of migrant community clubs that staged musical events in support of highland cultural expression. Simultaneously, migrants' social and political power was rising in the capital, as they had become a very large interest group that was increasing their presence and participation as stakeholders in city politics, affairs, business and economics (Ibid, 139-143).

In the economic realm, the swelling migrant population led to a boom of highlanderowned-and-operated businesses (both in the formal and informal sectors) and it also provided a market to support them. In earlier decades, criollos controlled the job market and migrants were forced into the position of supplicants for employment. By the 1980s the situation had changed considerably (Ibid, 139).

Turino illustrates that this amalgamation of migrant population and the decrease in exclusively criollo dominance and power had a strong impact on musical forms and practices. In a similarly unfolding process, the status of hybridized urban-highland forms finally became broadly accepted as popular music and "musica folklorica" associated with a general Peruvian national identity. Concentrating his research on migrants from the highlands of the Puno region (Puneños), Turino describes how, as of 1970, musical practices associated with highland indigenous lifeways began to reappear in those communities as well as in general public contexts, as exemplified by the resurgence of pan-pipe (sikuri) ensembles. Writes Turino,

The Puneño migrants' reluctance to perform panpipe music in Lima before the 1970s was obviously linked to criollo power, prejudices, and the dominant social consensusinternalized by highlanders that relegated an inferior status to them and to their cultural resources [...] Puneños state that as more Andeans arrived in Lima their self-confidence increased and they began to take up musical performance. Clearly, the reduction of inhibition attached to being a highlander is the result of larger demographic, sociopolitical, and economic changes. A shift in criollo/highlander power relations and the weakening of criollo hegemony led to a new social strategy; that is, the bolstering of 
highland identity units as opposed to the previous pattern of denying their heritage in the process of assimilation (144).

Turino points out, however, that this freer expression of highland culture was primarily evidenced in musical practice and performance, and not necessarily in other cultural forms such as language and religion, which at the time of his research, was still very much supressed (emphasis mine: HH) (Ibid, 144).

Guzman's experience, unfolding in this period, exemplifies some of the contradictions, complexities, and tensions of these relationships of power and assignments of social status as pertains to musical practice, and indeed, highlights how long these patterns have lasted. According to his own narration, Guzman's performances of popularized versions of music/tunes in Lima's buses that were signifiers of formerly shunned Andean highland culture brought him recognition, appreciation and money, on one hand — as he said "the people liked it". He felt excited at the prospect of earning more at this activity than his father did in his full time occupation. As he said, "this was a good thing for me!” (Guzman Roman interview, 2018). In other words, playing popularized Andean tunes in the buses was for Guzman, a life-changer. On the other hand, as he indicates later in his narrative (and in his development), it was through distancing himself from his Andean identity and from this bus-busking activity (or the mistaken distancing according to his schoolmates' perception) that he was awarded the admiration of his female schoolmates. In these scenarios, when his fellow students heard him play in school they saw him as not one of "those mountain people" (who play in the buses), and therefore, a legitimate and laudable "musico" (musician). In Guzman's experience, both affiliating himself with, and distancing himself from Andean highland (indigenous) identity elevated his status in various ways, depending on context, audience perception and the value that listeners/observers 
assigned to his activity and to Andean highland identity generally, as well as how they

understood and indexed the music being performed. ${ }^{95}$

The musical path of young Guzman unfolded quickly, and soon sent him on further

migrations across cultural and geographical divides. I asked him to explain the circumstances

and story of his migration to Europe.

CGR: When I was fourteen or fifteen, they took me to play in front of the Minister of Education. So there were a bunch of other guys there, older than me, in their twenties and they came with girl things, with their gringas [white girls, in this case from Europe] they had travelled there [to Europe] and come back [with European girlfriends]. I'm sorry but it's true, sincerely.

HH: So with a foreign girlfriend, it raised their status?

CGR: Yes, of course, they came back better musicians, with money, and their girlfriends, and for me at fourteen it was like "I want to do that". But not only, I'm referring to, not only that... I am talking also about music. I wanted to be able to play like them. I was jealous. Anyway what happened was...I was always meeting other Andean musicians, and they didn't know I played in buses, and there was some shame in it, people thought that, the musicians who played in buses, oh poor them. And I would go back to my neighborhood/community [barrio] and say look at those guys, they went to Europe they have money and European girlfriends, look at that.

$\mathrm{HH}$ : Are you a bit prideful?

CGR: Yes, yes, but thanks to my charango and my art, very much. I remember I would play six hours a day, at twelve years old. I would take my charango and start playing and then oops! It was six hours later. So I learned to play well.

HH: But to go to Europe, you had to be invited?

CGR: Yes, eventually someone asked me, another friend, with his group. That was twenty years ago. I was twenty-nine years old.

Guzman is now a merchant of crafts and tourist souvenirs. He is married to another Peruvian and they have three children together. He is no longer engaged professionally in music-

\footnotetext{
${ }^{95}$ Similarly, as seen throughout this work, the charango's connection to indigenous lifeways has either been emphasized, romanticized and even commercialized or pushed away from by adapting the instrument and its music to adhere to mestizo, criollo, and cosmopolitan aesthetics and values, depending on historical, cultural, and commercial situations.
} 
making because of economic needs and lifestyle shifts. However in his case, the choice to play the charango led to many serious life altering changes and opportunities and eventually, to his own immigration and that of sixty extended family members to southern Spain. His entry into musical life as a folkloric musician nonetheless coincided handily with the increasing power hold of the migrant community in Lima. Because of this, he was advantaged by the continuing rise in the status of "musica folklorica" from the Andes and the instruments with which it was associated in Lima, in South America at large, and certainly, in Spain at the time he landed there.

In his social and political context in Lima, playing charango and engaging in musical performance elevated his social and economic status, which had a deep psycho-emotional impact that transformed his self-esteem and boosted his sense of masculinity and attractiveness to girls. As Guzman gained recognition as a young musician, he was able to connect with new social circles where opportunities such as going to Europe were possible. Finally a concrete plan for travel presented itself and he entered the international music scene in Europe, which further raised his status and expanded opportunities for himself and his family. ${ }^{96}$ Given the chain of events in his life, it is no wonder his attachment to the charango is charged with emotion and gratitude. However as many others, the conditions for these personal transformations were contextualized in the historical moment both locally and globally, expressed in public sentiment and public attitudes towards Andean music (and by extension, the charango) in the city in Lima as well as on the world stage. The stakeholders, promoters and supporters ranged from national

\footnotetext{
${ }^{96}$ According to studies by Joshua Tucker, Peruvians in Spain seek each other out in small diasporic communities perhaps as a "respite from the daily indignities they suffered as Peruvians and their disempowering relationship to Spanish society generally" (Tucker 2014, 907). Casually and outside of the interview, Guzman Roman did reveal to me that most of his social time is spent with other Peruvians, primarily in his extended family circles. He said he has adequate business relations with some Spanish colleagues but does not pursue them socially. His comments were careful but I suspect his preferences are seeded in the same issues Tucker problematizes in his research. In it Tucker asserts that Peruvians (living in Madrid) struggle both with Spanish bias against immigrants generally as well as a tendancey to be collapsed into an overarching "Latino" category in a broad stroke of "othering" used to discriminate against them (Ibid 2014).
} 
political entities, record labels and music industry professionals, to both local and cosmopolitan audiences on both sides of the ocean. Hence it is not surprising that other Latin Americans I interviewed in Europe had similar feelings and stories, albeit from a range of positions.

\section{The charango means everything in my life- encierra todo (it encompasses everything).}

(Parra Madriaga interview, 2018)

Shifting conditions and adaptations - Teaching "otherness": Luis Parra Madriaga

Luis Parra is a somewhat older player than Cesar Guzman-Roman. He is originally from Chile, and told me his own moving story from his home office in his apartment in Vienna. He has become a dual citizen of Austria and Chile since his arrival twenty-seven years ago as a political refugee. Parra's first explorations in music began in a prison cell during the Pinochet regime, where he spent a year as a result of student activism against the dictator's human rights abuses and repressive policies. His cell mate's guitar (that oddly, the prison guards allowed) marked the initiation of Parra's musical life. His cell mate taught him to play, and during his year of political incarceration, he became a musician. I asked him how he was first exposed to the charango.

Luis Parra (LP): I didn't see it, I heard it first, on Inti Illimani recordings. I just heard it, and I fell in love with it and I started asking people about it, they told me about it, that it was from the altiplano (highlands). (But) it was mestizo music... I learned a lot from recordings, because well, there weren't teachers in that time...

(The charango) means everything in my life --encierra todo [it encompasses everything...]. It was something I discovered in a very difficult moment in my life [...] and this is a special instrument, the charango. With this instrument I discovered new things in my life, not only musically.

$\mathrm{HH}$ : It was like a portal?

LP: Yes, exactly, like a portal. You could present your feelings, things about what is happening in your country, and in music you could find ways to survive. Everything I 
have achieved as a human being, everything I've gained I have reinvested in music. I'm working on a book now, and new compositions...

For Parra, the charango was a way to have a political voice while living in exile (in Argentina, Uruguay, and later in Austria). It has also been a means to make a living throughout his life, and a way of giving meaning to his life both before and after his migration.

Interestingly, Parra has found a way to continue to "vivir de la musica" (to make a living from music). His main activity now, he told me, is giving "cultural presentations" in primary and secondary schools in Austria, which constitute eighty percent of his wage-earning activity. These presentations showcase Andean instruments in an educational forum, as part of "multicultural" education in Austrian schools. Presenting himself as a representative of an“other" culture, Parra, formerly primarily a performer, has innovated his way around the decline in the pan-Andean music scene (outlined in Chapter Two) to be able to continue to generate funds from cosmopolitan tastes and in this case, educational agendas through the promotion of Andean music. Although certainly not presenting the music and the instruments costumed in a hyped up caricature of a transnational mega-Indio with wolf howls and a light show, one could assert that these seemingly more benign forms of post-colonial sales still reproduce and reinforce the same relations between the white European cosmopolitan (schoolchildren) and the so-called "foreign"_-“other" culture representative with his exotic musical artefacts, including of course, the charango.

Parra himself does not see it this way. When I asked him if he thinks there is a taste for "other" music and culture (in Austria) that sells well he responded obliquely:

LP: I don't totally agree. It's a distinct culture here (in Austria). They have evolved a very just society, more than Chile, Germany, United States [...] I like being here a lot. Yes, there are some things I don't like but [...] I have to adjust/adapt to their ways of life_-yes life is much more strict/regulated/square [...] but this society functions like a clock-now I like it. I come from a system where nothing works. 
I never let go of being connected to my country, but I can do more here than I could do there. Music is what has kept me connected to Chile. What I do here is to show what I have to offer [from another culture]. I'm clear that I'm Chilean and I will die feeling Chilean. I have friends and fans [who are] Austrians, I have some public recognition here that I would never have there. Nobody in Chile is interested in what I do.

According to one source on the topic of intercultural education in Austria, a broad ethnic diversification of the primary and secondary school population due to the influx of immigrants in recent decades has necessitated new policy. Since the early 1990s, the Austrian Ministry of Education has had to address issues connected to these increases in ethnic and linguistic diversity among its student population. It has done so primarily through the articulation of a broad system of educational principles that attempt to address the issues of its increasingly multicultural student body (Luciak, Mikael \& Gabriele Khan-Svik 2008). One of these principles, called "Intercultural Learning" has been mandated for integration across all school subjects in order to “develop intercultural competence among all students" (Ibid, 494). Among others, one goal of this initiative is "to arouse interest and curiosity in cultural differences, in order to foster appreciation of both cultural unity and cultural diversity"; and, "to explore cultural assets (habits, languages, customs, traditions, tales, myths, songs etc.) of autochthonous and immigrant groups (in particular in regions with ethnically diverse classrooms)" (Ibid, 494). Such aims are pinpointed in these relatively new programming concerns in the school system (Ibid, 495). One could imagine that this turn of policy has provided an open market for "difference" based "cultural workshops" such as the ones that Parra offers. Indeed, these policy initiatives have created an opening for someone like Parra to mitigate the economic impossibility of living from street and stage performances of pan-Andean music in current day Austria. ${ }^{97}$

\footnotetext{
${ }^{97}$ Some of the points of critique offered by Luciak and Kahn-Svik are that the Austrian school system leaves the implementation of intercultural policy up to individual teachers who lack training; has an early "tracking" system which reinforces inequalities; relies on parent involvement and private tutors which privileges students from
} 


\section{Other shifting conditions in Vienna-Paulino Alejo Cruz}

Another player living in Austria spoke of similar issues as pertains to Latin American musicians living in Vienna. Paulino Alejo Cruz, previously mentioned charango player from the Norte Potosi area of Bolivia, has been living in Austria for more than twenty years. He plays with a group of Andean musicians called "Thunupa", which has existed for more than a decade. However, in recent years, he recounted, conditions have changed for musicians like himself working in and around Vienna. Cruz recounted:

It's not like before. There were many events, more life [in the form of Latino cultural events] in the city. But since they started controlling it, they are charging big fees and taxes for any events or parties now, so there is a lot less. Anyone who organizes something has to apply for permission from the government, and stipulate many details like how much it costs, from what time to what time, the location, if they will sell food, and so forth. If you don't do this, if you don't get permission, and they stumble upon your event, there is a fine of at least five hundred euros, or more maybe. Before it was totally open, anyone could organize parties or events for whatever, there was a lot. But now there are hardly any events, and we have had to focus more on our [stable] jobs, not music (Alejo Cruz interview 2018).

Cruz now works full time at a restaurant, sometimes up to sixty hours a week to make ends meet for himself and his family. Many of his band mates have similar entry level jobs in the service sector in Vienna. They can no longer "vivir de la musica" (live from music-making) as they did when they first arrived in Europe. In Vienna, regulations about parties and events have further reduced the number of opportunities for remunerated performances, besides the general downturn in the street music scene.

Same b(r)and, different stages-Parra (continued...)

Austrian-educated families and students with economic resources; lacks research on the perceptions of minority groups about Austrian education; and has a homogenous Austrian faculty presiding over multi ethnic classrooms across the country. Further conceptual critiques have to do with the underlying concepts of cultural "difference"; a problematic perception that these policies are only needed in classrooms with a multi-ethnic student body; and an assumption that students in Austrian schools should be and are naturalized citizens. 
Certainly Luis Parra is an example of adaptability in a number of ways, given the changes in the street scene and the above outlined official regulations that affect performing musicians in Vienna. His work in the schools is a clever and substantial replacement. However, what he is doing musically has not changed very much. Aside from pan-Andean projects, Parra has released a solo album of original works that evidences broader musical influences, which he was exposed to through earlier residencies in Brazil, Uruguay and Argentina (Luis Parra Madriaga Buscando Caminos 2017). This album features a smattering of various Latin American rhythms and styles along with the usual pan-Andean fare. However, Parra continues to brand himself primarily as the director of his pan-Andean band called "Pachamanka" as his main musical flag.

He established this group in Chile in 1978 but not surprisingly, none of the band members are the same as the original group and in fact have ongoing rotations, even now. But, the band plays on — just a few times a year now — under the same moniker, as is common with many pan-Andean bands, and a point of great pride with Parra. With six recordings to its name, the band's repertoire has not strayed much from the pan-Andean sound with which it was founded, despite the diasporic experience of its director over almost three decades. And why would it? Luis Parra's "difference" both in sound and cultural identity, is the product that he sells and what keeps him working and "viviendo de la musica" (living from music) in his immigrant situation: the very thing that "nobody in Chile" is interested in. Given that his musicmaking as a charango player has sustained him through a long trajectory that has included incarceration, exile, migration and immigration it is no wonder that Parra feels that, "For me, the charango, it's everything." 


\section{I identified with the charango and it identified with me}

(Béréhouc interview, 2018)

\section{Travellers and troubadours:}

Antuco Perez, Yann Béréhouc, Sebastian Janis Cerda, Ignacio Kaen

For many musicians, playing the charango has led to travel and immigration opportunities that they wouldn't otherwise have had, and in many cases, long careers as musicians. "Without the charango I wouldn't have been here," recounted Perez. A long time transplant to Europe, he is a charango player but more primarily, a luthier who now lives outside of Paris. Antuco left Peru to arrive directly into the hubbub of the Paris scene thirty years ago, where he played actively on stages and in the streets for more than a decade, including in the scene at L'Escale described in Chapter Two. "I am grateful that the charango gave me the opportunity to know various parts of the world," he said (Perez interview 2018).

New music, new worlds: Yann Béréhouc

French born Yann Béréhouc echoes Perez’s sentiments, stating, “The charango has given me many opportunities to travel, and to have beautiful international exchanges." From the other side of the post-colonial coin, Béréhouc's very active and current career as a solo charango (and ronroco, the baritone variant) player performing a repertoire of almost exclusively original works is being built upon the new friendships he has formed through connections in the international charango music scene as well as rigorous self-promotion through social media. In particular, a collaboration in Europe with Argentinean player Patricio Sullivan helped him access the Argentinean scene. He now visits and performs frequently in Buenos Aires and other cities there, as well as in Chile, and is well received by primarily urban audiences. Such was not his luck in 
Bolivia, however, where he encountered some resistance to his presence as a European charango player, and a poor reception of his original charango music (Béréhouc interview 2018). ${ }^{98}$

Ticket to Ride: Sebastian Janis Cerda

Another travelling musician, Sebastian Janis Cerda, first came to Europe with his brothers' musical theatre troupe in which he played charango and other instruments on their street tour of major European cities. This thirty-three-year-old Chilean from Santiago carries on the Latino tradition of exploring Europe through street performance tours a few decades after the height of this trend. He too reports a "love at first sight" experience with the charango, which he first encountered at home in Santiago around the age of seven, also in a street performance. "It really caught my attention," he said. "I was transfixed. It was so unique, and I loved the fast strumming (repiques)." At the end of the brothers' musical street theatre tour all over Europe, he returned to live in Berlin because in this city he found

a really international music scene, with lots of exchanging, and fusion, and many places to play, like the metro, and bars, and places on the streets. And the public, too, if they like it, they give good money... because they have money here, you can live from (playing) music, which I can't do in Chile (Janis Cerda interview 2018).

He now plays primarily in the metro trains, mostly as a duo with a guitarist, or whomever he can find who is available in their network of musician friends. At the time I met him, Sebastian was semi-homeless and looking furtively for an apartment in Berlin's crunched housing scene. This situation created stress for him but also lessened his overall cost of living for the time being, making his street salary of twenty-five to sixty euros a day (from two to three hours of playing) more than adequate for his needs. "The charango is mine," he said, "it is part of my culture...I hate these debates about the charango origins, does it belong to Peru or Bolivia?

\footnotetext{
98 This is not surprising given the propensity of Bolivian players and audiences to be traditionalists against both the backdrop of the Bolivian "claim" on the instrument as solely their national heritage, as outlined in the previous chapter.
} 
The charango is mine, too. It's a part of history in Chile, and it's how I am living today" (Ibid, Oct. 2018).

\section{Sentient journeys: Ignacio Kaen}

I met another young player living in similar circumstances in Granada, Spain. Ignacio Kaen at that time was also a wandering charango troubadour but with time gone by since the interview, he has left for several months and returned again to live in Granada. In fact, this was a common occurrence with earlier arrivals to Europe. Young players would come for a few months for (sponsored or independent) tours, return to their home countries, and then go back to Europe again until they eventually settled somewhere.

Kaen is Argentinean, of partly Jewish ancestry tied to Turkey and Spain through his father's side. He grew up in Catamarca, in the Northwestern region of Argentina, the Andean zone that is historically and currently home to various indigenous peoples. ${ }^{99}$ This region of Argentina, bordering Chile, is the area most associated with the charango both in terms of roots and current folkloric practice. Hence, he was surrounded by local Andean musics growing up, but recordings and bands representing more cosmopolitan pan-Andean styles were also circulating from Buenos Aires and from Europe as well as North American music and modern genres such as as rock, hip-hop and jazz. Kaen began his forays into music as a percussionist, as did his brothers who also played guitar and bass, mimicking typical teenage boy "garage" (rock) bands of North America, England, and Western Europe. He recently turned thirty and so, is more contemporary than the older players whom I interviewed during this study. Accordingly, his story unfolds at different intersections of past and present conditions and influences.

Kaen was introduced to playing the charango by a band mate, Luis Carisso, who was deeply involved in Andean music and instruments, primarily learning from recordings that he

\footnotetext{
${ }^{99}$ Here again I refer to rural highlanders of the Andes.
} 
also shared with Kaen. Carisso loaned a charango to Kaen, who picked it up quickly. He could soon perform on it well enough to play it in their band. Sometime later he purchased his first charango at a large artisans' festival in Catamarca, where luthiers from various South America countries came to display and sell their work. Later on at a similar festival in Aiquile, Bolivia, Kaen spotted his second charango, a small variant called the walaycho, in the workshop of a Bolivian luthier. In detail, he told me the story of how was able to purchase the coveted walaycho for five hundred bolivianos (approximately seventy U.S. dollars) by persistently returning to the vendor's shop for a week. ${ }^{100}$

I recount this story because access to and availability of instruments seems to have guided this musician's path as much as or more than his own aesthetic tastes or desires. This may be a function of youth, or economy, or both: or it may be related to patterns of movement and travel that has already peppered Kaen's young adult life. However, he expresses very particular attachments to the instruments that he has been able to acquire.

Kaen identifies strongly as a "viajero" (traveller, as opposed to "tourist") and has a very flexible mindset both to place and culture as well as to music. He told me that his first stringed instrument was an ukulele, which he purchased while living in Hawaii for a number of months. He then brought this instrument to Brazil, where he lived for one and one-half years. I asked if this was because it was small, and easy to carry. "Not really," he said. "It's just what I had at the time. I've travelled with all kinds of instruments: bombos (large South American drums), bateria (drum kits) ... all kinds of stuff' (Kaen interview 2018).

As a musician Kaen is playful, open and diverse. He does not limit himself in repertoire, style or instrument. He does not compose original music, but he is an avid improviser and

\footnotetext{
100 Sound sample of Kaen playing this walaycho Audio Index 7.
} 
“jammer". In fact, he is able to perform on all these instruments at quite an advanced level, in a variety of musical styles and scenarios. ${ }^{101}$

In this vein, Kaen's philosophy and sentiments about the charango and music-making are quite eclectic and open-minded. I asked if the charango was for him just one instrument among the many that he plays, or if it had some connection or special relevance to him.

I identify the charango a lot with the Andean zone, but more in connection with me, myself, it liberates that which is in my center. Because I have played percussion and I love it because I love to dance, I love to feel the rhythm. But charango, its more [...] it can bring out the purest part of me, which is at times hard for me to open because it presents an emotional part of me. The sound has happiness and party energy, but a sensitivity too, and a melancholy something profoundly of the earth, of the sierra [mountains] and the altiplano [high plains]. It can bring you to happiness or to the center of the mountains (Ibid 2018).

Kaen's commentary is oriented towards his experience of the sound of the instrument, and what emotional qualities these evoke related to his body and as such, demonstrates another way of relating to instruments, which as Dawe has noted, unfolds as "a kind of "sensescape" to which [he] respond[s], sensing (touching, feeling) the instrument" (Dawe 2003). Secondarily, Kaen cites associations with Andean landscapes which in his case make sense, since he is from Andean mountain territory. However, these associations are probably at least in part based on tropes from popular pan-Andean music indexes that he has been exposed to through global circulation. Kaen's first forays into playing charango (and "Andean" music with his friend Luis Carrasco) were guided by recordings and live performances of touring pan-Andean groups in the 1980s, such as Victor Jara (Chilean Nueva Canción hero), Inti Illimani and Illapu (Chile, Nueva

\footnotetext{
${ }^{101}$ In the short time I knew him in Granada, I saw Kaen play walaycho and cajon with a Cuban singer-songwriter, walaycho, guitar, and cajon with an array of South American and European musicians in a "jam" scenario at a party, charango and walaycho with a Brazilian guitarist from Paris, and he says he had previously played his walaycho with a Spanish Flamenco group on the street as well. At the time we parted he was rehearsing original works on various instruments with two other Argentinean friends for further street performances. I myself had the pleasure of playing with him informally in a number of musical exchange scenarios where instruments were passed around and repertoire was everything from "free jamming" to charango traditionals to American Motown. We also embarked on an attempt to co-compose a charango "original" and did reinterpretations of traditional songs from Ayacucho, Peru on charango and walaycho.
} 
Canción), Los Kjarkas, Savia Andina (Bolivia, pan-Andean and Bolivian folkloric) as well as modernized pan-Andean rock groups like Los Tekis (modern folk-rock with folkloric and Andean flavorings) and Argentinean Bruno Arias (modernized, rock-flavored spins on Andean highland folkloric tunes).

I asked Kaen about his experience with the ukulele, and if it had any emotional associations for him of a similar kind. "No, not really," he said. "The ukulele was related to study for me, more technical and cerebral" (Ibid 2018).

As Kaen is not technically living diasporically but certainly, via his travels and various lengthy stays outside of Argentina, has a lot of experience living outside of his own culture, I asked him how playing music in these different environments affects him and the music he makes.

People have an energy, and places have an energy, too [...] How a place receives us and our music is different; every rhythm, every style has [unique] personality and energy that you have to get to know [...] some things might seem similar, but they aren't the same (Ibid 2018).

Indeed, Kaen's sensitivity, flexibility and openness because of being a traveller are certainly reflected in his musical life, but his attachment to the charango is particular. I asked Kaen where he felt "at home", and how he defines his identity.

HH: Where do you feel at home, in terms of culture or situation? You feel Argentinean, no? Do you feel at home in Argentina? Or does it change because you are moving around a lot?

IK: Where do I feel at home? Or from where do I feel I'm from?

HH: No... where do you feel at home in terms of culture, or identity? The next question is, how do you identify yourself culturally, nationally...

IK: Hmmm, this is like ... I've just been asking myself that recently. What can I say? What can I consider my own tradition, or my own place? I've been in different places and I've shared different moments, different things that honestly, are made of a tradition but 
also it's the moment that I'm in, and a"t home"? Well, I don't know. I believe that home is here, its inside (points to chest), one carries it inside oneself (Ibid 2018).

Kaen might be fairly described as "New Age" in his philosophy, conceptual framework, and language in talking about music, identity and the charango. ${ }^{102}$ However his narrative springs primarily from his own sentient experience, which presents a new and interesting organological intersection for the charango. Other players, especially Europeans, relate to the instrument more primarily through romanticized imaginings about its native geographies. This is also the case with many players from large cosmopolitan cities in Latin America.

\section{The charango is like my alter-ego: \\ It's very important to me... It changed my life.} (Laduron, from online survey 2018)

The Sound of the Mountains: New Age mysticisms and the Pacha Mama mystique: ${ }^{103}$ Marie Laduron, Deni Plavčić

${ }^{102}$ By "New Age" I refer to a philosophy of pan-spiritualism from a cosmopolitan position that prioritizes the individual emotional experience (somewhat overlapping with postmodern "therapy" culture's preferencing of "I" statements). The New Age "movement" (or (sub)-cultural trend, apparent since the late 1980s) on one hand has tended to romanticize and appropriate various non-Western traditions usually taking them out of context to interpret (and sell) them in capitalist neo-liberal frameworks to seekers (legitimately) distressed by the dissociations of late industrial-capitalism forms. The New Age "trend" has extended to music as well, overlapping to some degree with "world music" and all of its problems but also opening up some spaces for "alternative" perspectives. On the other hand, New Age culture has challenged the hegemony of Western/orthodox medicine and religion, raising awareness of non-Western healing practices and paganistic spiritual belief systems, and in some cases, to the plights of indigenous peoples to whom these traditions belong. It has however in many cases created new problems for the communities whose traditions are being benignly sought out by some and outright stolen and repackaged for sale by others (Gomez-Barris 2012). In its dissociation from post-colonial political analysis and subsequent action lies its main Achilles heel. These trends have sometimes overlapped with feminist challenges to gender categories that have assigned the sphere of emotional sensitivity to women, dovetailing with the "Men's Movement", and this is perhaps some of what resonates in Kaen's awareness of his emotional self (Bridges 2012).

In Kaen's case (and that of Laduron), I mean simply to point to threads in their narratives of New Age philosophy that can be held up for critique. I do not mean to suggest that New Age culture is particularly interested in the charango, however, some players such as Camilo Gomez have intentionally brought the charango into New Age spiritual and musical contexts, promoting it as a player of "meditation music". Certainly, the Andean wind instruments have entered the genre alongside the Native American flutes. New Age forms commonly (albeit unconsciously) propagate problematic "othering" and subsequent exoticization with a kind of romanticism that probably sows the same (neo-colonial) seeds despite the benevolent intentions of many of its actors.

${ }_{103}$ Among other things, New Age spiritualists involved in Andean and Latinamerican intersections have adopted the Quechua term "Pacha Mama"- mother earth in a decontextualized and somewhat cartoonish way, without really understanding the deeply contextualized meaning of it in practices, rituals and ontology in the Andes. 
An alter-ego, a past life : Marie Laduron

One player in this study, Marie Laduron, was one of just two Europeans who submitted their interviews in writing, via an online survey that I made available on the project website. ${ }^{104}$ Among Laduron's responses were some that demonstrate not only a strong emotional attachment to the charango, but some of her spiritual ideas about herself and the instrument.

Laduron was raised for her first four years in Africa where she was born to Belgian parents. As her participation in the research was limited to her written responses, more is not known about the possible effects of these early years of her life living outside of Europe on her sense of cultural identity or experience in cross-cultural situations. Laduron is Belgian, residing outside of Brussels, and is now married to a Chilean. She has been playing the charango for more than twenty years, and also reported a "love at first sight" experience with the charango. She says the charango is her "companion" and "alter-ego" and that it "changed her life", echoing some of the sentiments of other players in this study. Laduron commented (in a similar vein to Ignacio Kaen) about the physical position of the charango "held close to the heart" as an attractive feature that inspires emotional expression and attachment. ${ }^{105}$ Laduron is now primarily (like Yann Béréhouc) a self-promoting composer and solo player of original charango music that is, as she describes, a blend of European folk, jazz, classical and Andean music.

Laduron wrote in the survey that she "feels at home when she is in the "altiplano" (Andean highlands)." In response to a question concerning engagement with an instrument from another culture, she said:

\footnotetext{
104 The online survey connected to my research website was intended to facilitate reaching a larger participant group. This method failed, in part due to technical failures and in part probably due to the length of the survey. Only two players (both Belgian women) responded, including Laduron.

105 Although this position describes the position of the majority of modern charango players, some do not hold the instrument in front of their chest. Some rest it on their knee or leg; others let it hang lower, in front of the abdomen, from a strap.
} 
I think that it is very interesting. I could never play like a Bolivian who was born and lived since they were small listening to the charango. I love listening and sharing with musicians from South America. Expressing yourself with an instrument is universal [...] you don't have to be from the country of origin of the instrument [...] including if I think that maybe in a past life I lived there in the altiplano and that this love I have for this instrument comes from that life ;-) (Laduron, from online survey 2018).

In this comment Laduron both de-essentializes the charango ("expressing yourself with an instrument is universal [...] you don't have to be from the country of origin") as well as introducing the idea of a past life in the altiplano as a reason for her strong attachment to the instrument and its music, a kind of mystification of the matter at hand.

This de-contextualized, playful (given the placement of the winking emoji at the end of the sentence) mention of "past life" philosophy, adopted certainly from Buddhist theories of reincarnation into a New Age world view, reveals the cosmopolitan filter with which this player talks about her perceptions about the charango. The instinct to assign mystical qualities to the charango is not isolated to Laduron: it is just that in her comments it appears most obviously from a cosmopolitan perspective. It is possible that she has also been influenced by Andean mystical beliefs about the instrument (perhaps mediated through pan-Andean representations), although these of course are seeded in a different context than New Age imaginaries and carry different meanings. ${ }^{106}$

\section{Digital interfaces, cross-cultural dreams: Deni Plavčić}

Charango aficionado and self-taught player Deni Plavčić made similar comments to those of Kaen and Cerda, who are also young auto-didacts. Plavčić, who lives in Zagreb, Croatia, had never heard a live performance of Andean music at the time we first spoke in October 2018. He discovered Andean music via random YouTube surfing and "fell in love" with it. Said Plavčić:

\footnotetext{
${ }^{106}$ For example, beliefs about the charango and otherworldly powers as embodied by Mermaids/Sirens who inhabit magical waterways in the Andes as previously mentioned (Turino 1983).
} 
For me, it [Andean music] was love at first hearing. I really liked the melodies, and I'm attracted to the mountains. I was imagining all kinds of things, the mountains, the birds, freedom [...] It [Andean music] evoked all these imaginations for me.

I really like things that can leave an impact if you play it well, really fast, and, you know, it represents these high mountains and the sound is really high [...] I like that it was really small, it's right in front, you hear it very well. [I thought it was an] art to be able to be in front with such a small instrument. And the sound is really organic. I'm not a huge fan of produced sound... (Plavčić interview 2018).

Incredibly, Plavčić has learned to play the charango competently (and left-handed!) and is fairly well versed in Bolivian folkloric and pan-Andean repertoire. As previously mentioned, I invited him to attend a Bolivian National day party in Vienna, Austria, to which I had been invited by a few of the musicians involved in staging the event. When Plavčić took out his charango and began to play it (after some coaxing), the Bolivians (and myself) were spellbound. This "non-musician" (according to Plavčić) had not only learned to play the charango solely from YouTube recordings and videos, he had learned to play it well! Far exceeding my own playing level as well as that of many native players of the instrument, it was an impressive moment in music-making.

Plavčić is studying Spanish and is very interested in learning about the cultures of the charango's home countries, which he has already begun to do. In Croatia, he has found one Chilean guitarist to play with, and added an Argentinean percussionist they met on the street to form a trio. His trio was invited to play informally at an art gallery opening in Zagreb. Although he was at first, terrified to perform in public, the success of this first gig has inspired him to work towards further public presentations. "It is my dream to have an Andean band," he told me (Ibid, Sept 2018).

Clearly Plavčić's engagement with the charango is a conscious cross-cultural endeavour, and in this he is like most European players of the instrument. Unique to the others, his access to learning to play was through a "global" port — the internet (as was his acquisition of instruments 
as he ordered them online), which may have to do with his age demographic, his employment in the technology sector and his position in Eastern Europe. As far as his romantic and spiritual associations, he shares these with the other mostly young cosmopolitan players. There is one notable exception to this trend. To examine this case we turn to Iceland, where the charango has landed in the hands of a singer-songwriter named Ólöf Arnalds.

\section{I'm always looking for new sounds, new ways to express myself.}

(Arnalds interview 2018)

Different sounds or sounds of difference? Ólöf Arnalds and the Reykjavik Indie scene

On my way to begin fieldwork in Europe, I scheduled a stopover in Reykjavik in hopes of meeting and interviewing Ólöf Arnalds. At my rental accommodation, I mentioned Arnalds's name and the hostess, who spoke limited English, got very excited. "She is so beautiful!" she effused, "and very talented! You should meet her! She is a very good Icelandic musician!" The next day she emerged from her home office with a small piece of paper with Arnalds's personal cellphone number on it. This hostess was not the effusive, going-out-of-her-way-for-you type, but her excitement about presenting Ólöf Arnalds as a representative of Icelandic music to an international researcher seemed to have motivated her. Perhaps my experience in finding Arnalds was a typical one in an island culture, and particularly, in Reykjavik. I had tried to contact her in advance through her website and U.S. and U.K. management teams and on Facebook Messenger, with no response, so now I considered myself lucky. After a bit of nervous stalling, I dialed the number, and she answered. 
Arnalds is an Icelandic troubadour whose professional image is wind-swept and coastal with a dash of avant-garde without shying away from a stereotypically "Nordic" look. She is an acoustic style singer-songwriter and performing musician who, as I experienced, is well known in her own country. She has made significant strides in the folk scene in the U.S. as well, including feature performances on National Public Radio. She tours actively in Scandinavia, England, and in the U.S.; sometimes solo and sometimes with supporting players. She follows in the footsteps of countrywoman Björk's international success (sharing the same record label, Little Indian Records, based in the U.K.) and has carved out her own career behind the headwinds of her predecessor.

Arnalds has formal musical training in classical violin and voice, both of which she studied in Iceland. When performing her original songs, she accompanies herself on guitar, violin, Japanese koto, and the charango. As a charango player, she is atypical in a number of ways. First of all, she is Icelandic. This alone is quite remarkable, as there is negligible precedence or connection in Iceland to Latino cultures, and Arnalds herself has no particular interest in or experience with Latin America. She is the first professional musician in Iceland to take up the charango, and of course being female sets her apart as well, as the overwhelming majority of charango players both in and outside South America are male. ${ }^{107}$

\section{"Foreign" instrument, local impacts}

I interviewed Arnalds at her workplace in Reykjavik, a graphic design company with a two floor office and a number of other employees. Like many musicians both inside and outside Iceland, she holds down a "regular" job at home (out of financial necessity) besides pursuing her

\footnotetext{
${ }^{107}$ The charango is and has generally been the domain of male musicians. However, there are some exceptions and rising interest and participation among both Latin American and other women. As mentioned, five of the twentyeight in this study are female. All of these are European (including Ólöf Arnalds, Nina Dimitri, Zrinka Božičević, Marie Laduron, and Carole Stocklin. Only Dimitri and Laduron have concentrated on the charango primarily).
} 
music career internationally. According to research by ethnomusicologist Nick Prior, this is especially common in Iceland, as limited market size and economic opportunity for musical employment deeply impacts musical community transactions as well as the work lives of most Reykjavik musicians in similar ways (Prior 2015). Pictures I had seen on her website had presented a slick and glossy version of this artist but Arnalds in person had a humble, normal appearance. I comment here cautiously to this effect, only to highlight the distance between her countenance in person and her marketed image in online promotional shots, music videos, and CD covers. One might wonder at the gap, or consider it "normal" in the music industry. I am more interested in considering the pressure on this performer to create an image of herself as a marketing tool for export. How much have her management teams, or Arnalds herself, intentionally or subconsciously constructed an "exotic image” of Ólöf Arnalds the musician, highlighting both her Nordic looks and avant-garde "vibe" to match the strange wistfulness in her music and the growing international reputation of the highly eclectic Icelandic music scene (Ibid 2015)? Does Arnalds' entanglement with instruments from other countries and culturesthe charango and the Japanese koto_embellish this image with further sonic and visual decoration, enhancing it with an extra "multicultural" décor for her Nordic, European, and North American cosmopolitan listeners? Or is this simply and innocently who she is and how she chooses to express herself artistically? Could her use of the charango (and koto) be seen as a product of her positioning in an Icelandic indie music scene that actually is innovative, edgy, and experimental?

According to Arnalds, her use of these instruments is at least in part due to her interest in "different" sonic textures and her openness to using what is at hand to result in the sound she 
wants. She told me an interesting and quite pragmatic tale related to exporting herself and her music to foreign stages.

HH: Well, I just kind of want to talk to you about how you learned about this instrument, how you got involved in it, and then sort of how you connect to it, um, and how it's affected you to play it. So maybe just starting with the story of how you learned about the charango, and what it is...

Ólöf Arnalds (OA): “Well, I was working with a musician called Skulli Söreson ...

HH: Is he Icelandic?

OA: He's Icelandic, yeah... and he owned one, and had had it up on his wall for a long time, and it was um, it was one from an armadillo...

HH: Oh cool, so an old one?

OA: Yea an old one. And then, we had a song where I had been playing Japanese koto harp in, and then we were touring and we needed something for me to play in that particular song, and so we... he just brought this and said like, ah, why don't you try this one out?

$\mathrm{HH}$ : Ok and, the Japanese harp is too big to tour with?

OA: Yes

HH: Yea, ok. But where was the tour? Was it Iceland or global?

OA: It was global... Yea, and then I just tuned it in a way that made sense for the song, but then I just kept it in that tuning and started, you know, making my own songs in that same tuning.

HH: Ok, but, where did he get it?

OA: He got it from a friend who had a father who sailed the seas.

HH: So, his father had picked it up somewhere... we don't know where?

OA: No. But I think he picked it up in Peru.

HH: OK... It must have been a while ago, because it's hard to find that kind.

OA: Yea, I know that, because then I lost it! ...I forgot it on the plane.

(Arnalds interview 2018) 
As Arnalds explains, this particular charango had initially been handed off to the original owner's son, who gave it to their musician friend (Skulli Söreson), who then passed it on to Arnalds to accommodate the pragmatic needs of an international tour. This string of casual events however led to a more intentional use of the charango as a main instrument in her musicmaking. She found the tone interesting and unique, and has now become of note in her own scene for engaging this Latin American instrument.

Interestingly, Arnalds' adoption of the charango has had communal impact in Iceland's music scene. "I think I sort of started a trend," she commented. "They are selling [charangos] in Iceland now, and it's really funny, because when I last looked at it in the shop it was tuned in the tuning that I tune it in." Arnalds said that she has begun to see other Icelandic musicians playing the charango on stages, but she has never seen a Latin American playing it in Iceland.

Both this story and the account of Arnalds introduction to the instrument resonate with recent musicological findings from the field in Reykjavik. In Nick Prior's study of the Icelandic scene, these sorts of casual collaborations, sharing of ideas and material resources along lines of friendship, musical, social relationship are commonplace in the matrix of activity in the cultural scene focused primarily on "self-sustain(ing) music practices with friends" on the island (Prior 2015, 87). Writes Prior:

While one must be careful with deploying the term 'DIY' to describe a whole regional system of music-making, there is certainly evidence that much of the local scene is sustained by mutual practices of sharing, self-sufficiency and collective conduct. (Ibid, 87)

In fact, Arnalds' narrative about her initial exposure to and employment of the charango resonates with the description given to Prior in his interviews with other Reykjavik musicians, one of whom described a 
kind of 'pragmatic fearlessness', where musicians will often alight upon musical projects and collaborations without being haunted by failure, because planning is rare and obstacles are sorted out in each unfolding moment (Ibid, 87).

According to Prior, this is in part borne out of the situation of a small domestic market

base for musicians, where

[...] very few musicians make a living out of music... [resulting in what] one interviewee described [as] a kind of 'creative gemeinschaft' ['society/collective/community'], where reciprocal relations between musicians are based on forms of mutual recognition and collective identifications. Another stated it more succinctly: 'it all connects', he said (Ibid, 91).

Icelandic musical education scenarios across the country, according to Prior's research, promote music as a site of "interactional encounter and situation" through encouraging young people to form bands, and learn to experiment and improvise in addition to the traditional Western Art Music approach to musical education that is also quite prevalent throughout the school system (Ibid, 89). With all of that in mind, Arnalds's casual uptake of what was in her and her peer's experience an odd musical artefact and wall decoration without much associative significance might just fit into the general laissez-faire atmosphere of the Icelandic scene, according to Prior's description.

In interviews I have seen online, Arnalds does not generally delve into any story or explanation of the charango or its origins, besides mentioning its name. She did say that she had learned a little bit about it through online sources. She has not had any audience members approach her to ask or comment about her use of the charango, either in a critical or enthusiastic fashion. In fact, she said quite directly that she has little interest in knowing more about the charango, or learning anything of its traditional repertoire and context. When I asked her about this, and why she uses instruments from non-European traditions in her music-making, she said, I think I am pretty selfish about it-I'm just thinking, like, how can I use this instrument in my music? [...] I don't tune the instruments in the way they are tuned traditionally. I 
always tune them in my own tunings. I am always looking for new ways of expressing new sounds" (Arnalds interview 2018).

Is this independent and unattached approach to the charango, an instrument from worlds away from her Nordic island, a function of Icelandic cultural personality, simply Ólöf Arnalds' own unique approach, or both? This artist's neutral disinterest and unapologetically "selfish" approach to the adoption of the charango is singular, to say the least. On one hand, a dissociated and perhaps innocent approach to the instrument might be a product of the innovative norms of Reykjavik's indie and folk scene. But in an age where discourse about cultural appropriation is common, and postcolonial concerns churn in turbulent debates especially in "world music" contexts, this seems too simplistic.

The music of Ólöf Arnalds, with lyrics in both English and Icelandic, has some inferences of Björk and some of Suzanne Vega, with folksy sonic texture. It is not the charango but Arnalds herself who takes center stage. According to a blurb posted on her own website Ólöf’s most distinctive asset is [...] her voice [...] instantly captivating, spring water chasteness possessed of a magical, otherworldly quality that is simultaneously innocent yet ancient... "somewhere between a child and an old woman" according to no less an authority than Björk (from her website www.olofarnalds.com. My emphasis HH).

With a voice that supposedly sounds "possessed of a magical, otherworldly quality" perhaps Arnalds shares some terrain with the charango, which, as mentioned previously, in some South American highland and folkloric contexts is believed to embody the voice of the siren, gatekeeper to a watery dimension of similar qualities. ${ }^{108}$ In both cases, mystical associations with both of their sounds, individually and as a team in Arnald's performances garner a certain kind of attention and audience, perhaps most especially in an "exported" situation of music-making.

Meanwhile, Ólöf Arnalds’ visual branding of herself in promotional materials plays on the beauty and openness of the Icelandic landscape inhabited by the clear blue eyed and ultra-

\footnotetext{
108 See Turino, 1983.
} 
blonde haired female wandering pensively in quiet Nordic moments, or gazing off into the endless sea and sky of her winter island nation as represented in her online and professional materials. Into this sonic and visual Icelandic scene, the charango integrates seamlessly. To the unknowing eye and ear, it is as devoid of cultural associations in the music of Ólöf Arnalds as she herself intends it to be. Is it, then, in that moment, an Icelandic instrument?

Whereas many players I interviewed engage the charango through a common repertoire and/or tradition in order to articulate affiliation with a national or ethnic community (including European players like Béréhouc, Stocklin, Plavčić, Božičević, and Dimitri, who are all driven by their interest in the culture as well as the music of the Andes), one could claim that Arnalds presents a contrasting case. Her creativity focuses on personal expression and her career hinges on standing out as "unique", "distinctive" and individually of note, rather than serving a teleos of belonging or maintaining a connection to a group identity. ${ }^{109}$ If, as the new organologists posit, the meaning and agency of instruments has primarily to do with their social entanglements, the charango in Arnalds's hands might have a very different meaning than in every other case we have considered.

As Arnalds herself says, her purpose in engaging the charango is to create unique sounds that are interesting and resonant with her expressive practice as a singer songwriter. Then again, perhaps in asserting her individual uniqueness is a way to belong to her own musical community in Reykavik, with the charango (and koto) as her emblem of personal distinctiveness. Is Arnalds'

\footnotetext{
${ }^{109}$ This is not in itself unique for a cosmopolitan artist with an international career trajectory. However, in the case of others like Béréhouc or Laduron, affiliations to the mestizo charango's traditional reach are strong both in musical style and social and professional musical networks. Both of these players nurture ties to the charango's home contexts and social connections to Latin American players and audiences, and pursue their careers at least in part in these circles, as well as European circles that are warm to "world" music and pan-Andean flavoured expression.
} 
charango then (still) primarily a metaphorical sonic wall decoration in her "indie" Icelandic

music scene's house of cards?

Charanguito amigo: Armando Ramos

Charango!

Charanguito amigo...compañero

A veces virtuoso!

A veces celoso.

Tu que me acompañas por la vida

Tu que haces bailar

Tu que haces cantar

Tu que puedes hacer llorar

Tu que me acompañas

Tu que me suportas

En mis malos momentos, y mis malos humores

Me lo salgo apagar contigo

Sin embargo

Siempre estas conmigo
Charango!

Charango friend... companion

Sometimes a virtuoso

Sometimes jealous

You who accompany me throughout life

You who [inspire] dance

You who [inspire] song

You who can make [someone/me] cry

You who accompany me

You who support me

In my bad moments and my bad moods

I [am able] to put it out with you

Without a doubt

You are always with me.

(Poem by Armando Ramos as recited in Ramos interview 2018. (Audio Index 8))

This ode to the charango echoes almost identical sentiments as Ernesto Cavour's loving dedication to the instrument cited at the beginning of this chapter. Almost forty years after Cavour wrote these words, teacher and musician Armando Ramos, living as an immigrant in Brussels, recites his own hauntingly similar verse that could almost be taken as an unbounded love poem. Ramos, also a Bolivian (but not particularly traditionalist or nationalist), runs a small music project which offers classes to Bolivian and Belgian students who want to learn to play Andean instruments. Ramos told me he is not primarily a charango player; rather, he picked up the instrument in Belgium in order to be able to teach it to the children of his Bolivian immigrant friends (at their request). Given that, it is surprising that he broke spontaneously into lyrical 
adulations in the middle of our interview, with a text that casts the charango not only as a companion, but as a super healer, if not a super hero.

It is certainly difficult to draw conclusions as to the meaning of these kinds of personifications, of the strong feelings about the instrument that many players expressed, or of the roles they assign to the charango in their lives. These things reflect personal realities and stories as well as social perceptions and political associations. Clearly the charango is important to the people who play it, but in a charged and powerful way that may be quite particular. This could be traceable to Andean contexts, or to assigned associations at other intersections of history, tradition and meaning that have held up the charango as a potent signifier. From a perspective of new organology, the meaning of the charango has shifted with the associations given to it, articulated through shifts in human engagement. However, the charango remains quite tightly tied to both its past and recent histories in the minds and choices of its aficionados (who also think of it as an Andean instrument). In the next section however, we will look at the instrument in the hands of a few rare players who break open new musical and cultural spaces through innovation and genre crossings with the charango. What are their motivations for doing so, and what are the conditions in which this kind of "stretching" of the charango's reach is taking place in scenarios in their European scenes? Are these innovators inventing new meanings for the charango in organological terms? These questions will be considered in the following chapter. 


\section{Chapter Six: The Innovators: New musics in cross-cultural intersections}

Of the charango players interviewed in this study, less than one=third are involved in musical activity that takes them outside the bounds of charango tradition, crosses cultural lines with the "host" culture in immigrants' or travellers' situations and/or generally involves an innovative approach to music-making with the charango. Some of these players have been discussed in previous sections, as pertains to other themes. Rather than revisiting the individuals already discussed, this section will present three profiles of charango players in whose musical lives innovation with the charango is central. These three players stand in the foreground of the small group that is engaged in cross-cultural and/or cross-genre practices as a primary focus. All three have an advanced command of the instrument and its traditional repertoire in their home contexts (Chile, Peru, and loosely, Argentina) as well as broad general knowledge of Latin American music from other countries and regions.

In many ways, these three players exemplify what I expected to find broadly among my informants, yet findings proved the opposite. As previously noted, the majority of this study's interlocutors are still primarily playing repertoire that is the same or nearly the same as the music they performed on the streets when they arrived in Europe. Or, they are playing traditional "folkloric" music from their home countries, with some overlap between the two. European charango players are also mostly playing repertoire and style within these realms. One can at the very least say that the majority of charango players who I interviewed are mostly still adhering to traditional and established genre and style. However, in the examples below to the contrary, much can be observed about innovation, flexibility, and cultural and musical "openness" and exchange in musical lives. 
The portraits of these three charango innovators will illustrate the various factors that combine to create conditions where players were interested in, open to and in pursuit of innovation and cross-cultural musical exchanges. Their stories show how their fluidity in music mirrors their adaptability in life circumstances and flexibility in ideologies about culture, music and the charango. While they are exceptions to the majority, these case studies provide an opportunity to observe music-making that pushes beyond traditional bounds in cross-cultural circumstances and because of cross-cultural circumstances. Their musical engagements in new intersections suggest that the charango may have some stretch beyond tradition into more "global" musical terrain in their European scenes.

\section{$\underline{\text { Jorge Cervantes }}$}

Jorge Cervantes is a charango player, multi-instrumentalist and sound recording professional who has been living in Lisbon, Portugal since 1990. He plays guitar, charango and many other Andean instruments at a professional level. His work as a recording engineer has brought him into contact with a wide range of musicians, and has afforded him opportunities to interact musically and personally across a plethora of cultural identities and musical styles with many clients and colleagues in musical circles in Lisbon. This was not accidental; rather, as we will see, he nurtured these connections and created his own path into a cross-cultural, multimodal musical career.

Cervantes has very recently begun to reawaken his relationship with the charango and with traditional music from Peru because of his teenage son, who is focusing his own musical interests on Andean wind instruments (quena and siku). His son was born and has been raised in Portugal, speaking Spanish at home and Portuguese in public, and knows his parents' home culture only through visits and a short return migration period of two years in 2015 to Lima. 
During this period Cervantes's son attended public school in Peru and was introduced to Andean music. Now back in Portugal, father and son are working on a recording project together, (led by the now seventeen-year-old) that features original compositions and reinterpretations of Andean tunes. $^{110}$

This composition and recording project has brought Cervantes back to a traditional Andean repertoire in a new way. And so he is rediscovering himself as a charango player and Andean musician, as well as accompanying his son on guitar and other instruments, depending on the song. I asked Cervantes about this during his interview with me at his home in Lisbon.

[My son] has a lot of original, innovative ideas, just like I did when I was a kid, but I had nobody to support me in developing those ideas. I would be learning a traditional tune, and I could hear other ways to play it. I wanted to experiment. But I was told, "no, we do it this way", and so I didn't have the space for that creativity. I want my son to have a different experience. I am supporting him to follow his musical instincts" (Cervantes interview 2018).

Cervantes's son is the fortunate beneficiary of his father's immigrant experience, as Cervantes's musical life in Portugal has given him the chance to explore musically beyond traditional genre. Further, Cervantes's ability to step up to these musical opportunities has actually enabled him to continue a career in music since pan-Andean music's decline in Western and Central Europe.

Cervantes grew up in a Puneño migrant community in Lima (Peruvians from the Puno area in the south, now living in the capital city). His family's home was always full of musicians of all kinds, as his father led an "estudiantina" (a folkloric string ensemble) and his mother taught folkloric dance. These groups met and rehearsed in their house. He watched many rehearsals, observing the musicians closely. He told me that he secretly took up the accordion and easily learned to play it, but was scolded by his father who thought he might break the

\footnotetext{
${ }^{110}$ Cervantes and his son demonstrating one of these tunes in their home- Audio Index 9.
} 
instrument, which was quite a bit larger than he was at six years old. Despite this, young Cervantes continued to explore the instruments in the house when nobody was watching.

One day the accordionist was absent for a rehearsal of his mother's students' dance troupe. Cervantes volunteered and stunned them with his ability to play along. He exhibited an unusual level of auto-didactic musical talent at this young age, and sees the same in his son. After that, Cervantes's musical path was unimpeded, and he went on to learn guitar, charango and other instruments quickly. He found a place in the musical community in Lima easily because of his family's involvement in it.

In 1989 he was selected as the youngest member of a musical group sponsored by the Minister of Culture to perform Peruvian folkloric music in Europe. This group, who called themselves “Takile”, arrived in Madrid, Spain, to find out that there wasn't that much work available, despite promises made to them previous to departure. They went to Italy for a while, but things were not that much better. They were advised by promoters and other musicians to go to Portugal, where their luck improved. Cervantes said it seemed like the Portuguese audiences had not seen a lot of Andean musicians, and they responded very positively. Their breakthrough was at a festival called Fiesta de Avante, in which they got booked back to back with some wellknown acts, and from there things took off. Cervantes toured Portugal for three years with this group, playing standard pan-Andean repertoire for Portuguese audiences.

But Cervantes still had a deep instinct towards musical experimentation. He finally got his chance at a Casino dinner gig, when the producer approached the group and asked them to play "something Portuguese" with their Andean instruments. The audience received this performance so well, that their band started to incorporate pieces from Portuguese "Fado" repertoire into their regular act. These experiments in performing representations of Portuguese 
music on Andean instruments continued to be a big hit with their Portuguese audiences. The band's first recording on cassette was released a year later and included a medley of Portuguese songs, interpreted with Andean instruments. On tour, Cervantes encouraged his band mates to exchange and experiment with Portuguese folkloric musicians who they met. ${ }^{11}$ While it wasn't so terribly uncommon for pan-Andean bands in Europe to do "cover tunes" well-known to their particular European audiences (and in fact, some musicians saw this negatively (Mendivil, Bedoya interviews 2018)), in Cervantes's case it represented a first push towards experimentation and cross-cultural mixing.

According to Cervantes, as more groups began to appear on the streets of Portugal audiences couldn't differentiate between amateur musicians dressed like North American Indians (as discussed in Chapter Two- which in Cervantes's experience, were primarily from Ecuador) and more skilled musical groups such as his own. This flooding of the street scene had a financial impact on groups like his, as there was now more competition for stage performances, as well as a dwindling audience, as previously noted (Ibid 2018).

At this juncture Cervantes's resourcefulness and musical adaptability played a key role as he sought out and responded to requests to perform with a variety of musicians outside of panAndean constellations. He integrated himself into Brazilian, African, and Portuguese ensembles with relative ease, owing this capacity to his early exposure to a variety of musicians in the house of his family in Lima. "My family had a broad range of music in the house. I knew how to play a lot of other rhythms," he said, commenting on how he easily adapted in new musical environments (Ibid, 2018).

\footnotetext{
${ }^{111}$ Some members were open to this and others less so, and Cervantes feels that the difference was dependent on musical skill, not cross-cultural curiosity.
} 
Once the word got out, he received many requests to play with various musicians in Lisbon. He engaged whatever instrument was requested by these primarily African and Brazilian artists, who were interested in experimenting with the sounds of Andean instruments on their projects. Cervantes found new streams of income and artistic activity through these opportunities. New alliances and connections led to recording and performing opportunities across the cultural spectrum which had both social and economic advantages.

Cervantes also began to lend a hand on the technical side in various recording studios at this time, and slowly acquired the technical skills with which he runs his recording studio business today, serving a large base of African and Brazilian musicians, as well as many Portuguese clients. "You have to integrate yourself to have professional opportunities," he commented.

There are many Latino musicians who only play in their own circles, but that is not me. I have always looked for something different. In my original group, I always wanted to do something different. [Here in Portugal] I couldn't live only playing the charango-I couldn't concentrate on that. But I feel happy for these exchanges: not many people have that, he summarized (Ibid, 2018).

Yet Cervantes's recent return migration to Peru with his family has reawakened and re-solidified his identity as an Andean musician as he had the opportunity to reconnect with old friends, and found a renewed desire to play Andean music.

I always feel Peruvian...culturally..., musically...: Everything I do consciously and unconsciously has the base of Peruvian music. The last time I lived in Peru, it recharged my energy: it put me in touch again with everything that living abroad de-actualizes a little bit, in terms of [my] roots (Ibid 2018).

I asked him what differentiates someone like himself from other musicians who stick to one genre such as some of his South American colleagues.

You have to have the ability, of course, and the openness, and you have to want it. Maybe there is a pride issue, if they are embarrassed that they can't do it [adapt to other musics 
because of lack of skills...] the charango isn't an instrument that's easy to adapt to other styles (my emphasis HH; Ibid 2018).

Here Cervantes speaks to that which nobody really wants to say: that there is a skill challenge in bringing the charango out of standard/traditional repertoire; a skill in fact that not all players have. Obviously, Cervantes's musicianship not only on the charango but with a multitude of other instruments has proved up to the task of performing in a broad range of musics.

In this and other ways, Jorge Cervantes stands out. In some ways he appears to be the participant in this study who is the most engaged in cross-cultural musical interactions as the basis of his musical and professional life, as he has allowed his position as a Peruvian in Portugal to shape his musical path out of both artistic flexibility and to his advantage. He is aware of his own cultural identity and musical background, and has made very strategic musical and professional decisions out of awareness of his situation and the opportunities available to him in the diverse musical circles in Lisbon. This has resulted in a multi-faceted musical, professional and social life and conscious and celebrated integration into an international community of musicians in a large European city far flung from his Puneño roots. As a multi-instrumentalist he has introduced not only the charango but many other Andean instruments into new musical textures spanning a broad range of musics with African, Brazilian and Portuguese artists living in Lisbon. One might say that in circumstances such as the ones presented by Jorge Cervantes, the charango gets nearest to integration in "global" intersections: and from a perpective of new organology, it might even begin to be signified as a "global" instrument.

Impressively, Cervantes's early impulses towards musical experimentation have reached full fruition in his adult musical life. Simultaneously he is involved in a dynamic revitalization of his Andean roots through the musical interests of his talented son, who he supports with openness to musical experimentation and creativity that he had to find for himself. In this sense, 
Cervantes exemplifies a dynamic and highly adaptive approach to his own musical trajectory. In it, the place of the charango is equally a bridge to his homeland tradition and a way to explore new musical contexts. Additionally, in the project with his son Cervantes revisits his own tradition in current, unfolding, and open-ended ways. The charango in Cervantes's hands stretches the terrain of play and even seeds new soil for future possibilities for the instrument in broadening musical intersections. As seen from the perspective of new organology, Cervantes engages the charango in a multitude of ways which give a multitude of meanings, perhaps simultaneously, to the instrument.

\section{$\underline{\text { Ivan Latapiat }}$}

Ivan Latapiat is a Chilean born musician living in Lyon, France, where he moved in 2008 because of his marriage to a French citizen. He is a professional musician who primarily performs with his group The Newen Trio, which includes himself on charango and usually a guitar, a drum kit and a fretless electric bass. He writes and performs original instrumental music that plays with the boundaries between jazz, funk and rock with definitive Latin American textures. He uses an amplified round backed charango in standard tuning and sometimes mediates it through an effects pedal. He uses the harmonics of the instrument, lots of plucking patterns and arpeggios and strums in a variety of mostly non-traditional rhythms.

Previous to his migration to Europe, Latapiat spent many years living in Brazil and studying Brazilian guitar. This influenced his composition and technical approach to both charango and guitar. And of course, Andean textures of charango stylings seep through the cracks of this otherwise very eclectic music-making. He calls his music "charango moderne" and "jazz latein" for audiences in France, where he has been well received. 
Latapiat grew up in and near Santiago de Chile in the 1970s during a turbulent time where anti-Pinochet protests were gaining momentum (see Chapter Two). The music of this period embraced Andean sounds as part of a larger socialist, counter-cultural and anti-dictator protest movement. Latapiat said that his mother had a few recordings of Violeta Parra in the house and his older cousin, active in the student protest scene, brought them the music of Inti Illimani and other Nueva Canción music groups in the form of clandestine cassette tapes. Latapiat first heard the sound of the charango on these recordings, presented in interpreted textures of Andean rural folk music as pro-indigenous and pro-proletariat politics. In this time of social activism associated with the revaluation of traditional folkloric Chilean song, Latapiat was exposed to the sound of the charango, which would later become the center of his artistic world.

At age twelve Latapiat saw the Chilean group "Uraco" playing on the street one day and was invited to attend a rehearsal. It was this day that he saw the charango up close for the first time, and was instantly enchanted. "I already knew and liked the guitar, but this was different... it was love at first sight" he says, along the same lines as other interlocutors reviewed in Chapter Five (Latapiat interview 2018). One year later his godmother (who had more economic resources than his own single parent family) bought him his first charango. From that moment forward, he dedicated himself to learning the instrument from recordings and with friends, as the family didn't have the means or access to more formal training. He described his methodology as "fishing" on the charango, and translating it to the guitar, which he already played well enough. Slowly, he familiarized himself with the basic repertoire in the keys of A and E minor.

In 2008 Latapiat moved to France to reside with his wife, a French national. As a relatively recent immigrant, he has a heightened awareness of cultural differences between France and South America, and how they have impacted him and his musical life. Despite the 
existence of a Conservatory of Music in his current city and the concurrant presence of many accomplished musicians, Latapiat initially felt musically isolated in France. He struggled to find anyone to play with who was able to accompany him on the charango that suited the way he was accustomed to playing it. He still does not know any other Latin American musicians in Lyon and no professional charango players at all in Europe (although they exist, of course). He considers the charango a "collective" instrument that "needs accompaniment — needs to be balanced with a bass or a guitar." This mestizo custom and aesthetic along with his situation as an immigrant have directly resulted in Latapiat's expansion into new areas as a charango player and musician. In his first group collaboration in Lyon, for example, Latapiat only played a few numbers on the charango. He has since pushed himself to expand his style, repertoire and musical language in order to be able to collaborate with the European musicians whom he knows, primarily through the jazz scene.

At first, he tried to translate Brazilian guitar stylings to the charango, incorporating melody, rhythm and accompaniment inclusively on the instrument to substitute for accompianment. He then learned to play in other keys besides the typical ones used in traditional repertoire (A minor, E minor). Finally, he engaged a self-designed training process to acquire the "language" of jazz in order to be able to improvise on the charango at an equivalent level to that of his trained European jazz colleagues and collaborators. Said Latapiat:

I am not a great improviser [...] I don't have the technical 'language' of jazz improvisation yet. I can improvise by 'feeling', like, in a regular, non-technical way; but I am lacking certain fundamentals, which I am working towards learning (Ibid, 2018).

He told me that he has designed a very specific practice plan to gain these skills, and uses a loop pedal to practice improvising. 
Latapiat's first recording, entitled "Emisfero" (Hemisphere) was successfully released in France in 2015. He says that his original, innovative jazz-funk music with the charango and guitar have gone over well with live audiences in the region at concerts and other events. Here, far outside of the European audience's more known terrain of pan-Andean music, he feels that his following is (still) attracted to the charango's "difference", as they perceive it. In this case, the charango is doubly "exotic" as Latapiat presents it in new music genres as well. In social terms, though, is anything really different about a scenario where the charango represents exotic “otherness" for a European audience (Taylor 2007)? As we have seen in Chapter Two, this sort of angle of appeal is a long established pattern in the emergence of the charango into European scenes through pan-Andean musical representations. Although Latapiat's ultimate objective, of course, is artistic and financial survival (similar to Parra's, Cervantes's, and most other players still relying on musical and cultural income streams), his case presents just another variation on an established post-colonial theme. The charango in these cases is a tool that the immigrant players employ to bridge the hegemonic divide between themselves and the post pan-Andean markets of their current circumstances. From a perspective of new organology, these situations (and others like them in capitalist frameworks) present the charango not only as a means of musical and personal expression, but as a tool of commerce and economic survival for its human agents.

Latapiat feels confident enough about his artistic direction to foresee a subsequent recording project of original charango music in the coming year. He has some compositional plans for this future recording that rely on the construction of a charango variant which he has designed with a Chilean luthier. When he has the economic means, he plans to have it made in Chile and sent to him. 
Ivan Latapiat is successfully negotiating the particular challenges of his situation with awareness, skill, and tenacity. This involves, in his case, acclimating himself to the musical frameworks around him while strategically playing the unfamiliarity of the charango outside of customary genres to his benefit. Striking this balance has gained him acceptance and approval in the music scene in Lyon and growing audience support. Like Cervantes, his success is in large part due to his technical ability to stretch musically outside of folkloric and common (panAndean) repertoire. With this tenacity and flexibility, new charango horizons, including in material form, are being forged in order to sustain musical activity in terms of both artistic expression and commercial success. Within this apparent "newness", however, post-colonial frameworks still articulate the larger boundaries in which innovation takes place. Here, Latapiat's engagement with the charango in un-customary genres re-presents it with enough of an "exotic" edge to rewaken the interest of European audiences. For Latapiat, the decline in panAndean music around Europe several decades ago (discussed at the end of Chapter Two) places his current endeavor at an advantage.

\section{$\underline{\text { Patricio Zeoli }}$}

Patricio Zeoli is a classical guitar and charango player living in the outskirts of Berlin, Germany. He is a descendent of an Italian grandfather, an Argentinean father and an Irish mother. Zeoli was born in Argentina, raised in Ireland, and has lived the rest of his years in either South America or Europe. He speaks fluently in English, Spanish and German which are all part of his everyday life. Ethnically, nationally and culturally, Zeoli’s background articulates multiple points of identity, cultural reference and lived experience through a diverse trajectory of musicmaking with intersections on three continents. 
Zeoli's father was Argentinean of Italian descent and he married Zeoli's mother, an Irish national from Wales. Zeoli was born to this mixed nationality immigrant couple in Rosario, Argentina in the center of an Italian settlement. His parents separated when he was three years old, and his mother brought him back to Ireland to live in a small town outside of Belfast. This was a disturbing event in his early life that he said was "cloaked in secrecy and a sense of trauma" and had a strong impact even at that early age. Zeoli noted that there was "a sense of a painful association with Argentina" that he felt from his mother throughout his childhood years. She "didn't talk about it [Argentina] very much," he said. "There was secrecy around the departure...we never knew what actually happened" (Zeoli interview 2018).

Growing up in his new Northern Irish village, Zeoli went to primary school at four years old, and felt immediately "different" in various ways, beginning with his "strange" last name.

I knew I wasn't quite the same as the rest of them. It wasn't really a bad feeling, but... I remember the teacher asking us to say our names and where we were from. All the other kids were local, and had Irish names. I remember saying that I was from Argentina. Later that night I went home and asked, "Mom, what is Argentina?" Not where is Argentina, but what is Argentina (Ibid, 2018).

Despite the silence around the reason for their departure, Argentina was still a presence in the household that resonated with young Zeoli, primarily through packages sent from relatives on his father's side on holidays and special occasions. Included were vinyl records that became a sonic bridge to his South American roots. "I remember receiving those packages," Zeoli commented. "I would open them up and smell them — they smelled like Argentina, as I remembered it," he said "and the music really hit me" (Ibid, 2018).

In the Irish world outside his family home Zeoli integrated into local artistic culture through folkloric dancing, in which he won prizes in regional children's divisions. At the same time, British bands like the Beatles were popularizing the guitar as early rock and roll took over 
the airwaves. Soon young Zeoli got his own guitar as a gift from his uncle. He felt immense attachment to this instrument and cried when a string broke, not knowing that it was an easy fix.

Growing into adolescence, he made music with his local friends in the vein of the popular rock and roll bands of the time. Yet he still had a deep engagement with Argentinean music, which continued to arrive in packages from the South America. He immersed himself privately in these recordings, and felt this was a "secret little world that was [only] mine" connecting him emotionally with that part of the family that had been so suddenly absent (Ibid, 2018). Hence Zeoli's first experiences with music unfolded in parallel ways to the complexities of his own identity and situation as a bicultural immigrant with mixed ancestry.

By the time Zeoli was in high school in the late 1960s, civil unrest was ablaze in Northern Ireland. This was a disturbing and dangerous reality for Zeoli and his peers. When he graduated at eighteen, he left Ireland quickly, for France. "I just wanted to get out of there," he said, reflecting on the violent conflict that was disrupting everyday life in and around Belfast. For the second time in his young life, conditions outside of his own control prompted displacement. "But," added Zeoli, "I probably would have left anyway," he said, referring to the general wanderlust that was taking hold of him at that time (Ibid, 2018).

His move to Europe started off in San Tropez, France, where he scraped by playing guitar on yachts and in the street, primarily showcasing sixteenth century classical music to French and international listeners. Eventually he attended the Royal Conservatory in Holland, where he studied classical guitar for two years. In 1973 he moved to Germany to study further at the UDK (University of the Arts) in Berlin, where he would encounter (pan-) Andean music.

Zeoli spoke of the presence of South American students in Berlin at the time and about the folk music clubs where pan-Andean music was taking hold of certain leftist and bohemian 
sectors and of the public imagination in a similar vein to the early scene in Paris. Zeoli bought his first charango from one of these students and began to learn how to play it through immersion in this Latino music scene in Germany.

Once he graduated, he left Europe for South America, intending to go back to Argentina for the first time since his mother's abrupt departure so many years before. However, he was unable to enter Argentina because he had ignored an earlier call to serve in the military. He landed instead in Uruguay. Barred for many years, Zeoli cycled between Uruguay and Brazil, absorbing musical culture and gaining experience as a musician and traveller. With the fall of the Argentinean military government in 1984, Zeoli and others in his situation were granted amnesty and were permitted to enter Argentina. Zeoli visited family members and travelled all over Argentina that year, getting to know the country and local musics very well.

Throughout this period, Zeoli was still primarily focused on the guitar. But a trip to Bolivia would bring the charango again to his attention. In Bolivia he came upon a "kalampeador" playing in the market square in a highland village. Zeoli was riveted by this traditional style of playing. His interest in the charango resurfaced. He brought several instruments back to Uruguay with him, and began to devote more time to mastering them. Zeoli spent subsequent years in South America travelling, playing music, and immersing himself in all kinds of South American folkloric music scenes, most of which no longer exist, according to him. However, Zeoli's projected two-year sojourn to Argentina had turned into fifteen years of exploration that spanned the South American continent and expanded his musical foundations substantially.

In 1994 Zeoli finally returned to Europe and re-established himself in Berlin, where he has since kept his home base, and gained a following as a guitar instructor. He did not return to 
South America until 1999, when he was invited to an International Charango Festival in Potosi,

Bolivia. Attending and performing at this festival gave Zeoli some new perspectives on what was happening generally with music in the charango scene that would affect his next choices in his own musical life. Zeoli spoke in detail about this experience, and how it changed his thinking.

Cavour [Ernesto] gave the opening concert. What can I say? I was stunned. He performed the exact same repertoire and set; he even told the same stories and jokes that I had heard 30 years ago. I was shocked that there was no evolution in the time that had gone by [...] I also observed that there were basically two streams of music being performed: either it was a European or other foreigner playing Bolivian music note for note from recordings, and very well, I might add. Then there seemed to be an obsession or fascination and interest in playing European classical repertoire on the charango. The Latinos who could do this seemed to get elevated in status in the eyes of the others. I realized at that event that I can't go either of those ways. These arrangements of hit pieces of Bach or Mozart sounded flat to me, as the "rules" [of that canon] were not being followed [because the musicians were not trained for it]. I like the idea of using the charango in a classical way, but in my mind, it has to be done right (Ibid, 2018).

Soon after returning, Zeoli started his collaboration with Jose Cibilis, an Argentinean pianist who was living in Hamburg at the time. Their duo, which they called "Piarango", created some arrangements of traditional tunes as well as some original compositions based on Argentinean "chacareras". ${ }^{112}$ They made two excellent recordings and toured both in Europe and Japan for several years.

Zeoli's most current musical project is with a group of medieval musicians called Los Ymposibles. This group is based in Freiburg, Germany, and consists of three other musicians who play historical instruments with gut strings and historical tunings. Their repertoire is diverse, with a true sense of fusion between the medieval/classical world and more folkloric sounds from the British Isles and South America. Their first recording was released in 2016 and is highly accomplished in composition, musicality, and performance. "I feel fortunate," Zeoli noted, "to be able to bring the charango into this music with top quality people" (Ibid, 2018).

\footnotetext{
${ }^{112} \mathrm{~A}$ signatory Argentinean folkloric dance/song form.
} 
In the case of Patricio Zeoli's work with Les Ymposibles, and formerly, Piarango, we can get another glimpse (as with Cervantes and Latapiat) of a "new" charango emerging — at least in musical terms. Given the span of his points of identity and life experience, it is hardly a surprise, as his story has many intersections of nationality, culture and language, some of which cross over with Latin America. These affect how he engages musically with the charango, both connected to and far afield from its traditional reach. In this sense, Zeoli covers more ground than most of the other "innovative" players in this study. However, his position as an Irish national living in Germany is quite different than that of Latin American immigrants like Cervantes and Latapiat, despite his childhood experience of "difference". For instance, his earlier access to formal musical education on European terms has allowed him to pursue "legitimate" teaching in Europe (with the guitar) as another stream of income. Perhaps this advantage is what has afforded him the luxury of what seems to be a very conscious and evolving musical path that does not appear to be driven primarily by economic concerns. Of great interest to perspectives in new organology, in the "social" terms presented by Zeoli, the charango has the rare opportunity to be an explorer of new musical terrain, and the results are certainly unique. Still, in many ways Zeoli's narrative includes many intersections that are relevant to most, if not all of the "innovators" as well as many of the more traditional players involved in this study. This may explain why the common musical denominators (traditions) of the charango are still one area of reference in the new musics that he is forging. Certainly, his own roots in Argentinean tradition and long musical sojourn in South American contexts are a central grounding point in his evolving musical life, and a continued presence in his musical outputs in these unusual constellations. 


\section{Innovators on the global stage}

The musical lives of these three players - Jorge Cervantes, Ivan Latapiat and Patricio Zeoli- bring an array of issues to light concerning what conditions and circumstances encourage movement away from traditional musical choices. ${ }^{113}$ In their stories we can also see how certain personal characteristics rooted in life experiences or acquired skills have enabled them to embrace the opportunities to broaden musically. Among these, economic need accompanied by the ability to assess and understand the market and audiences ranks high. While for Cervantes this meant expanding his skill set and broadening his networks into other cultural groups, for Latapiat it meant delving into jazz studies and featuring the charango as an exotic presence in his ensemble to capture the attention of French audiences, echoing past trends in panAndean music. Artistic flexibility and competency, musical sensibilities and artistic choices have also influenced the paths of these three artists. Cervantes, certainly, has embraced and nurtured many different kinds of musical opportunities. Latapiat faced his own inadequacy as an improviser and applied himself to the learning process in order to be able to merge with the local jazz scene as his new context. Zeoli’s development has led, via many pathways of musical development and personal exploration, to a project that he feels has integrity, challenge and freshness: bringing the charango into neo-medieval musical expressions. Finally, openmindedness and perceptiveness about cultural differences have been key components which enable these players to meander into the realm of musical innovation with an instrument otherwise quite bound to tradition and common genre. These qualities were developed in the case of Zeoli, over a lifetime of personal transnational experiences. Cervantes certainly identified

\footnotetext{
113 To clarify, these three are not the only players in this study to engage in innovations and experiments, they are simply the ones in whose work innovation is most central, who have not already been discussed. The Table of Players (p. vi) shows, in the last column as "mix" or "orig", who could be said to be at least partially included in this group.
} 
early childhood exposure to all kinds of musics and people in his migrant parents' home as an important building block, while Latapiat has navigated cultural changes later in life as a migrant to France.

Because of their explorations across genre and musical languages as well as their own international experiences, the charango in these three innovators' hands is much more flexible than in the cases of most players in this study, as are also its musical impacts. In these players' trajectories, the charango is still tied to common and traditional meanings, but is being stretched significantly towards new definitions in new musical circumstances. In response to the prompts of new organology, examining the charango through the social intersections in the musical lives of more innovative players such as these opens the view to a broader terrain where a "global" charango has perhaps begun to appear. 


\section{Conclusion: Is there a "global" charango?}

Theoretically, this study was intended to focus on an instrument from South America in European fields: "fields" (plural) because there is no one location in any part of Europe where many charango players are living. Rather, participants were broadly dispersed, somewhat hard to locate, and not all immigrants from Latin America. How would the contemporary European positions of these players impact the social meaning and musical trajectory of the instrument? In the end I stood before an ethnographic data base with an extremely broad reach, gathered from a sparse but diverse group. In pursuit of charango players in European fields, I discovered not many, but surely, many different perspectives.

Charango players are living in contrasting situations and cultural intersections in just as varied locations in Europe, as we have seen, and there are undoubtedly many more than I was able to interview. Their stories are each unique, but have areas of overlap that have been thematized in this paper. This might be viewed as a disadvantage; or it could be considered, contrarily, to have stirred up that many more threads to weave together, making the task of conclusion difficult, but perhaps, rendering more textured results.

The standard charango played by most of the participants in this study is a homogenization of a number of diverse variants present in and stemming from Andean localities. This charango is known primarily to South Americans, and to non-Latino players that either have some kind of ties to the countries where it is most popular (Bolivia, Peru, Argentina, Chile), or were exposed to pan-Andean music at the height of its circulation in the 1980s in Europe and North America. A few others may have had some alternative point of access. Despite this recent history, it stands to point out that the charango is not a popular or well-known instrument in 
Europe today, which may give some renewed advantage to those who proceed to pursue professional musical careers with it (a good example being Ivan Latapiat in Lyon, FR). Of course, all kinds of charango music from many locations circulates on YouTube, and increasingly so, as digital infrastructure expands its reach and accessibility.

As described, the charango travelled widely with the emergence and popularization of pan-Andean music in the 1980s, in particular tied to the tours of Nueva Canción artists such as Inti Illimani and Quillapayun who performed all over Europe and North America during that time. ${ }^{114}$ Given all of the information, can we conclude that the charango is a "global" instrument? Well, that depends: looking at the music and its players as new organology suggests, rather than solely considering "the wood and strings" may provide a useful perspective.

\section{Tied to tradition}

There are still unanswered questions about why the majority of charango players involved in this study are not really "innovators", nor have crossed genre or cultural lines. In fact, as previously noted, the reality is quite the contrary. This leads to my tentative conclusion that the charango should probably not be considered a global instrument, despite its presence in Europe and elsewhere outside South America since the 1950s.

Why have the majority of charango players living outside of South America, in a variety of international and cross-cultural environments, not been wrested from their musical habits? Is it a question of attachment to home that keeps them comfortably nested in known repertoire? This is certainly true in some of the cases presented in this study, as exemplified in the Bolivia Day party I attended in Vienna, or the cultural gatherings of Peruvians in Joshua Tucker's study on migrants in Madrid, resonant with our own Cesar Guzman Roman's mini-diaspora further south

\footnotetext{
${ }^{114}$ As mentioned, a known affiliate following of the charango exists in Japan as well, tied primarily to Bolivia and Bolivian folklore to whom groups like Bigenho's “Musica de Maestros” continues to cater (Bigenho 2002, 2012).
} 
(Tucker 2014). In one case in particular (that of Alejo Cruz), developments at home (in Bolivia) drove him to pursue a traditional, local Bolivian music (kalampeo) from his immigrant position and location in Vienna with refreshed interest. For these players, traditional repertoire acts as an assertion and confirmation of identity and against the backdrop of European hegemonic norms in the foreign contexts in which they now live.

Others cling to tradition because of economic needs. In the case of Luis Parra, the charango's perceived "otherness" is pivotal to his financial survival, now in (multi)cultural presentations in Austrian schools instead of on the street. For Parra and others, the charango's continued placement in traditional musical genre secures its image as "foreign" and "exotic" and hence, sellable in cosmopolitan frameworks. But even in the case of non-traditional innovations by Ivan Latapiat, the perception of the charango as "exotic" is still an important selling point. Of course, many players have had to abandon artistic work to pursue non-musical professions and jobs (or rely more primarily on the sale of merchandise) to be able to survive economically (Meisch 2002).

But how do we explain why most Europeans and other non-Latinos who pick up the instrument follow suit, remaining within the bounds of customary sound, repertoire and technique? In some cases, such as Ólöf Arnalds, travel of the musician and of the instrument was a precondition for innovative explorations and musical invention. However, in other stories, such as that of Denis Plavčić, the opposite occurred. Perhaps his employment in the tech sector orients Plavčić toward the online world. After his "discovery” of digitally dispersed Andean music on YouTube, he used the material he found online in Andean and pan-Andean genres, both technically and musically, in order to learn to play it. Clearly, these three cases play out in 
radically different intersections of place and history, and so comparison may be irrelevant. However, they do illustrate the various ways the charango and its music has been dispersed.

There are of course questions about the physical and tonal aspects of the instrument. Does the relatively small tonal range restrict musical explorations with the charango? Is there something about it that makes it "difficult" to adapt to other musics, as Jorge Cervantes (and others) have suggested? Or, are the musical skills of most players not up to the task of "stretching" into other genres, rhythmic frameworks and harmonic scenarios? In several cases presented in this work, players resorted to physical adaptations of the instrument (Federico Tarazona and Camilo Gomez (and additional technology, in Gomez's case)) in order to accommodate their desire to push the envelope of repertoire and performance. Ivan Latapiat's future recordings or original compositions are also looking towards material invention of a new instrument for similar reasons.

This research can only attest that all of the above are possible pieces of the puzzle. The charango remains primarily in the hands of Latino musicians, primarily geographically in Latin America, and primarily situated in genres that are connected to traditional and pan-Latin American contemporary musics. In that sense, the modern charango has remained for the most part associated with and engaged in traditional and folkloric musical fabrics, despite the shifting nuances of association it has been assigned by its human agents and the global movements of many of its players and aficionados.

Future inquiry might benefit from an examination of gender intersections related to the charango and its traditions. Some preliminary work to this effect (Turino 1983, 2008, Stobart 2008) has looked at the charango's role as a symbol of virulent/dominant masculinity in a few 
Andean contexts. ${ }^{115}$ This gendered association and adherent "machismos" are still palpable in some scenarios that may intersect with origins' discourse. ${ }^{116}$ Increasing numbers of female players in Bolivia and Peru following the legacies of popular mestiza figures such as Mama Paulina and Norma Cueva may indicate a shift or signal further nuances around the issue, as well as the engagement of women outside of Latin America such as myself, Nina Dimitri, Marie Laduron, Ólöf Arnalds and Carole Stocklin. Study along these lines will doubtless unveil additional intricacies to the puzzle of the not-so-global charango, and lend new perspectives to organological inquiries that concentrate on the social meanings and processes surrounding musical instruments.

\section{$\underline{\text { Origins discourses }}$}

While origins claims dominate discourse and literature on the charango from a variety of perspectives, theories on national identity formation and nationalism can enlighten our understanding of them. The tug of war between Bolivia and Peru for exclusive heritage rights over the charango to inculcate a national image is yet another string attached to the instrument to manipulate its meaning. But as observed, the editorial commentary in the recent publication of a new collection of works on the charango (that includes a significant portion of works on the origins question) may help ease the whole debate into a more constructive framework (Mendivil 2018).

Besides further illuminating economic and nationalist agendas, future scholarship could examine the intersection of origins debates with issues about male domination and the exclusion

\footnotetext{
${ }^{115}$ An example is seen in the narrative of Cesar Guzman Roman, who commented obliquely on these topics (Interview with Cesar Guzman-Roman in Vienna, Austria, Oct 2018). The poem by Cavour that introduces Chapter Five, presents another example (as he personifies the charango as having the capacity to "dominate"). Nina Dimitri, one of the only female players in this study, spoke to these issues as well regarding her experiences in both Europe and Bolivia (Interview with Nina Dimitri in Vienna, Austria Sept 2018).

116 "Machismo"--loosely defined, is male chauvinism and sexist ideology.
} 
of women from national discourses and governance. Feminist analysis has long ago made the connection between nationalisms, patriotism, war, and male supremacy. If the charango represents a certain representation of dominant masculinity or is a mediator for its reiteration, then it stands to question whether the objective of the fight over the charango by male dominated nation states could be seen as a fight to determine who(se) is bigger or more powerful, as much as it is motivated by proprietary heritage interests, or that perhaps these are one and the same. How gender plays into concepts of property, heritage, and tradition in the variety of socioeconomic contexts in the countries involved begs further investigation and analysis, as it brings up issues about the charango and its ties to tradition that have yet to be explored.

Singular innovations on the global stage

In some rare corners both within and outside of its places of origin, the charango is being engaged in singular cases of innovation, adaptation, and crossings of both genre and culture that may indicate slight erosion at the edges of tradition, if only in the hands of a few experimenting musicians. This holds true for the participant group in this study, which has presented three particular musicians for closer analysis on that point. The meaning of the charango as performed by these players begins to prove the assertions of new organology that the meanings of instruments are determined by social interactions as much or more than traditional measurements of form and function, as they push into non-traditional musical terrains with the instrument in music-making (Dawe 2014).

History has shown us that in many affairs, there is often a "tipping point" for the popularization of anything, including music, when conditions become perfect for certain changes to occur. Paul Simon's adoption (or appropriation) of "El Condor Pasa" at a ripe moment in world markets fertilized by touring Nueva Canción bands like Inti Illimani and Illapu catapulted 
(pan) Andean music, signified in the sound of Andean panpipes (and the charango, by association) onto the global market. (Of course, these and other bands had already opened the musical space for Simon's world hit.) Will there be a "tipping point" for the charango apart from pan-Andean genre sometime in the near future that brings it to the recognition level of the ukulele, djembe, and dijeridoo and hence, out into the wild mix of music in international crossings? In the meantime, charango innovators remain rare birds thinly dispersed in the world music jungle, visible only to those who pursue a rare sighting. The rest of the charango scene carries on its business as usual, whether inside or outside of Latin American and Andean cultural contexts.

The wood and strings, and the something more

The charango is, of course, just an instrument; an object or artifact; wood and strings; a small, round or flat-backed chordophone from the Andes. The "something more" that it is or that we imagine it to be is determined in human transactions, human expressions and human projections. Among the somethings-more, the charango has been imagined to be a leftist hero, a friend, a healer, a traveller, a life saver, a nursing baby, a wandering pet and other such personified figures by various players and aficionados in diverse positions. These poetic metaphors, projections, and feelings expose how the instrument has and continues to captivate its interlocutors. Diasporic situations of course turn the flood lights on certain related issues that we have examined in this work. Clearly, social relationships predominate in determining the role, message, and overall meaning of the instrument, concurrant to the suggestions of new organologists like Dawe and Bates, who remind us that instruments "exist in webs" of discourse and interaction (Dawe 2012,114). These webs of relation and their subsequent musical impacts 
are of course, fluid. Yet certain themes resurface where the charango is implicated, as this work demonstrates.

\section{$\underline{\text { Fading out }}$}

The recent period of pan-Andean music on Central and Western European streets and stages, whether this is labeled a musical "boom" or not, seems to have faded out just as quickly as it occurred. This period has left behind a new genre of music that is perceived by many cosmopolitan audiences and musicians to be tied to both local and global imaginations of "the indigenous". Despite these perceptions by primarily non-indigenous agents, or the promotion of such ideas by non-indigenous beneficiaries, pan-Andean music is a contemporary genre that was formed through trans-local interactions in cosmopolitan spaces in central European and some South American cities. In these trans-continental loops of ideological and musical developments, the charango has acquired quite a variety of symbolic associations over just a few decades, compared to the first four hundred years of its history. Mobilizing indigenous associations for a modern cosmopolitan market in global intersections with the charango and pan-pipes leading the leftist (or exotic, or magical, or earth-loving) charge seems par for the course. But for its occasional appearance in the current (and, I believe, sparser) presentations of more recent "Mega-Indio" mercantile sound and light shows chronicled by Jana Jetmarová's field work, the charango's current presence in some of these same fields appears scarce.

While this assertion cannot be measured definitively based on my study alone, I can conclude from my outreach, networking and recruitment efforts that charango players do not abound in Europe. And yet, one or two can be shaken out of the bushes in almost any general geographical location: where Latin Americans from South American countries with Andean zones have migrated, a charango player or two can be turned up. In the turbulence of human 
movement, the charango has certainly travelled, and probably will continue to. However, in musical terms, it remains relatively stationary despite the movement of people and the configurations and reconfigurations of culture and music around the world. 


\section{References}

Albó, Xavier. "Our Identity Starting from Pluralism in the Base". In The Postmodernism Debate in Latin America. edited by J. Beverley, M. Aronna and J. Oviedo, 18-33. Durham, NC: Duke University Press, 1995.

Alcón, Christian, and Gonzáles Alcón. “Ch'ayantakas, Ch'arankus, Ch'ajwakus y Charangos. Los Vientos, Los Tueños y Las Lluvias.” Anales Reunión Annual Etnología, 12-29. 2011.

Anderson, Benedict R. Imagined Communities: Reflections on the Origin and Spread of Nationalism. Revised edition. London; New York: Verso, 2006.

Appadurai, Arjun, ed. The Social Life of Things: Commodities in Cultural Perspective. Cambridge: Cambridge University Press, 2009.

Arguedas, José-María. “El Charango: Indios, Mestizos, y Señores.” Lima: Editorial Horizonte, 1985: 53-57.

Barenboim, Daniel, Edward W. Said, and Ara Guzelimian. Parallels and Paradoxes:

Explorations in Music and Society. New York: Pantheon Books, 2002.

Bates, Eliot. "Actor-Network Theory and Organology”. Journal of the American Musical Instrument Society 44, (2018): 41-51.

. "The Social Life of Musical Instruments". Ethnomusicology. University of Illinois Press, 56, no. 3, (Fall 2012): 363-395.

Baumann, Max Peter. "The Charango as Trans-Cultural Icon of Andean Music." Revista Transcultural De Música, Sociedad de Etnomusicologia, 2004.

BBCMundo.com. "El Charango Mas Grande del Mundo.” Accessed on 20/11/2018. http://news.bbc.co.uk/hi/spanish/misc/newsid 4197000/4197100.stm.

Becker, Howard S. Art Worlds. Berkeley: University of California Press, 1982.

Bigenho, Michelle. Intimate Distance: Andean Music in Japan. Durham: Duke University Press, 2012.

. Sounding Indigenous: Authenticity in Bolivian Music Performance. 1st ed. New York: Palgrave, 2002.

Born, Georgina and David Hesmondhalgh. Western Music and its Others: Difference, Representation, and Appropriation in Music. Berkeley: University of California Press, 2000. 
Bravo Pinto, Arturo. "Guitarras y Charangos." Folklore: Tribuna del pensamiento peruano. Lima, no. 14-15 (1945): 368.

Bridges, Tristan. Liquid Masculinities: Transformations in Gender and Politics Among Men. $\mathrm{PhD}$ diss., Univerisity of Virginia, 2012. http://search.proquest.com/docview/1322717290/.

Calderón, L. Eduardo. “El Charango.” El Diario (La Paz), October 1, 1940.

Cavour, Ernesto. El Charango: su vida, costumbres, y desventuras. La Paz: Producciones CIMA, 1980 .

Chaquilla, Óscar. "Origen Del Charango En El Perú Virreyñal." Folklore, Cultura, e Identidad, Lima: AFINED; CENDAF, (2006): 283-290.

Cifuentes, Luis. Fragmentos de un sueño: Inti-Illimani y la generación de los 60 Santiago: Ediciónes Logos, 1989.

Clifford, James. "Diasporas". Cultural Anthropology 9, no. 3 (1994): 302-334.

Colectivo de Charangos del Peru. "Pronunciamiento Del Colectivo Los Charangos Del Perú." Accessed on 20/11/2017. http://www.charangoperu.com/charangoperu/contenido/articulos/charango_declaratoria.p df.

Cornejo Diaz, Marcela. "El charango y el Carnaval: Notas sobre el charango de Arequipa." Colesúyo (2010). Accessed on 13/14/2018. https://sites.google.com/site/colesuyo/costumbres-tradicionales/notas-sobre-el-charangode-arequipa (April 13, 2018).

Cornejo-Purán, Marcelo. Citandino: Las Rutas Del Charango En Chile. Santiago de Chile: Editorial Cuarto Propio, 2016.

Davis, Colin. "Diasporic Subjectivities." French Cultural Studies 17, no. 3 (2006): 335-348.

Davis, Sarah and Melvin Konner. Being There: Learning to Live Cross-Culturally. Cambridge, MA: Harvard University Press, 2011.

Dawe, Kevin. "The Cultural Study of Musical Instruments". In The Cultural Study of Music: A Critical Introduction, edited by Martin Clayton, T. Herbert and R. Middleton, 274-284. New York and London: Routledge, 2003.

. "Guitar Ethnographies: Performance, Technology and Material Culture". Ethnomusicology Forum, 22, no 1 (2013): 1-25. 
. "People, Objects, Meaning: Recent Work on the Study and Collection of Musical Instruments." The Galpin Society Journal 54 (May, 2001): 219-232.

Devine, Jack. "What Really Happened in Chile: The CIA, the Coup Against Allende, and the Rise of Pinochet." Foreign Affairs 93, no. 4 (2014): 26-35.

Dibben, Nicola. "Nature and Nation: National Identity and Environmentalism in Icelandic Popular Music Video and Music Documentary". Ethnomusicology Forum, 18, no. 1 (2009): 131-151.

Dorr, Kristie. "Mapping 'El Condor Pasa': Sonic Translocations in the Global Era." Journal of Latin American Cultural Studies 16, no. 1 (2007): 11-25.

Ellison, Michael. "Secret Files Bury Facts of CIA Dirty Tricks Against Allende's Regime." The Guardian (London, UK), Oct 21, 1998.

Fairley, Jan. "Inti-Illimani: Living a Life through Making Music (2002)." In Living Politics, Making Music, edited by Simon Frith, and Ian Christie, 55-68, New York and London: Routledge, 2014.

Gallac, Hector I. "El Origen De Charango.” Boletin Latino-Americano De Musica, Montevideo, 3, no 3 (1937): 73-75.

Garcia, Jose Uriel. Pueblos Y Paisajes Sudperuanos. Cultura Antártica. Lima, Perú, 1949.

García, Leonardo. "Músicas Populares y Bicentenarios en El espacio urbano Andino. El Caso de la Guerra Del Charango." Nuevo Mundo Mundos Nuevos, (January 2011). Accessed 20/03/2018. https://doi.org/10.4000/neuvomundo.62250.

Georgiou, Myria. "Does the Subaltern Speak? Migrant Voices in Digital Europe." Popular Communication 16, no.1 (2018): 45-57.

Gómez-Barris, Macarena, Tamar Diana Wilson, and Annelou Ypeij. “Andean Translations: New Age Tourism and Cultural Exchange in the Sacred Valley, Peru." Latin American Perspectives 39, no. 6 (2012): 68-78.

González Bravo, Antonio. “Trompeta, Flauta Traversa, Tambor y Charango.” Boletín Latinoamericano De Música 4, no. 4 (1938): 167-75.

Gomez Vela, Andrés. “Los Charangos Cambian Del Temple.” La Razón. (April 2000).

Goyena, Hector Luis. "El Charango En El Departamento De Chuquisaca (Bolivia).” Temas De Etnomusicología 2 (1986): 6-28.

Grassler, Jean-Marc. "Bolivie - charangos du Norte Potosi". Boletín de la Sociedad Suiza de Americanistas, Geneva: 61 (1997): 39-44. 
Hadley, Peter Duncan. The Didjeridu Dispersion: The Transmission and Transformation of a Hollow Log. Unpublished Thesis, Boston: Wesleyan University, 2007.

Haig-Brown, Celia. Indigenous Thought, Appropriation, and Non-Aboriginal People. Canadian Journal of Education. 33, no. 4 (2010): 925-50. http://journals.sfu.ca/cje/index.php/cjerce/article/view/2189.

Herzfeld, M. Cultural Intimacy: Social poetics in the nation-state. Routledge: New York, London. 2014.

Jetmarová, Jana. "'I Am Proud to be an Indian': The Music of Andean Musicians in Europe as an Expression of Pan Indianism." Comparative American Studies an International Journal 11, no. 2 (2013): 185-200.

Johnson, Henry. "Old, New, Borrowed ...: Hybridity in the Okinawan Guitarscape." Ethnomusicology Forum, 22, no.1 (2013): 89-110.

Kalir, Barak. “Afterword: On Transitive Concepts and Local Imaginations - Studying Mobilities from a Translocal Perspective." In Mobilities, Boundaries and Travelling Ideas: Rethinking Translocality Beyond Central Asia and the Caucasus. Edited by Manja Stephan-Emmrich and Philipp Schroder. Cambridge, U.K.: Open Book Publishers, 2019. https://doi.org/10.11647/obip.0114.

Kamboureli, Smaro. Making a Difference : Canadian Multicultural Literature. Toronto: Oxford University Press, 1996.

Kelly, Peter. "Intercultural Comparative Research: rethinking insider and outsider perspectives." Oxford Review of Education. 40, no. 2 (2014).

Kohl, Benjamin and Rosalind Bresnahan. "Introduction: Bolivia under Morales: Consolidating Power, Initiating Decolonization. ” Latin American Perspectives 172, 37, no. 3 (May 2010): 5-17.

Krüger, Simone and Ruxandra Trandafoiu. The Globalization of Musics in Transit: Music Migration and Tourism. 4, no. 4. New York: Routledge, 2014.

Krims, Adam. "Music, Space, and Place: The Geography of Music.” In, The Cultural Study of Music: A Critical Introduction, 162-170, Edited by Middleton, Richard, Trevor Herbert, Martin Clayton, New York: Routledge, 2011.

Kymlicka, Will. The Essentialist Critique of Multiculturalism: Theories, Policies, Ethos. European University Institute, Robert Schuman Centre for Advanced Studies Global, Governance Programme, 2014.

Levi, E and F. Scheding (eds). Music and Displacement: Diasporas, Mobilities, and Dislocations in Europe and beyond. Lanham, MD: Scarecrow Press. 2010. 
Lindig, Vincent. Das Charangoeine Reise in die Seele der Bolivianischen Musik. Goethe-Institut Kolumbien, November 2015. https://www.goethe.de/ins/bo/de/kul/mag/20806392.html.

Luciak, Mikael \& Gabriele Khan-Svik. "Intercultural education and intercultural learning in Austria - critical reflections on theory and practice." Intercultural Education, 19, no. 6 (2008): 493-504.

Marie, Sophie. "Bono Hits the Wrong Note over Guitar: Final Edition One." Daily Bulletin, (Kimberley, BC), March 2006.

Meisch, Lynn. Andean Entrepreneurs: Otavalo Merchants and Musicians in the Global Arena. Austin: University of Texas Press, 2002.

Mendívil, Julio. “A Manera de Introducción.” In El Charango: Historias y Tradiciones. Vivas, Wien: Holitzer Verlag, 2018.

. "Indians in Pedestrian Zones". Stories, www.Norient.com. Oct (2015).

. ¿Hermanando Pueblos?: Las Historias Del Charango y Los Discursos Nacionalistas En Bolivia y Perú." Artigo - Tiempo Da Ciencia vol 20, no 39 (2013): 61-84.

. “Apuntes Para Una Historia Del Charango Andino”. In Escuela Moderna Del Charango Una Nueva Propuesta a La Técnica Instrumental - Federico Tarazona, 9-12. Lima: Abril Ediciones Musicales, 2004.

. "La Construcción De La Historia: El Charango En La Memoria Colectiva Mestiza Ayacuchana.” Revista Musical Chilena 56, no. 198 (August 12, 2002): 63-78.

Mestries Benquet, Francis. "'Let's Be Realists: Let's Ask the Impossible.' Notes on the May 1968 Movement in France." Sociologica 13, no. 38 (September 1, 1998): 153-162. http://search.proquest.com/docview/61645064/.

Mendoza, Zoila S. Creating Our Own: Folklore, Performance, and Identity in Cuzco, Peru [English ed.]. Durham: Duke University Press, 2008.

Mesa Gisbert, Carlos D. La Sirena Y El Charango: Ensayo Sobre El Mestizaje. 3rd ed. Editorial Gisbert Y Fundación Comunidad, 2014.

Osorio, Adriel. "Hacia una antología del charango peruano." Charango, música y canto. Lima: INDECOPI, Nro. 0025 (texto inédito, mecanografiado), 1995.

Pacini-Hernandez, Deborah. Oye Como Va: Hybridity and Identity in Latino Popular Music. Philadelphia: Temple University Press, 2010.

Paniagua Loza, Félix. El Charango. Puno: Oficina Universitaria De Proyección Social Y Extensión De La Universidad Nacional Del Altiplano, 2005. 
. "El Q'ajjelo Del Altiplano Peruano." El Boletín De Lima., 40 edition, 1985.

Papastergiadis, Nikos. The Turbulence of Migration: Globalization, Deterritorialization, and Hybridity. Cambridge, UK and Malden, Mas: Polity Press, 2000.

Park, Minsu, Jaram Park, Young Min Baek, and Michael Macy. "Cultural Values and CrossCultural Video Consumption on YouTube." PLoS 12, no. 5 (2017): e0177865. https://doi.org/10.1371/journal.pone.0177865.

Pedrotti, Italo. "Charango Indígena Y Charango Mestizo: Dos Universos En Contraste y Correspondencia." Revista De Pedagogía En Música Ano 1, 1 (2013). . El Charango Kalampeador En La Construcción Identitaria Del Charango Boliviano. Thesis, Univ. De Chile, Santiago, Chile, 2012.

Ponce Valdívia, Omar. Del Charango a Chillador: Confluencias Musicales En La Estudiantina Altiplánica. Thesis, Univ De Chile, Facultad Des Artes, Santiago, chile, 2008.

Postero, Nancy. "Morales's MAS Government: Building Indigenous Popular Hegemony in Bolivia." Latin American Perspectives 172, 37, no 3 (May 2010): 18-34.

Prior, Nick. "'It's a Social Thing, Not a Nature Thing': Popular Music Practices in Reykjavik, Iceland" Cultural Sociology. 9, no.1(2015): 81-98.

Ramiro Quiroga, J.C. "De cómo Violeta Parra se trajo a Chile un charango de Bolivia y también un revólver." Mar con Soroche 7, Santiago de Chile/La Paz (2009): 5-16.

Ramnarine, Tina K. "Musical Performance in the diaspora: Introduction". Ethnomusicology Forum, 16, no. 1 (June 2007): 1-17.

Rios, Fernando. "'They're Stealing our Music": The Argentinísima Controversy, National Culture Boundaries, and the Rise of a Bolivian Nationalist Discourse." Latin American Music Review / Revista De Música Latinoamericana 35, no. 2 (2014): 197-227.

. "La Flûte Indienne: The Early History of Andean Folkloric-Popular Music in France and its Impact on Nueva Canción." Latin American Music Review/Revista De Música Latinoamericana 29, no. 2 (2008): 145-181.

Robertson, Roland. "Glocalization: Time -- Space and Homogeneity -- Heterogeneity." Global Modernities, (1995): 25-44. http://search.proquest.com/docview/60030474/.

Saez, Fernando. La Vida Intranquila: Violeta Parra, Biografía Esencial. Santiago: Editoríal Sudamericana (1999).

Salomon, Thomas. "Theorizing Diaspora and Music". Lidé města 2, no. 17, (2015): 201-219. 
Simalchik, Joan. "The material culture of Chilean exile: a transnational dialogue." Refuge (Summer 2006): 95+.

Slobin, Mark. "The Destiny of "Diaspora" in Ethnomusicology." In The Cultural Study of Music: A Critical Introduction. 2nd ed." by Middleton, Richard, Trevor Herbert, Martin Clayton. 2nd ed. New York: Routledge, 2011.

. "Music in Diaspora: The View from Euro-America." Diaspora 3, no. 3 (1994): 234-252.

Stobart, Henry. "In Touch with the Earth? Musical Instruments, Gender and Fertility in the Bolivian Andes." Ethnomusicology Forum 17, no. 1 (May 12, 2008): 67-94.

. Music and the Poetics of Production in the Bolivian Andes. Aldershot, Hants, England: Ashgate, 2006.

. "Los Charangos Del Norte De Potosí". Guía De Instrumentos Musicales De Bolivia. 1991.

Stokes, Martin. "Music and the Global Order." Annual Review of Anthropology 33 (2004): 4772. https://doi.org/10.1146/annurev.anthro.33.070203.143916.

. "Globalization and the Politics of World Music." In The Cultural Study of Music: A Critical Introduction. 2nd ed." edited by Middleton, Richard, Trevor Herbert, Martin Clayton. New York: Routledge, 2011.

Tagg, Phillip. Fernando the Flute. Liverpool: Institute of Popular Music, 1991.

Tarazona, Federico. "El charango de los pueblos andinos." Asociación Internacional del Charango, 2008. Accessed 13/02/2018. http://www.aicharango.org.

Tarazona Padilla, Roel. "El Charango: Una Aproximación a Su Origen Y Desarrollo." Cuadernos Arguedianos: (Revista de Investigación de la Escuela Nacional Superior de Folklor Jose Maria Arguedas) No. 8 (2007)

Taylor, Timothy Dean. Beyond Exoticism Western Music and the World. Durha: Duke University Press, 2007.

Tenzer, Michael. "Integrating Music: Personal and Global Transformations." In Analytical and Cross Cultural Studies of World Music, edited by Michael Tenzer and John Barlow Roeder, New York: Oxford University Press. 2011.

Tucker, Joshua. "Sounding the Latin Transatlantic: Music, Integration, and Ambivalent Ethnogenesis in Spain." Comparative Studies in Society and History 56, no. 4 (October 2014): 902-933. 
. "Permitted Indians and Popular Music in Contemporary Peru: The Poetics and Politics of Indigenous Performativity." Ethnomusicology 55, no. 3 (September 2011): 387-413.

Turino, Thomas. Music in the Andes: Experiencing Music, Expressing Culture. New York: Oxford University Press, 2008.

. "Nationalism and Latin American Music: Selected Case Studies and Theoretical Considerations.”. Latin American Music Review 24, no. 2 (2003):169-209.

. "Are We Global yet? Globalist Discourse, Cultural Formations and the Study of Zimbabwean Popular Music." British Journal of Ethnomusicology 12, no. 2 (January 2003): 51-79. http://www.tandfonline.com/doi/abs/10.1080/09681220308567363.

. Nationalists, Cosmopolitans, and Popular Music in Zimbabwe. 2nd ed. Chicago: University of Chicago Press, 2000.

. Moving Away from Silence: Music of the Peruvian Altiplano and the Experiment of Urban Migration. Chicago: University of Chicago Press, 1993.

. "The Music of Andean Migrants in Lima, Peru: Demographics, Social Power, and Style". Latin American Music Review / Revista de Música Latinoamericana 9, no.2 (Autumn Winter 1988): 127-150.

. "The Urban-Mestizo Charango Tradition in Southern Peru: A Statement of Shifting Identity." Ethnomusicology 28, no. 2 (1984): 253.

. "The Charango and the "Sirena": Music, Magic, and the Power of Love." Latin American Music Review / Revista de Música Latinoamericana 4, no.1 (Spring 1983): 81-119.

Valdillo, José. “Charango Mío.” Investigación en la Música Andina. El Peruano. Lima, December 2015. http://www.elperuano.com.pe/noticia-charango-mio-36113.aspx.

Van Der Lee, Pedro. "Latin American Influences in Swedish Popular Music." Popular Music and Society 21, no. 2 (1997): 17-45.

Vasquez, Chalena. "El Charango Peruano.” Unpublished work. Lima, Peru. 2008.

. "El Charango en el Peru: Notas explicativas del CD Charango." Serie Musica Peruana, Vol I. Lima: Centro de Musica y Danza Peruana de la Pontificia Universidad Catolica del Peru (Cemduc), s. n. Version actualizada por la autora, 2007.

. "El Charango: Mediador Entre Dos Mundos." Arawiwa, May 2005.

Verba, Ericka Kim. "To Paris and Back: Violeta Parra's Transnational Performance of Authenticity." The Americas 70, no. 2 (2013): 269-302. 
Woodward, Ian. Understanding Material Culture. London: Sage, 2007.

Zevallos Aguilar, Ulises Juan. "El Cóndor Pasa. Apropiaciones y Reapropiaciones Musicales En Globalización." Revista De Crítica Literaria Latinoamericana 40, no. 80 (2014): 73-86.

\section{Discography}

Cibilis, Jose and Zeoli, Patricio. Piarango. Independent. Berlin, Germany 2011 Compact disc

Gomez, Camilo. Lazador de Mundos. Independent, Valparaiso, Chile 2018 Compact disc.

Gomez, Camilo. Huella de Oro. Independent, Valparaiso, Chile 2015 Compact disc.

Inti Illimani. Palimpsesto. Redwood, Italy, 1981/Cassette; 1993/CD.

Latapiat, Ivan and the Newen Trio. Emisfero. Independent, Lyon, France 2015 Compact disc.

Parra Madriaga, Luis. Buscando Caminos. Independent. Vienna, Austria 2017 Compact disc. 